\title{
EVALUATION OF HFIR VESSEL SURVEILLANCE DATA AND HYDRO-TEST CONDITIONS
}

\section{R. D. CHEVERTON}

\section{R. K. NANSTAD}

Manuscript Completed: July 26, 1994

Date Published: August 5, 1994

\author{
Prepared by \\ OAK RIDGE NATIONAL LABORATORY \\ Oak Ridge, Tennessee 37831-6285 \\ managed by \\ MARTIN MARIETTA ENERGY SYSTEMS, INC. \\ for the \\ U. S. DEPARTMENT OF ENERGY \\ under contract DE-AC05-84OR21400
}




\section{DISCLAIMER}

This report was prepared as an account of work sponsored by an agency of the United States Government. Neither the United States Government nor any agency thereof, nor any of their employees, make any warranty, express or implied, or assumes any legal liability or responsibility for the accuracy, completeness, or usefulness of any information, apparatus, product, or process disclosed, or represents that its use would not infringe privately owned rights. Reference herein to any specific commercial product, process, or service by trade name, trademark, manufacturer, or otherwise does not necessarily constitute or imply its endorsement, recommendation, or favoring by the United States Government or any agency thereof. The views and opinions of authors expressed herein do not necessarily state or reflect those of the United States Government or any agency thereof. 


\section{DISCLAIMER}

Portions of this document may be illegible in electronic image products. Images are produced from the best available original document. 


\section{CONTENTS}

Section

List of Figures $\ldots \ldots \ldots \ldots \ldots \ldots \ldots \ldots \ldots \ldots \ldots \ldots \ldots \ldots \ldots \ldots \ldots$

List of Tables $\ldots \ldots \ldots \ldots \ldots \ldots \ldots \ldots \ldots \ldots \ldots \ldots \ldots \ldots \ldots \ldots \ldots \ldots$ iv

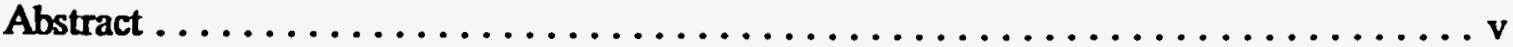

Acknowledgements $\ldots \ldots \ldots \ldots \ldots \ldots \ldots \ldots \ldots \ldots \ldots \ldots \ldots \ldots \ldots \ldots \ldots \ldots \ldots$

1. Introduction and Summary $\ldots \ldots \ldots \ldots \ldots \ldots \ldots \ldots \ldots \ldots \ldots$

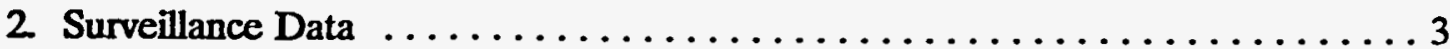

3. Review and Update of Vessel Integrity Evaluation

Based on ASME Code Approach $\ldots \ldots \ldots \ldots \ldots \ldots \ldots \ldots \ldots \ldots \ldots$

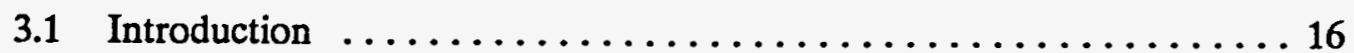

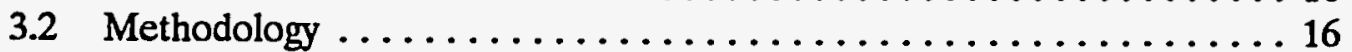

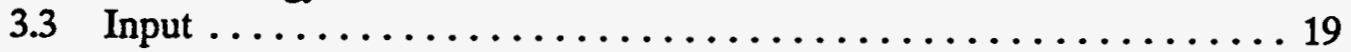

3.4 Results of analysis for calculation of $\Delta t \ldots \ldots \ldots \ldots \ldots \ldots \ldots \ldots$

3.5 Results of analysis for pressure-temperature limits . . . . . . . . 22

4. Probability of Propagation of Flaws in the HFIR Vessel

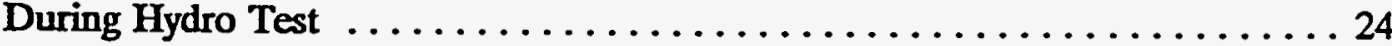

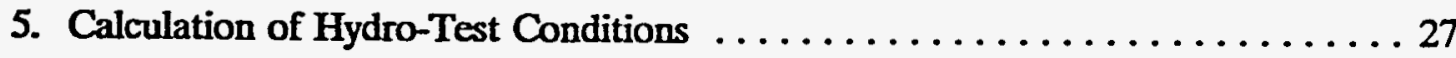

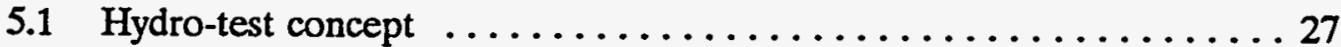

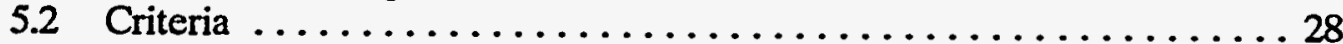

5.3 Derivation of equations for $\mathrm{p}(\mathrm{HT})$ and $\Delta \mathrm{t} \ldots \ldots \ldots \ldots \ldots \ldots \ldots$

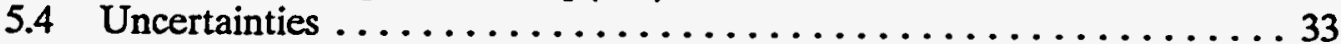

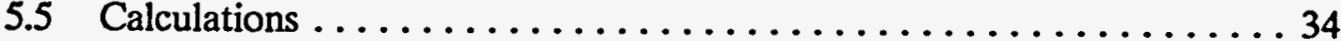

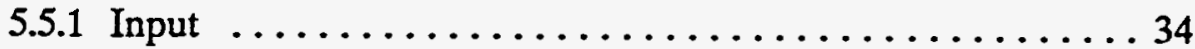

5.5.2 Calculation of $\mathrm{p}(\mathrm{HT}), \Delta \mathrm{t}$ and related parameters $\ldots \ldots \ldots 37$

5.6 The distinction between $\Delta t$ and vessel

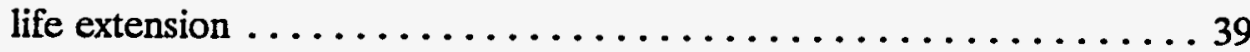

6. Reevaluation of Hydro-Test Conditions $\ldots \ldots \ldots \ldots \ldots \ldots \ldots \ldots \ldots \ldots$

7. Suggestions for Future Hydro Testing $\ldots \ldots \ldots \ldots \ldots \ldots \ldots \ldots \ldots$

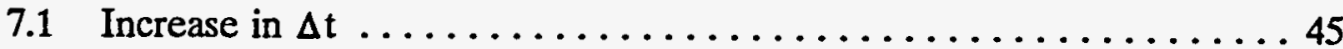

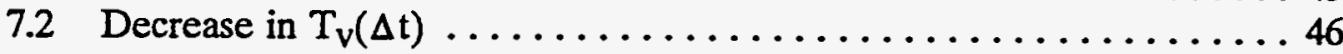

8. Progress in Understanding the "Accelerated" Damage Rate of the HFIR Vessel Surveillance Specimens . . . . . . . . . . . . 48

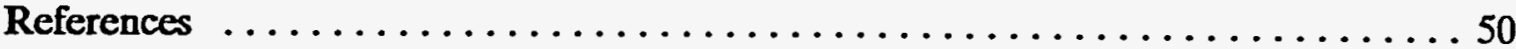




\section{CONTENTS (CONT'D)}

Section

Page

Appendix A. Comments on the Derivation and Use of $\Delta$ NDTT for the Nozzle Weld Material ..................... 51

Appendix B. Establishing a Reasonable Range of e, the Uncertainty

Factor for $\Delta \mathrm{ND} T \mathrm{TT} \ldots \ldots \ldots \ldots \ldots \ldots \ldots \ldots \ldots \ldots \ldots$

Appendix C. Comments on the Accuracy of the Neutron Fluxes

Used for Transposing $\Delta$ NDTT $\ldots \ldots \ldots \ldots \ldots \ldots \ldots \ldots \ldots$

Appendix D. Analysis of HFIR Pressure Vessel Wall Surveillance

Dosimetry ...........................60

Appendix E. Neutron Fluxes Calculated for HFIR in Connection with 1993 Vessel-Material Surveillance Activities . . . . . . . . . 69

Appendix F. Selection of Flaw Sizes for Calculating $p(H T)$ and $\Delta t \ldots \ldots \ldots$

Appendix G. Calculation of $\mathrm{p}(\mathrm{HT})$ and $\Delta t=f(\mathrm{e}) \ldots \ldots \ldots \ldots \ldots \ldots \ldots$ 


\section{LIST OF FIGURES}

Figure

2.1 Charpy V-notch impact surveillance test results for A212 grade B, HFIR shell material, locations HB1A and HB4A (Keys 6 and 7, 1993) . . . . . 11

2.2 Charpy V-notch impact surveillance test results for HFIR seam weld reproduction, location HB1 (Key 1), 1993

2.3 Charpy V-notch impact surveillance test results for HFIR HB2/HB3 nozzle weld metal, location HB2 (Key 2), 1993

2.4 Results for HFIR pressure vessel materials irradiated in ORR, indicating the way in which HFIR surveillance data were used in 1987 to index the ORR results to HFIR. All materials in ORR were irradiated to the same fluence, and curves are linear fits through the origin (from ORNL/TM-10444)

2.5 Change in NDT temperature versus effective full-power years $(100 \mathrm{MW})$ for HFIR surveillance program in $1993 \ldots \ldots \ldots \ldots \ldots \ldots \ldots$

5.1 Fracture toughness curves used in the calculation of $p(H T)$ and $\Delta t \ldots \ldots 41$

5.2 $p(H T)$ and $\Delta t$ vs e and $T_{v}(\Delta t)$ for two crack depths and two bounding fracture toughness curves 


\section{LIST OF TABLES}

Table

Page

2.1 HFIR surveillance capsules removed for testing in $1993 \ldots \ldots \ldots \ldots \ldots \ldots$. . . . 7

2.2. Charpy impact surveillance test results for HFIR shell material, A212 grade B, $1993 \ldots \ldots \ldots \ldots \ldots \ldots \ldots \ldots \ldots \ldots \ldots \ldots \ldots$

2.3 Charpy impact surveillance test results for HFIR seam weld metal, 1993

2.4 Charpy impact surveillance test results for HFIR nozzle weld metal, 1993

2.5 Summary of 1993 surveillance results for HFIR pressure vessel materials

2.6 Normalized $\triangle$ NDTT and embrittlement rates for 1993 HFIR

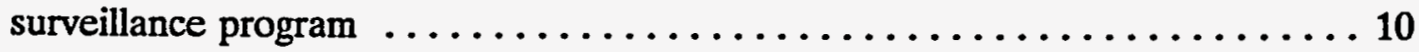

3.1 Input data for ASME Code analysis (flaw in nozzle weld above HB-3 nozzle)

3.2 Values of $\Delta t, \Delta t-$ and $K_{I_{T}}$ for an axially oriented flaw in the HB-3 nozzle weld directly above the nozzle $\ldots \ldots \ldots \ldots \ldots \ldots \ldots \ldots \ldots \ldots$

3.3 Same as Table 3.2 except that fracture toughness increased by $25 \% \ldots \ldots 22$

3.4 Pressure-temperature limits based on ASME Code analysis $\ldots \ldots \ldots \ldots \ldots 23$

5.1 Input data for the calculation of $p(H T)$ and $\Delta t \ldots \ldots \ldots \ldots \ldots$

5.2 "Minimum" values of $\Delta t$ as a function of vessel temperature and corresponding to the two bounding fracture toughness curves

7.1 Maximum permissible values of $\Delta t$ vs $T_{v}(\Delta t)$ for $p(H T)=900$ psi, $\mathrm{T}_{\mathrm{V}}(\mathrm{HT})=85^{\circ} \mathrm{F}$ and a safety factor of 0.5 on the calculated nominal value of $\Delta t$ 


\begin{abstract}
Surveillance specimens for the High Flux Isotope Reactor (HFIR) pressure vessel were removed and tested during 1993, after the vessel had accumulated 701,469 MWd of operation. The data agree well with HFIR surveillance data obtained in previous years. In conjunction with this effort, the vessel hydro-test conditions were reevaluated and found to be more than adequate. In view of this result, and because there are economic incentives for reducing the frequency of hydro testing, an analysis was performed to determine the minimum permissible frequency. The value obtained is substantially less than that presently specified. It was also determined that a somewhat lower cooling-tower-basin temperature is acceptable (improves operational flexibility).
\end{abstract}

In 1986, after $\sim 20$ years of reactor operation, it was discovered that the vessel embrittlement rate was substantially greater than expected. Possible reasons for the accelerated rate are reviewed in this report. 


\section{ACKNOWLEDGEMENTS}

The authors appreciate the efforts of the many people who contributed to this project and would particularly like to note Fahmy Haggag, Eric Manneschmidt, John Henry and Lloyd Turner and staff, for performance of the Charpy impact testing; David Thomas, for instrumentation support; Chuck Baldwin, for dosimetry; Joe Inger and staff, for planning the overall program and for disassembly of the surveillance capsules; and Darlene Stratman, for final preparation of this document. 


\section{EVALUATION OF HFIR VESSEL SURVEILIANCE DATA AND HYDRO-TEST CONDITIONS}

\section{Introduction and Summary}

In 1986, it was discovered that the embrittlement rate of the High Flux Isotope Reactor (HFIR) pressure vessel was greater than expected. ${ }^{1}$ As discussed in Ref. 1, the higher rate resulted in the design criterion for safe operation of the vessel being violated before the design life [20 effective full-power years (EFPY)] was achieved. In an effort to extend the life of the vessel by 10 years (well beyond design life and eventually specified as 10 EFPY at $85 \mathrm{MW}$ ), updated methods of analysis were applied, and reactor operating conditions were changed somewhat. ${ }^{1}$ This was not sufficient, however, and hydrostatic proof testing (hydro testing) of the vessel was adopted. ${ }^{1}$

Periodic hydro testing demonstrates with a high degree of confidence that the vessel is safe to operate, but selection of the hydro-test pressure, temperature and frequency requires knowledge of the embrittlement rate, which is determined from the HFIR surveillance program. The most recent set of surveillance specimens tested was removed from HFIR during August 1993.

A Memo of Understanding pertaining to the 1993 HFIR surveillance activities ${ }^{2}$ states that "The M\&C FMGL shall be responsible for performing tests on the (surveillance) specimens as outlined in Evaluation of HFIR Pressure-Vessel Integrity Considering Radiation Embrittlement, ORNL/TM-10444 (April 1988), HFIR Pressure-Vessel and Structural Components Materials Surveillance Program, ORNL/TM-1372, and HFIR Pressure Vessel and Structural Components Materials Surveillance Program, Supplement 1, ORNL/TM-1372/S1"; "The M\&C FMGL shall be responsible for (1) analyzing the test results; (2) determining the reference temperature $\left(\mathrm{RT}_{\mathrm{NDT}}\right)$; and (3) reporting findings of the analysis, including data, and an opinion as to whether or not embrittlement is proceeding as predicted in accordance with ORNL/TM-10444 and ORNL/TM-1372/S1"; and "The ETD PVTSH shall be responsible for comparing embrittlement rates to the worst-case assumptions made in the calculations to 
establish the hydrostatic test pressure in ORNL/TM-10444 and ORNL/TM-1372/S1." In addition, the HFIR technical specifications ${ }^{3}$ state that "If embrittlement rates indicated by the surveillance tests exceed the worst-case assumption made in the calculation to establish the hydrostatic test pressure, a new hydrostatic test pressure or test frequency shall be established to maintain equivalent safety margins."

HFIR vessel surveillance specimens were removed from the reactor in 1969, 1974, 1983, 1986 and, most recently, in 1993 (end of fuel cycle 320). Testing of the 1993 specimens, evaluation of all the data and re-evaluation of the adequacy of the hydro-test conditions, in light of the new data, have been completed and a letter report submitted. It is concluded that (1) the embrittlement rates for each of the materials included in the surveillance program are essentially the same as determined earlier, ${ }^{1}$ and (2) the previously specified hydro-test conditions (vessel differential pressure $=900 \mathrm{psi}$, vessel temperature $=85^{\circ} \mathrm{F}$, and frequency of testing equal once every effective full-power year) are more than adequate.

There are operational and economic incentives for reducing the frequency of hydro testing and for permitting a lower vessel temperature during "normal" operation. Both possibilities have been evaluated and were found to be reasonable.

A continuing perplexing problem with regard to radiation damage in the HFIR vessel is that the accelerated rate of damage, relative to that in other reactor vessels, and for similar materials tested in materials testing reactors, is not yet understood. Several possibilities have been suggested and evaluated to some extent, including fluence-rate and spectral effects, chemistry, and most recently, a contribution of gammas.

This report provides details of the evaluation of the surveillance data and of the re-evaluation of the hydro-test conditions, including justification for reducing the frequency of testing and of lowering the minimum permissible temperature of the vessel. It also includes a brief discussion of the possible reasons for the accelerated damage rate and what impact this has on the specification of hydro-test conditions and the calculation of the probability of vessel failure during the hydro test. 


\section{Surveillance Data}

The embrittlement rate of the HFIR pressure vessel is monitored with Charpy impact specimens that are tested, following exposure in the reactor, to obtain the increase in the nil ductility transition temperature (NDTT). In accordance with the HFIR technical specifications, $^{3}$ nine Charpy specimens (three per capsule) for each of the three vessel materials [nozzle weld, seam weld, and A212 grade B plate (A212B)] were removed and tested at the end of HFIR fuel cycle 320 (1993 data). [Specimens of the two nozzle materials (A105 grade II and A350 grade LF3) were not scheduled for removal at this time.] Capsule and specimen identification, location in the reactor, and exposure are provided in Table 2.1." As indicated, the exposures were 61,535 MWd for the seam-weld and nozzle-weld specimens and $701,469 \mathrm{MWd}$ for the A212B specimens. The exposure for the weld specimens was at a reactor power level of $85 \mathrm{MW}$ (fuel cycles 288-320), ${ }^{\dagger}$ while the A212B specimens received the same exposure as that for the weld specimens, at $85 \mathrm{MW}$, in addition to the previous exposure at $100 \mathrm{MW}$ (fuel cycles 1-287). For convenience and comparison purposes, all of the data were normalized to exposure in terms of effective full-power years at $100 \mathrm{MW}$ [EFPY $(100 \mathrm{MW})$ ], and these values are included in Table 2.1. As indicated, by the end of fuel cycle 320 , the seam-weld and nozzle-weld specimens had received only 1.69 EFPY(100 MW), while the A212B specimens received 19.2 EFPY(100 MW).

Also included in Table 2.1 are the neutron fluxes and fluences $(E \geq 1.0 \mathrm{MeV}$ ) calculated in 1987 for each capsule location. These fluxes and the corresponding fluxes in the vessel wall were used to transpose the surveillance data to locations of interest in the vessel wall, as was done in Ref. 1

The 1993 HFIR surveillance specimens were tested during the period August 23-27, 1993, following appropriate calibration of the Charpy testing machine and of the temperature measuring system (the testing machine was calibrated following the tests, as well, and was

- In Sect. 2, tables and figures are at the end of the section; in subsequent sections, only figures are at the end of the section.

t The power level for fuel cycles 288 and 289 varied with time and was $\leq 85 \mathrm{MW}$ (lowpower testing and training). 
found to still be in calibration). In general, Charpy-specimen tests were conducted in groups of three at each test temperature. Following the tests at the initial temperature, additional test temperatures were chosen with a view toward obtaining average results above and below the energy level at which the nil-ductility transition temperature shifts ( $\triangle$ NDTT) are determined. Tables 2.2, 2.3 and 2.4 provide the detailed test results for the A212B, seam weld and nozzle weld, respectively. Figs. 2.1, 2.2 and 2.3 provide graphical plots of these test results as well as the test results of the unirradiated material in each case. The NDTTs shown for the unirradiated material on each plot were obtained from Ref. 1 and are $0^{\circ} \mathrm{F}$ for the nozzle weld and $-5^{\circ} \mathrm{F}$ for the seam weld and A212B plate.

As discussed in Ref. 1, the NDTT and $\triangle$ NDTT values are determined at the $15 \mathrm{ft}-\mathrm{lb}$ level for the A212B plate and at $20 \mathrm{ft}-\mathrm{lb}$ for the weld metals. A second-order polynomial was fitted to the irradiated data for the A212B and seam weld; in each case, the coefficient of the highest order term was about $10^{-4}$. For the nozzle weld, a linear regression was performed (the datum at $-5^{\circ} \mathrm{F}$ was not included in the fit for the reasons discussed below). The resulting equations were used to determine the NDTTs for the irradiated data. The NDTT and radiation-induced $\triangle$ NDTT values are shown in the figures and given in Table 2.5 for each material. As shown, the $\triangle N D T T$ values are 0,35 and $58^{\circ} \mathrm{F}$ for the seam weld, nozzle weld and A212B plate, respectively. These results are close to those predicted.

For the A212B plate and seam weld, the average energies at each test temperature increase nearly linearly with temperature. For the nozzle weld, however, that is not the case. The datum at $-5^{\circ} \mathrm{F}$ was ignored in the fitting for two reasons. First, its inclusion results in a curve with a derivative that is not representative of these materials at these levels of exposure. Secondly, using the generally conservative approach adopted in the 1987 study, ${ }^{1}$ exclusion of that datum results in a somewhat larger $\triangle$ NDTT. As observed with the unirradiated data, this weld metal exhibits a high degree of scatter, and thus the conservative approach seems prudent.

Following shutdown of HFIR in 1986, HFIR-vessel weld specimens were irradiated in the Oak Ridge Research Reactor (ORR) because no welds were included in the original HFIR surveillance program. These specimens were irradiated at a considerably higher flux than they would have been exposed to in the HFIR surveillance program. Thus, A212B specimens were 
also irradiated in the ORR to provide data for comparison as well as for indexing the weld results to HFIR surveillance conditions. Figure 2.4, reproduced from Ref. 1, shows that the welds exhibited less radiation-induced $\triangle$ NDTT than the $A 212 \mathrm{~B}$; it also illustrates the method used to index the weld results to the A212B surveillance results. The solid line was constructed from the origin through the HFIR surveillance result at 17.5 EFPY ( $\triangle N D T T=$ $75^{\circ} \mathrm{F}$ ). The $\triangle N D T T$ value for the $A 212 B$ specimens irradiated in the $\mathrm{ORR}$ was $100^{\circ} \mathrm{F}$. That result was simply located on the extension of the solid line and thus in principle corresponded to an exposure in HFIR, at the same location as the actual A212B capsules, of 23.4 EFPY. Because the weld-metal specimens were irradiated in the ORR at the same flux and to the same fluence as the A212B, they were indexed to 23.4 EFPY, and the equivalent location in HFIR would be the location of the A212B specimens that provided the 1986 data point included in Fig. 2.4. Because only one data point was available for each weld, embrittlement rates were determined by the linear fits shown in Fig. 2.4 .

All of the data in Fig. 2.4 correspond to irradiation of each indicated material at an average position (flux/fluence) corresponding to the A212B specimens associated with the $75^{\circ} \mathrm{F}$ shift. Recently, all of the data points in Fig. 2.4 and all of the 1993 data points were, as a matter of convenience and for comparison purposes, transposed to a capsule position referred to as Key 7, Position 8, using the flux ratios calculated in 1987 (Ref. 1). These results are included in Table 2.6.

The transposed $\triangle$ NDTT vs EFPY $(100 \mathrm{MW})$ data in Table 2.6 are plotted in Fig. 2.5 and fitted with linear regressions. For the $\mathrm{A} 212 \mathrm{~B}$ and the seam weld, the best fit resulted in a negative intercept, so the intercept was set to zero. For the nozzle weld, the best fit resulted in a slightly positive intercept, but the curve was forced through zero because (1) there are only two data points, (2) the transposition method uses that assumption, and (3) the resulting embrittlement rate is somewhat more conservative. The slopes of these curves are the embrittlement rates corresponding to the flux at Key 7, Position 8, and are given in Table 2.6. The embrittlement rates used in the previous HFIR evaluation, ${ }^{1}$ corresponding to Key 7 ,

* In the figures and tables in this report, the Key 7, Position 8 location is referred to as the normalizing position, and the corresponding values of $\triangle$ NDTT and $\triangle N D T T$ are referred to as normalized values. 
Position 8, are also given in Table 2.6 for comparison. As indicated, the updated rate for A212B is $4 \%$ less than estimated in Ref. 1 , and the updated rates for the seam weld and nozzle weld are the same as before. 
Table 2.1. HFIR surveillance capsules removed for testing in 1993

\begin{tabular}{|c|c|c|c|c|c|c|c|c|c|}
\hline \multirow[b]{2}{*}{$\begin{array}{c}\text { Capsule } \\
\text { Identification }\end{array}$} & \multirow[b]{2}{*}{$\begin{array}{c}\text { Specimen } \\
\text { Identiflicallon }\end{array}$} & \multicolumn{2}{|c|}{ Locatlon } & \multicolumn{6}{|c|}{ Exposure } \\
\hline & & Kay & Position & \multicolumn{2}{|c|}{$\begin{array}{l}\text { MWd } \\
\text { at power } \\
\text { level }\end{array}$} & $\begin{array}{c}\text { EFPY } \\
\text { at } \\
85 \\
\text { MW } \\
\end{array}$ & $\begin{array}{c}\text { EFPY } \\
\text { at } \\
100 \mathrm{MW}\end{array}$ & $\begin{array}{c}\text { Flux } x^{A, b, c} \times 10^{\circ} \\
{\left[\mathrm{n} /\left(\mathrm{cm}^{2} \cdot \mathrm{s}\right)\right.} \\
(>1 \mathrm{M} V \mathrm{~V})]\end{array}$ & $\begin{array}{c}\text { Fluence } \times 10^{10} \\
{\left[\left(\mathrm{n} / \mathrm{cm}^{2}\right.\right.} \\
(>1 \mathrm{M \theta V})]\end{array}$ \\
\hline \multicolumn{10}{|c|}{ A 212 Grado B } \\
\hline$H B-1 A-64$ & $A-25, A-27, A-131$ & $\begin{array}{l}6 \\
6\end{array}$ & $\begin{array}{l}4 \\
7\end{array}$ & $\begin{array}{r}61,535 \\
639,934 \\
\text { Total } 701,469\end{array}$ & $\begin{array}{l}(85 \mathrm{MW}) \\
(100 \mathrm{MW})\end{array}$ & 1.98 & $\begin{array}{c}1.69 \\
\frac{17.5}{19.2}\end{array}$ & $\begin{array}{l}1.83^{\circ} \\
1.89^{\circ}\end{array}$ & $\begin{array}{l}1.15 \\
\frac{10.4}{11.6}\end{array}$ \\
\hline$H B-1 A-71$ & A-152, A-154, A-159 & $\begin{array}{l}6 \\
6\end{array}$ & $\begin{array}{l}5 \\
8\end{array}$ & $\begin{array}{r}61,535 \\
639,934 \\
\text { Total } 701,469\end{array}$ & $\begin{array}{l}(85 \mathrm{MW}) \\
(100 \mathrm{MW})\end{array}$ & 1.98 & $\begin{array}{l}1.69 \\
\frac{17.5}{19.2}\end{array}$ & $\begin{array}{l}1.70^{\circ} \\
1.74^{\circ}\end{array}$ & $\begin{array}{l}1.06 \\
\frac{9.61}{10.7}\end{array}$ \\
\hline$H B-4 A-76$ & A115, A-118, A-119 & 7 & 4 & $\begin{array}{r}61,535 \\
\text { Total } \frac{639,934}{701,469}\end{array}$ & $\begin{array}{l}(85 \mathrm{MW}) \\
(100 \mathrm{MW})\end{array}$ & 1.98 & $\begin{array}{c}1.69 \\
\frac{17.5}{19.2}\end{array}$ & $\begin{array}{l}2.08^{\mathrm{b}} \\
1.9 \gamma^{\circ}\end{array}$ & $\begin{array}{l}1.30 \\
\frac{10.9}{12.2} \\
\frac{11.5}{11.5}\end{array}$ \\
\hline \multicolumn{10}{|c|}{ Soam Wold } \\
\hline SW'-1.7 & SW-19, SW-20, SW-21 & 1 & 7 & 61,535 & (85 MW) & 1.98 & 1.69 & $3.17^{\circ}$ & 1.99 \\
\hline SW.1-B & SW-22, SW-23. SW-24 & 1 & $\boldsymbol{\theta}$ & 61,535 & (85 MW) & 1.98 & 1.69 & $2.84^{\circ}$ & 1.77 \\
\hline SW-1.9 & SW-25, SW-26, SW-27 & 1 & 9 & 61,535 & (85 MW) & 1.98 & 1.69 & $3.17^{b}$ & $\frac{1.98}{1.91}$ \\
\hline \multicolumn{10}{|c|}{ Nazele Wold } \\
\hline NW-2-1 & $N W-1, N W-2, N W-3$ & 2 & 2 & 61,535 & $(85 \mathrm{MW})$ & 1.98 & 1.69 & $9.43^{b}$ & 5.90 \\
\hline$N W-2-4$ & $N W-10, N W-11, N W-12$ & 2 & 6 & 61,535 & $(85 \mathrm{MW})$ & 1.98 & 1.69 & $9.43^{b}$ & 5.89 \\
\hline \multirow[t]{2}{*}{ NW-2-8 } & $N W-22, N W-23, N W-24$ & 2 & 16 & 61,535 & $(85 \mathrm{MW})$ & 1.98 & 1.69 & $9.43^{b}$ & $\frac{5.89}{5.89}$ \\
\hline & Normalizing postllon & 7 & 8 & $\begin{array}{r}61,535 \\
\frac{639,934}{701,469}\end{array}$ & $\begin{array}{l}(85 \mathrm{MW}) \\
(100 \mathrm{MW})\end{array}$ & 1.98 & $\begin{array}{c}1.69 \\
\frac{17.5}{19.2}\end{array}$ & $\begin{array}{l}2.35^{\circ} \\
2.76^{\circ}\end{array}$ & $\begin{array}{l}1.47 \\
\frac{15.2}{16.7}\end{array}$ \\
\hline
\end{tabular}


Table 2.2. Charpy impact surveillance test results for HFIR shell material, A 212 grade B, 1993

\begin{tabular}{|c|c|c|c|c|c|c|c|}
\hline \multirow{2}{*}{ Identification } & \multicolumn{2}{|c|}{ Temperature } & \multicolumn{2}{|c|}{ Energy } & \multicolumn{2}{|c|}{ Expansion } & \multirow{2}{*}{$\begin{array}{c}\text { Shear } \\
(\%)\end{array}$} \\
\hline & $P F$ & $\left.{ }^{\circ} \mathrm{C}\right)$ & $(f t-1 b)$ & (J) & (in.) & $(\mathrm{mm})$ & \\
\hline $\begin{array}{l}\text { A25 } \\
\text { A118 } \\
\text { A159 } \\
\text { A131 } \\
\text { A152 } \\
\text { A27 } \\
\text { A154 } \\
\text { A115 } \\
\text { A119 }\end{array}$ & $\begin{array}{l}40 \\
40 \\
40 \\
55 \\
55 \\
55 \\
85 \\
85 \\
85\end{array}$ & $\begin{array}{r}4.4 \\
4.4 \\
4.4 \\
12.8 \\
12.8 \\
12.8 \\
29.4 \\
29.4 \\
29.4\end{array}$ & $\begin{array}{r}4.2 \\
14.5 \\
9.2 \\
14.8 \\
10.9 \\
21.3 \\
23.9 \\
36.2 \\
28.5\end{array}$ & $\begin{array}{r}5.7 \\
19.7 \\
12.5 \\
20.1 \\
14.8 \\
28.9 \\
32.4 \\
49.1 \\
38.6\end{array}$ & $\begin{array}{l}0.0041 \\
0.0139 \\
0.0077 \\
0.0141 \\
0.0118 \\
0.0180 \\
0.0210 \\
0.0298 \\
0.0231\end{array}$ & $\begin{array}{l}0.1041 \\
0.3531 \\
0.1956 \\
0.3581 \\
0.2997 \\
0.4572 \\
0.5334 \\
0.7569 \\
0.5867\end{array}$ & $\begin{array}{l}10 \\
20 \\
15 \\
20 \\
20 \\
20 \\
35 \\
45 \\
30\end{array}$ \\
\hline
\end{tabular}

Table 2.3. Charpy impact surveillance test results for HFIR seam weld metal, 1993

\begin{tabular}{||l|c|c|c|c|c|c|c||}
\hline \multirow{2}{*}{ Identification } & \multicolumn{2}{|c|}{ Temperature } & \multicolumn{2}{|c|}{ Energy } & \multicolumn{2}{c|}{ Expansion } & \multicolumn{2}{c|}{$\begin{array}{c}\text { Shear } \\
\text { nyyyyyyn}\end{array}$} \\
\cline { 2 - 8 } & $(\%)$ & $\left({ }^{\circ} \mathrm{C}\right)$ & $(\mathrm{ft}-1 \mathrm{~b})$ & $(\mathrm{J})$ & $(\mathrm{in})$ & $(\mathrm{mm})$ & \\
\hline SW20 & -25 & -31.7 & 8.2 & 11.1 & 0.0043 & 0.1092 & 10 \\
SW23 & -25 & -31.7 & 8 & 10.8 & 0.0052 & 0.1321 & 5 \\
SW26 & -25 & -31.7 & 12.1 & 16.4 & 0.0089 & 0.2261 & 25 \\
SW21 & -5 & -20.6 & 9.1 & 12.3 & 0.0055 & 0.1397 & 15 \\
SW27 & -5 & -20.6 & 35.1 & 47.6 & 0.0263 & 0.6680 & 30 \\
SW24 & -5 & -20.6 & 16.7 & 226 & 0.0130 & 0.3302 & 25 \\
SW19 & 10 & -12.2 & 25.1 & 34 & 0.0185 & 0.4699 & 25 \\
SW22 & 10 & -12.2 & 19.8 & 26.8 & 0.0152 & 0.3861 & 30 \\
SW25 & 10 & -12.2 & 40.1 & 54.4 & 0.0272 & 0.6909 & 40 \\
\hline
\end{tabular}

Table 2.4. Charpy impact surveillance test results for HFIR nozzie weld metal, 1993

\begin{tabular}{||l|c|c|c|c|c|c|c||}
\hline \multirow{2}{*}{ Idertification } & \multicolumn{2}{|c|}{ Temperature } & \multicolumn{2}{c|}{ Energy } & \multicolumn{2}{c|}{ Expansion } & \multirow{2}{*}{$\begin{array}{c}\text { Shear } \\
\text { (\%) }\end{array}$} \\
\cline { 2 - 8 } & $\left({ }^{\circ} \mathrm{F}\right)$ & $\left({ }^{\circ} \mathrm{C}\right)$ & $(\mathrm{tt}-\mathrm{lb})$ & $(\mathrm{J})$ & $(\mathrm{in})$ & $(\mathrm{mm})$ & \\
\hline NW24 & -5 & -20.6 & 19.9 & 27 & 0.0164 & 0.4166 & 15 \\
NW1 & 25 & -3.9 & 15.2 & 20.6 & 0.0153 & 0.3886 & 20 \\
NW10 & 25 & -3.9 & 17.5 & 23.7 & 0.0154 & 0.3912 & 30 \\
NW22 & 25 & -3.9 & 17.4 & 23.6 & 0.0161 & 0.4089 & 25 \\
NW3 & 35 & 1.7 & 13 & 17.6 & 0.0159 & 0.4039 & 30 \\
NW12 & 35 & 1.7 & 15.2 & 20.6 & 0.0152 & 0.3861 & 30 \\
NW2 & 50 & 10 & 21.8 & 29.6 & 0.0222 & 0.5639 & 35 \\
NW11 & 50 & 10 & 19.8 & 26.8 & 0.0191 & 0.4851 & 30 \\
NW23 & 50 & 10 & 49.6 & 67.2 & 0.0380 & 0.9652 & 45 \\
\hline
\end{tabular}


Table 2.5. Summary of 1993 surveillance results for HFIR pressure vessel materials

\begin{tabular}{|c|c|c|c|c|}
\hline \multirow[t]{2}{*}{ Material } & \multicolumn{2}{|c|}{$\begin{array}{c}\text { Unirradiated } \\
\text { transition } \\
\text { temperatures } \\
\left({ }^{\circ} \mathrm{F}\right) \\
\end{array}$} & \multicolumn{2}{|c|}{$\begin{array}{l}1993 \text { surveillance } \\
\Delta \text { NDTT results } \\
\text { (F) }\end{array}$} \\
\hline & NDTT & $R T_{N D T}^{a}$ & $\begin{array}{l}\text { Measured } \\
\Delta N D T T\end{array}$ & $\begin{array}{c}\text { Normalized } \\
\Delta \text { NDTT }\end{array}$ \\
\hline A 212 grade $B$ & -5 & 20 & 58 & 84 \\
\hline Seam weld & -5 & 60 & 0 & 0 \\
\hline Nozzle weld & 0 & 10 & 35 & 10 \\
\hline \multicolumn{5}{|c|}{$\begin{array}{l}\text { aDetermined from } \mathrm{T}_{50}-60^{\circ} \mathrm{F} \text {, where } \mathrm{T}_{50} \text { is the } \\
\text { temperature at which the mean Charpy energy less } \\
\text { one standard deviation is equal to } 50 \mathrm{ft}-\mathrm{lb} \text { (from } \\
\text { ORNL/TM-10444). } \\
\text { bNormalized to Key } 7 \text {, Position 8, for exposure at } \\
100 \mathrm{MW} \text {. }\end{array}$} \\
\hline
\end{tabular}


Table 2.6. Normalized $\triangle N D T T s$ and embrittlement rates for 1993 HFIR surveillance program

\begin{tabular}{|c|c|c|c|c|c|}
\hline \multirow{2}{*}{ Material } & \multicolumn{2}{|c|}{$\begin{array}{c}\Delta N D T T \\
\left({ }^{\circ} \mathrm{F}\right)\end{array}$} & \multirow{2}{*}{$\begin{array}{l}\text { EFPY } \\
\text { at } 100 \mathrm{MW}\end{array}$} & \multicolumn{2}{|c|}{$\begin{array}{c}\text { Embrittlement rates } \\
\left({ }^{\circ} \mathrm{F} / \mathrm{EFPY}\right)\end{array}$} \\
\hline & Measured & Normalized $^{\mathrm{a}}$ & & Current & Previous $^{a, b}$ \\
\hline A212B & $\begin{array}{c}52 \\
75 \\
58 \\
100^{\circ}\end{array}$ & $\begin{array}{r}59 \\
84 \\
84 \\
112^{c}\end{array}$ & $\begin{array}{l}15.0 \\
17.5 \\
19.2 \\
23.4^{\circ}\end{array}$ & 4.6 & 4.8 \\
\hline Seam weld & $\begin{array}{c}0 \\
85^{\circ}\end{array}$ & $\begin{array}{c}0 \\
95^{\mathrm{c}}\end{array}$ & $\begin{array}{r}1.69 \\
23.4^{\circ}\end{array}$ & 4.1 & 4.1 \\
\hline $\begin{array}{l}\text { Nozzle } \\
\text { weld }\end{array}$ & $\begin{array}{l}35 \\
80^{\circ}\end{array}$ & $\begin{array}{l}10 \\
89^{\circ}\end{array}$ & $\begin{array}{l}1.69 \\
23.4\end{array}$ & 3.8 & 3.8 \\
\hline $\begin{array}{l}\text { aNormali } \\
\text { bFrom O } \\
\text { 'Results } \\
\text { ORNL/TM-16 }\end{array}$ & $\begin{array}{l}d \text { to Key } 7 \\
\text { JL/TM-104 } \\
\text { m irradiati } \\
14 .\end{array}$ & $\begin{array}{l}\text { osition 8, ar } \\
\text { in Oak Ric }\end{array}$ & $\begin{array}{l}100 \mathrm{MW} . \\
\text { Research }\end{array}$ & eactor & R), see \\
\hline
\end{tabular}




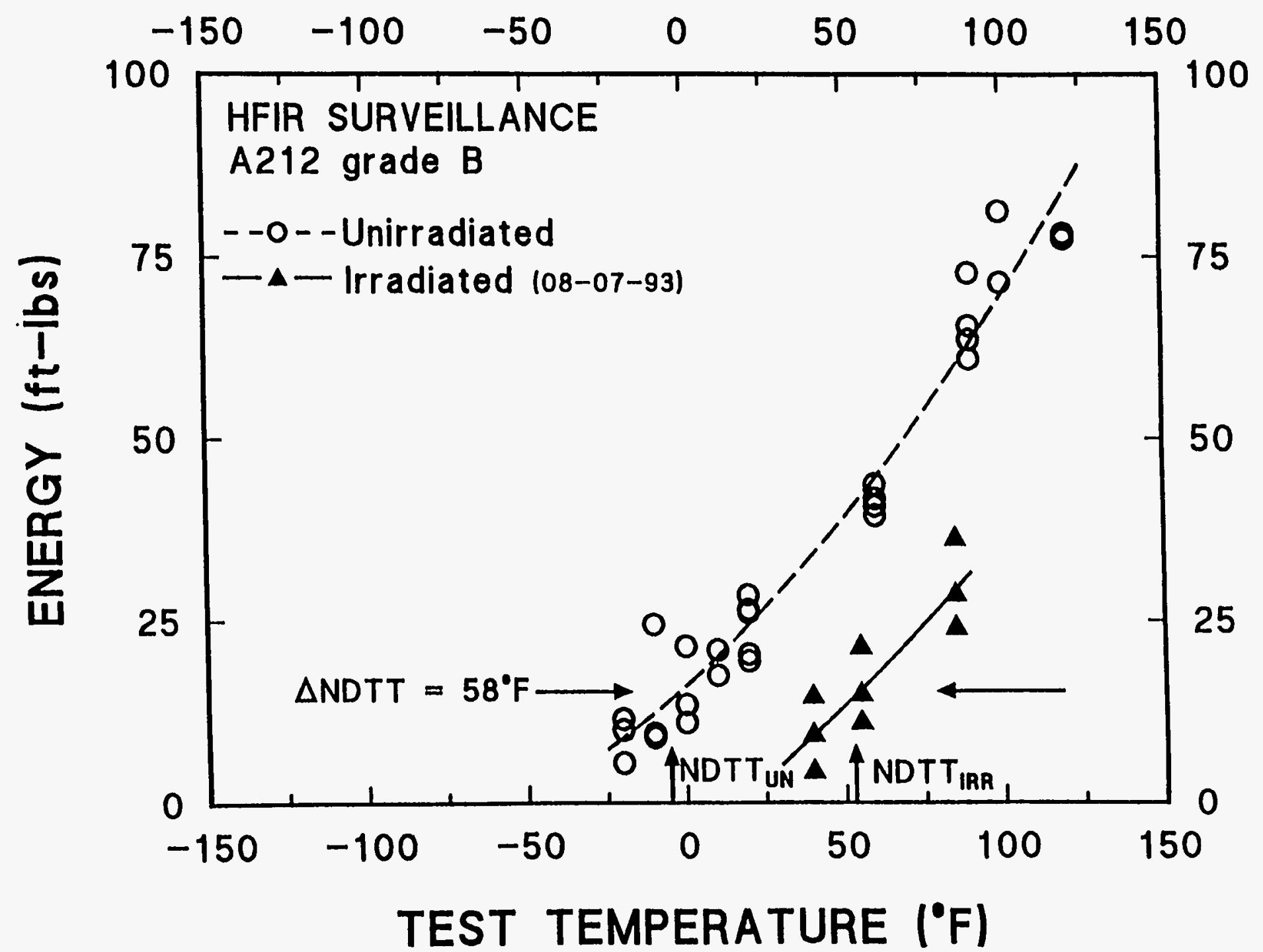

Fig. 2.1 Charpy V-notch impact surveillance test results for A 212 grade B. HFIR shell material, locations HB1A and HB4A (Keys 6 and 7), 1993. 


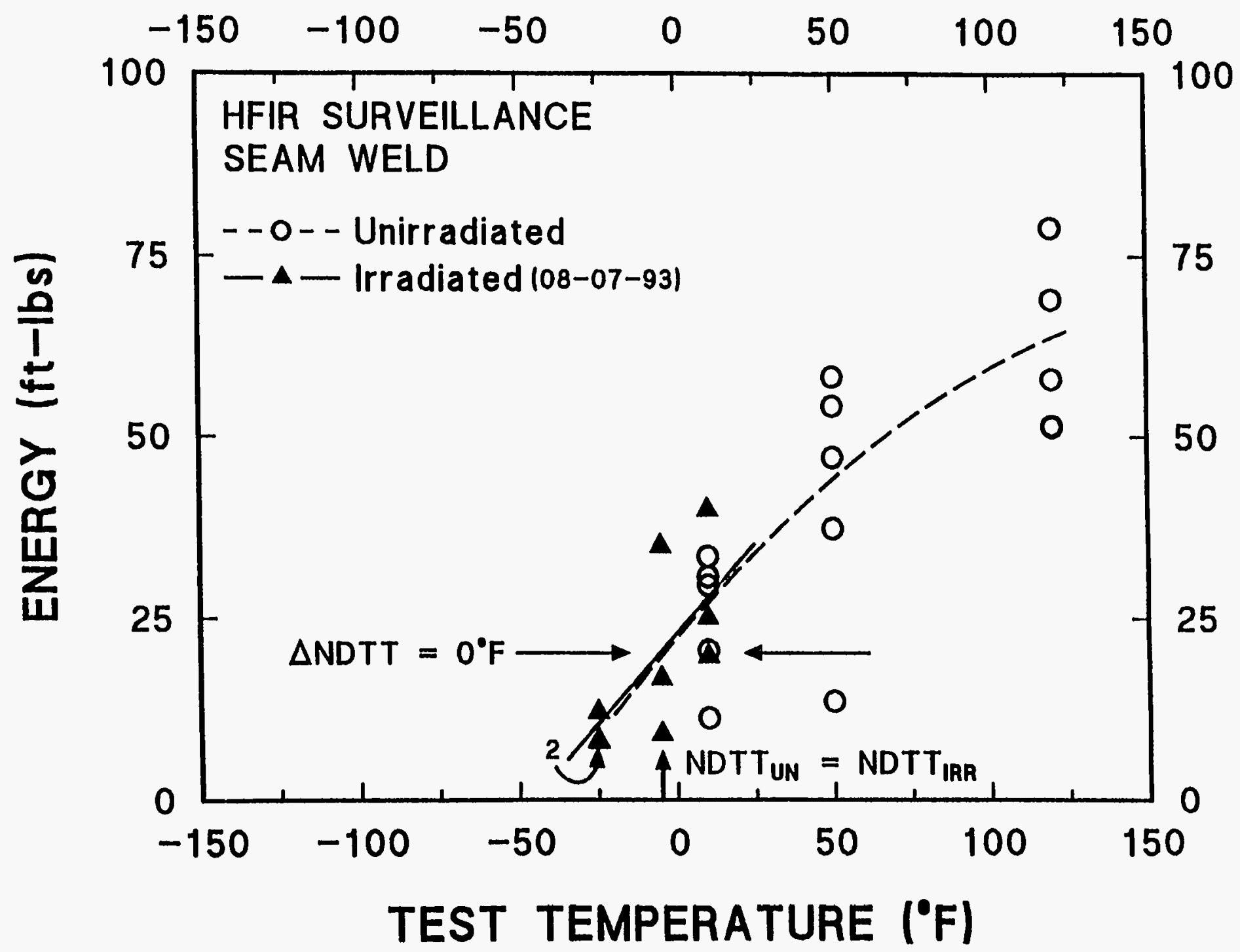

Fig. 2.2 Charpy V-notch impact surveillance test results for HFIR seam weld reproduction, location HB1 (Key 1), 1993. 


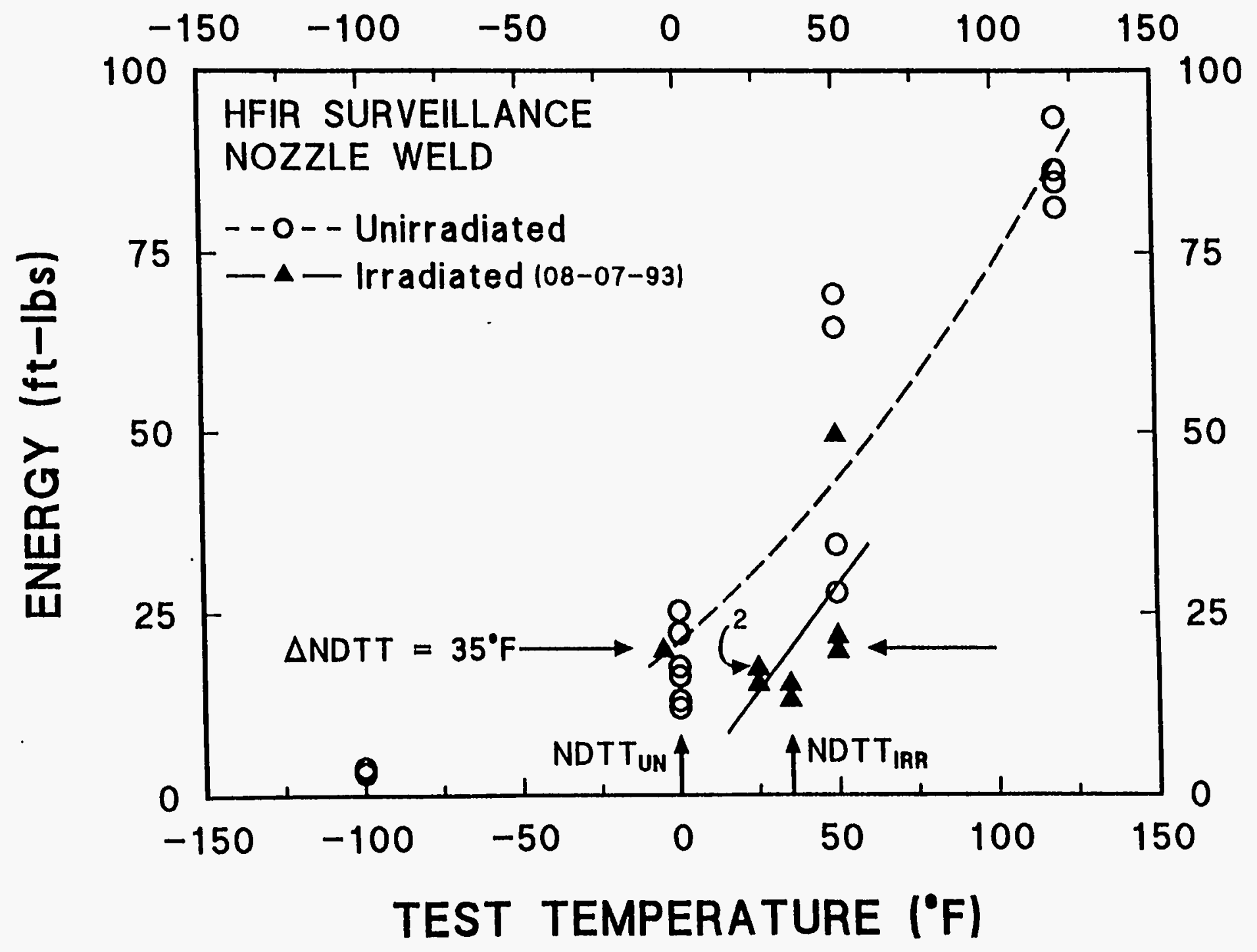

证 Fig. 2.3 Charpy V-notch impact surveillance test results for HFIR HB2/HB3 nozzle weld metal, location HB2 (Key 2), 1993. 


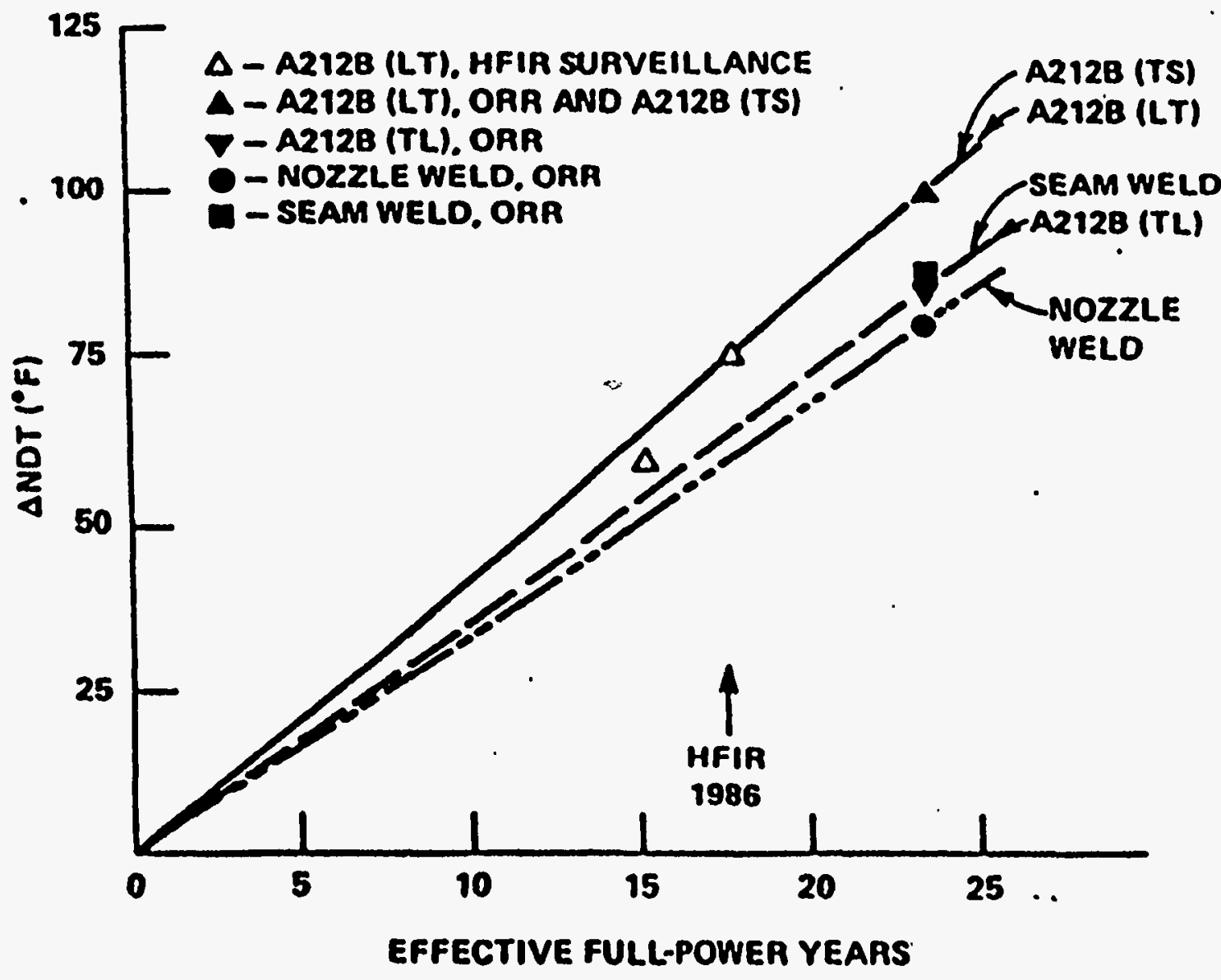

Fig. 2.4 Results for HFIR pressure vessel materials irradiated in ORR, indicating the way in which HFIR surveillance data were used in 1987 to index the ORR results to HFIR. All materials in ORR were irradiated to the same fluence, and curves are linear fits through the origin (from ORNL/TM-10444). 


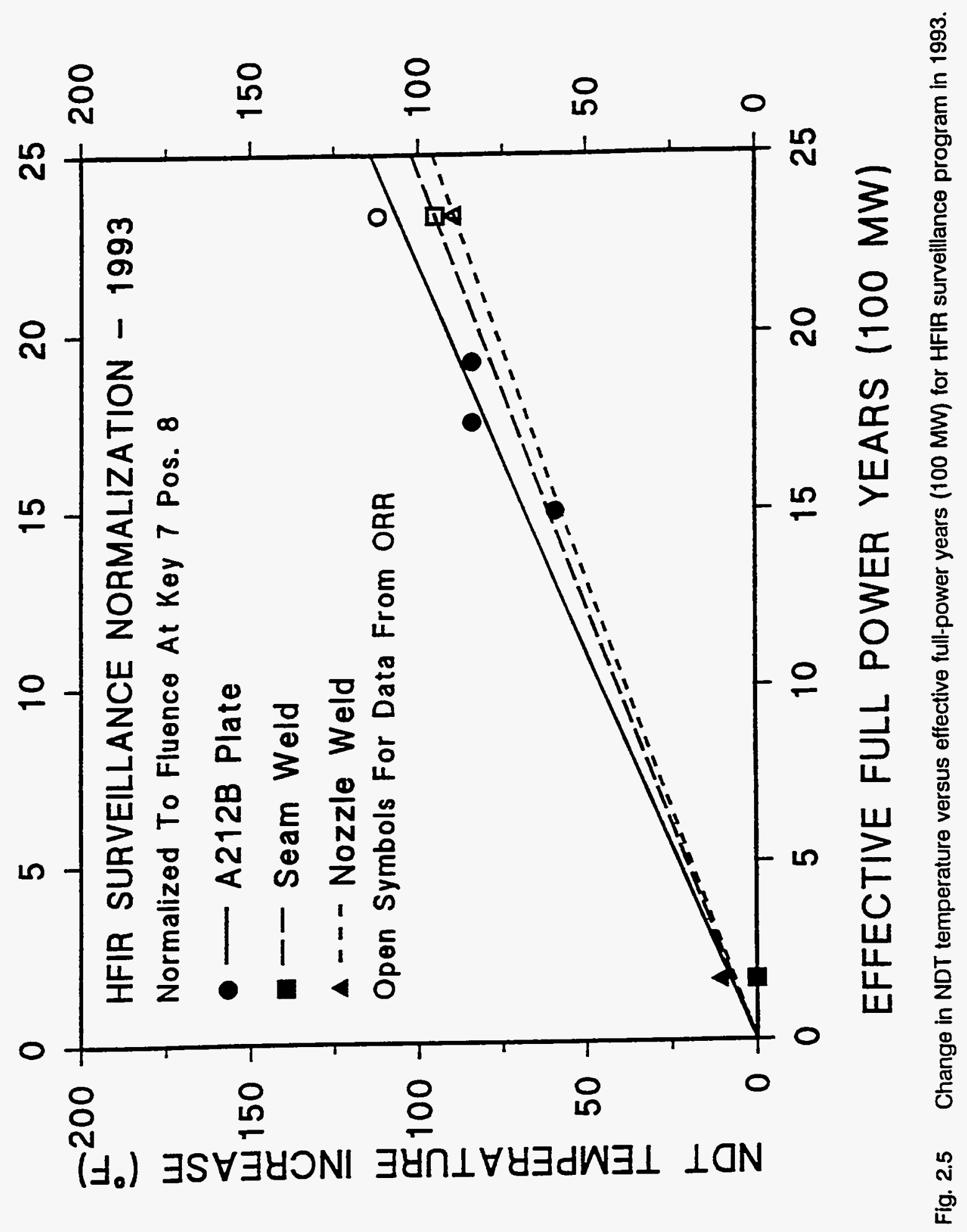


3. Review and Update of Vessel Integrity Evaluation Based on ASME Code Approach

\subsection{Introduction}

The particular concern addressed in this report, with regard to the integrity of the HFIR pressure vessel, is propagation of a sharp, crack-like defect (flaw) as a result of the radiation-induced embrittlement of the vessel material in the vicinity of the beam-tube nozzles. As discussed in Ref. 1, the potential for propagation of flaws is evaluated using linear elastic fracture mechanics (LEFM), an approach that is included in the ASME Code $^{4,5}$ and accepted by the NRC ${ }^{6}$ for nuclear pressure vessels. The ASME Code approach was used in Ref. 1 to determine the required reduction in pressure loading, and thus power level, to compensate for radiation damage over an additional 10 EFPY operating period. The calculated reduction was not acceptable, and thus hydro testing was resorted to in order to demonstrate integrity. Even so, it is of interest to review and update the Code-type analysis.

The Code-type analysis was also used to calculate the vessel pressure-temperature limits, which are more concerned with low-temperature, low-pressure operation (start up, etc.), and these analyses are reviewed herein, as well.

\subsection{Methodology}

The Code requires consideration of two loading conditions: normal/upset and emergency/faulted. In accordance with Appendix G, Division 1 of Section III of the ASME Code, for normal and upset conditions ${ }^{4}$

$$
K_{I_{T}}=2 K_{I_{P}}+K_{I_{S}}
$$


where

$K_{I_{T}}=$ total stress intensity factor

$K_{l_{P}}=$ stress intensity factor associated with primary loads (primary-system pressure)

$K_{I_{S}}=$ stress intensity factor associated with secondary stresses

The secondary stresses included in the Ref. 1 analysis were those resulting from discontinuities (bending stresses), thermal gradients (thermal stresses) and welding (residual stresses). Thus,

$$
K_{l_{T}}=2 K_{I_{P}}+K_{l_{b}}+K_{I_{t}}+K_{I_{r}}
$$

The condition that must be satisfied to demonstrate integrity for normal and upset conditions is

$$
K_{l_{T}} \leq K_{I R}
$$

where $\mathrm{K}_{\mathrm{IR}}=$ ASME-Code lower-bound fracture toughness corresponding to dynamic-loading initiation and to crack arrest.

Section III of the Code does not specify what safety factor or fracture-toughness curve should be used for emergency and faulted conditions, but Appendix A of Section $\mathrm{XI}^{5}$ allows use of $K_{I c}$ instead of $K_{I R}\left(K_{I c}>K_{I R}\right)$ for fracture toughness and $\sqrt{2}$ instead of 2 for a safety factor for emergency and faulted conditions. Section XI pertains to actual flaws, which are characterized conservatively, and thus part of the safety factor is included in "sizing" of the flaw. For that reason, the safety factor of 2 from Section III was retained in the Ref. 1 analysis for emergency and faulted conditions, but $K_{I c}$ was used instead of $K_{I R}$. Thus, for emergency and faulted conditions, Eq. (1) applies, and the following condition must be satisfied: 


$$
K_{l_{T}} \leq K_{I_{c}},
$$

where $\mathrm{K}_{\mathrm{Ic}}=$ ASME-code lower-bound fracture toughness corresponding to static crack initiation (onset of propagation).

$\mathrm{K}_{\mathrm{Ic}}$ and $\mathrm{K}_{\mathrm{IR}}$ are calculated from (see Sect. 5)

$$
K_{\mathrm{Ic}}, K_{\mathrm{LR}}=A+B \exp \left[C\left(T_{V}-R T_{N D T_{\circ}}-e \cdot \Delta N D T T \cdot \Delta t\right)\right]
$$

where

$\mathrm{A}, \mathrm{B}, \mathrm{C}=$ constants

$$
T_{\mathrm{V}}=\text { vessel temperature }
$$

$\mathrm{RT}_{\mathrm{NDT}}$ = initial (no radiation-induced embrittlement) value of the reference nil ductility transition temperature

$\Delta \mathrm{NDTT}=$ rate of increase of nil ductility transition temperature

e $=\Delta$ NDTT uncertainty factor

$\Delta \mathrm{t}=$ time of reactor operation

$$
=17.53 \mathrm{EFPY}(100 \mathrm{MW})+\Delta \mathrm{t}^{\prime}
$$

$\Delta t^{\prime}=$ permissible life extension of vessel beyond 17.53 EFPY(100 MW) (17.53 corresponds to the shutdown in November 1986)

On the basis of the HFIR surveillance data (Sect. 2), $\Delta$ NDTT was assumed to be linear with fluence and thus zero for zero fluence.

Substituting Eq. (5) into (3) or (4) and solving for $\Delta t$ gives

$$
\Delta t=\frac{\left(T_{V}-R T_{N D T_{\mathrm{o}}}\right)-\frac{1}{C} \ln \left[\frac{A}{B}\left(\frac{K_{I_{T}}}{A}-1\right)\right]}{e \cdot \Delta N \dot{D} T T} .
$$

$K_{I_{T}}$ can be written as (see Sect. 5)

$$
K_{I_{T}}=\sqrt{\pi a}\left[p\left(2 c_{m} s_{m}+c_{b} s_{b}\right)+c_{r} \sigma_{r}\right]
$$


where $\mathrm{m}, \mathrm{b}$, and $\mathrm{r}$ refer to membrane (primary), bending and residual stresses. The thermal stresses are not included in Eq. (7) because, as discussed in Ref. 1, they are relatively small.

For the purpose of calculating the pressure-temperature limits, Eqs. (5) and (7) are combined to obtain

$$
p=\frac{A+B \exp \left[C\left(T_{V}-R T_{N D T_{o}}-e \cdot \Delta N D T T \cdot \Delta t\right)\right]}{\left(2 c_{m} s_{m}+c_{b} s_{b}\right) \sqrt{\pi a}}-\frac{c_{r} \sigma_{r}}{\left(2 c_{m} s_{m}+c_{b} s_{b}\right)}
$$

\subsection{Input}

The flaw required by Section III of the Code is at and perpendicular to the surface (surface-breaking flaw), and it is semielliptical in shape with a depth (a) of 1.0 in. and a surface length of 6.0 in. The analysis in Ref. 1 indicated that the limiting flaw was in the HB-3 nozzle weld, directly above the nozzle and oriented axially, and that the limiting point on the crack front was the deepest point. Corresponding values of $c_{m}$, $c_{b}, c_{n} s_{m}, s_{b}$ and $\sigma_{r}$ are given in Tables 5.3 and 5.4 of Ref. 1 and are included herein in Table 3.1, which summarizes all of the input for Eqs. (6), (7) and (8). The appropriate value of $\triangle N D T T$ is derived in Appendix $A$ of this report and is $2.44^{\circ} \mathrm{F} / \mathrm{EFPY}(100 \mathrm{MW})$. An uncertainty factor for $\triangle N D T T$ of 1.5 was specified by a DOE review committee. ${ }^{1}$

For the calculation of $\Delta t$, values of $p$ and $T_{v}$, worst-case consistent values of the primary-system pressure and the vessel temperature, and of $A, B$ and $C$, depend upon the assumed loading conditions. As already indicated, the ASME Code requires consideration of two loading conditions: normal/upset and emergency/faulted. Appropriate values of the affected parameters are included in Table 3.1.

For the pressure-temperature-limits analysis, $\mathrm{p}$ and $\mathrm{T}_{\mathrm{V}}$ are dependent/independent variables, $\mathrm{K}_{\mathrm{IR}}$ is used for the fracture toughness and $\Delta \mathrm{t}=17.5+8.5=26 \mathrm{EFPY}$ 
(100 MW). This particular value of $\Delta t$ corresponds to the target life extension of the vessel [10 EFPY(85 MW) or 8.5 EFPY (100 MW)].

Table 3.1 Input data for Code analysis (flaw in nozzle weld above HB-3 nozzle)

\begin{tabular}{|c|c|c|}
\hline PARAMETER & \multicolumn{2}{|c|}{ VALUE } \\
\hline Fracture Toughness Curve & $\mathrm{K}_{\mathrm{Ic}}$ & $\mathbf{K}_{\mathrm{IR}}$ \\
\hline $\mathrm{A}, \mathrm{ksi} \sqrt{\text { in }}$ & 33.2 & 26.8 \\
\hline $\mathrm{B}, \mathrm{ksi} \sqrt{\text { in }}$ & 20.73 & 12.44 \\
\hline $\mathrm{C},{ }^{\circ} \mathrm{F}^{-1}$ & 0.020 & 0.0145 \\
\hline $\mathrm{a}$, in. & \multicolumn{2}{|c|}{1.0} \\
\hline$c_{b}$ & \multicolumn{2}{|c|}{0.741} \\
\hline$c_{m}$ & \multicolumn{2}{|c|}{1.146} \\
\hline$c_{r}$ & \multicolumn{2}{|c|}{0.860} \\
\hline $\mathbf{s}_{\mathrm{b}}$ & \multicolumn{2}{|c|}{4.24} \\
\hline$s_{\text {m }}$ & \multicolumn{2}{|c|}{16.8} \\
\hline$\sigma_{r}, \mathrm{ksi}$ & \multicolumn{2}{|c|}{8.5} \\
\hline$R T_{N D T_{\circ}},{ }^{\circ} \mathrm{F}$ & \multicolumn{2}{|c|}{10} \\
\hline$\triangle \mathrm{ND} T \mathrm{~T},{ }^{\circ} \mathrm{F} / \mathrm{EFPY}(100 \mathrm{MW})$ & \multicolumn{2}{|c|}{2.44} \\
\hline e & \multicolumn{2}{|c|}{1.5} \\
\hline Loading Type & normal/upset & emergency/faulted \\
\hline $\mathrm{p}, \mathrm{ksi}$ & $0.508^{\mathrm{a}}$ & $0.679^{b}$ \\
\hline $\mathrm{T}_{\mathrm{V}},{ }^{\circ} \mathrm{F}$ & $90^{c}$ & $85^{b}$ \\
\hline \multicolumn{3}{|c|}{$\begin{array}{l}\text { a Pressurizer-pump cutoff pressure } \\
\text { b Rupture-disc upper limit } \\
{ }^{\text {c }} \text { Trip point for depressurization of primary system } \\
\text { d Minimum control point for cooling-tower basin }\end{array}$} \\
\hline
\end{tabular}




\subsection{Results of analysis for calculation of $\Delta t$}

Results of the analysis are given in Table 3.2

Table 3.2 Values of $\Delta \mathrm{t}, \Delta \mathrm{t}^{\prime}$, and $K_{I_{T}}$ for an axially oriented flaw in the HB-3 nozzle weld directly above the nozzle

\begin{tabular}{||l|c|c|c||}
\hline \hline Loading Condition & \multicolumn{2}{|c|}{ Normal/Upset } & Emergency/Faulted \\
\hline \hline $\mathrm{e}$ & 1.5 & 1.0 & 1.5 \\
\hline$\Delta \mathrm{t}, \mathrm{EFPY}(100 \mathrm{MW})$ & 9.7 & 14.6 & 15.5 \\
\hline$\Delta \mathrm{t}^{\prime}, \mathrm{EFPY}(100 \mathrm{MW})$ & -7.8 & -2.9 & -2.0 \\
\hline$K_{I_{T}}, k s i \sqrt{\text { in }}$ & 50.5 & 50.5 & 63.1 \\
\hline
\end{tabular}

The values of $\Delta t^{\prime}$ in Table 3.2 are much less than calculated in Ref. 1 because values of $e$ and $\triangle N D \dot{T} T$ corresponding to the recent analysis are greater than those used in Ref. 1 (1.5 and 2.44 compared to 1.0 and 2.18), and the values of $T_{V}$ are less $\left(90^{\circ} \mathrm{F}\right.$ for normal/upset conditions compared to $110^{\circ} \mathrm{F}$, and $85^{\circ} \mathrm{F}$ for accident/faulted conditions compared to $105^{\circ} \mathrm{F}$ ).

The use of $e=1.5$ is believed to be excessively conservative because of the large safety factors required in the ASME analysis, but the larger value of $\triangle$ NDTT represents an appropriate update (see Appendix $A$ ), and the smaller values of $T_{V}$ correspond to upset and faulted conditions not considered previously.

In Ref. 1, it was argued, on the basis of "appropriate" fracture toughness data, that an increase in the allowable values of $\mathrm{K}_{\mathrm{Ic}}$ and $\mathrm{K}_{\mathrm{IR}}$ of $25 \%$ would be reasonable. If this is done, the $\Delta t$ values in Table 3.3 are obtained. 
Table 3.3 Same as Table 3.2 except that fracture toughness increased by $25 \%$

\begin{tabular}{||l|c|c|c|c||}
\hline \hline Loading Condition & \multicolumn{2}{|c|}{ Normal/Upset } & \multicolumn{2}{c|}{ Emergency/Faulted } \\
\hline $\mathrm{e}$ & 1.5 & 1.0 & 1.5 & 1.0 \\
\hline$\Delta \mathrm{t}, \mathrm{EFPY}(100 \mathrm{MW})$ & 20.2 & 30.3 & 23.0 & 34.5 \\
\hline$\Delta \mathrm{t}^{\prime}, \mathrm{EFPY}(100 \mathrm{MW})$ & 2.7 & 12.8 & 5.5 & 17.0 \\
\hline$K_{I_{T}}, k s i \sqrt{\text { in }}$ & 50.5 & 50.5 & 63.1 & 63.1 \\
\hline
\end{tabular}

In 1987, the criterion was that $\Delta t^{\prime} \geq 8.5$ EFPY(100 MW). For the conditions imposed on ORNL by DOE, that criterion could not be achieved at a power level of $85 \mathrm{MW}$ (Table 3.2), and reducing the power further was not desirable. Thus, the fracturetoughness safety factor was reduced somewhat to obtain the $\Delta \mathbf{t}^{\prime}$ values in Table 3.3, which, considering a reasonable intermediate value of $e$, do satisfy the criterion. Even so, the Code is not literally satisfied, and thus the integrity of the HFIR vessel must be demonstrated by some other means. That "means" is, of course, a hydro test and a probabilistic fracture-mechanics analysis to show that the probability of failure during the hydro test is acceptable. The probabilistic analysis is reviewed in Sect. 4, and an update of hydro-test conditions is included in Sects. 5, 6 and 7. .

\subsection{Results of analysis for pressure-temperature limits}

Results of this analysis are included in Table 3.4, which shows that $\mathrm{p}$ is not very sensitive to $T_{V}$ over the range $70-85^{\circ} \mathrm{F}$, and that for $T_{V}=80^{\circ} \mathrm{F}, \mathrm{p}=304 \mathrm{psi}$. The reason for the lack of sensitivity is that, because of the use of the $\mathrm{K}_{\mathrm{IR}}$ curve and an uncertainty factor of 1.5 for $\triangle \mathrm{NDTT}$, the portion of the fracture toughness curve involved in the analysis is the lower-shelf (little change in $\mathrm{K}_{\mathrm{IR}}$ with change in $\left.\mathrm{T}_{\mathrm{V}}-\mathrm{RT}_{\mathrm{NDT}}\right)$.

As discussed in greater detail in Sect. 5, a successful hydro test for the HFIR vessel demonstrates that the permissible vessel pressure, for a vessel temperature of $85^{\circ} \mathrm{F}$, is 679 psi just prior to the time of a successive hydro test. Thus, the results of the 
ASME Code analysis are quite conservative and need not represent a true limit. However, the Code analysis does satisfy the HFIR technical specifications ${ }^{3}$ requirement for the vessel temperature to be at least $85^{\circ} \mathrm{F}$ when the vessel pressure is above 300 psi.

Table 3.4 Pressure-temperature limits based on ASME Code analysis

\begin{tabular}{||c||c|}
\hline $\mathrm{T}_{\mathrm{V}},{ }^{\circ} \mathrm{F}$ & $\mathrm{p}, \mathrm{psi}$ \\
\hline 70 & 289 \\
\hline 75 & 296 \\
\hline 80 & 304 \\
\hline 85 & 313 \\
\hline
\end{tabular}




\section{Probability of Propagation of Flaws in the HFIR Vessel During Hydro Test}

The probability of vessel failure during normal/upset and emergency/faulted conditions and during a hydro test was evaluated in Ref. 1, using probabilistic fracture mechanics. A review and reevaluation is included in this report. In summary, at the completion of 26 EFPY $(100 \mathrm{MW})$ the conditional probability of failure $[\mathrm{P}(\mathrm{F} \mid \mathrm{E})]$ for all loading conditions is less than the maximum permissible value of $10^{-6}$ (Ref. 7 ).

Calculations included in Ref. 1 used a best-estimate value of $\mathrm{RT}_{\mathrm{NDT}}$ at the inner surface of the vessel wall of $140^{\circ} \mathrm{F}$. This was a conservative estimate made early in the HFIR vessel integrity reevaluation study and thus without the benefit of the later detailed surveillance and fracture-analysis results. Eventually, it was determined that an axially oriented inner-surface flaw in the weld above the HB-3 nozzle had the greatest potential for propagating (see Ref. 1 and Sect. 3 of this report). The best-estimate end-of-extended-life value of $\mathrm{RT}_{\mathrm{NDT}}$ for this material (nozzle weld) and location (above HB-3) is (see Tables 5.1 and 5.2 of Ref. 1 and Appendix A of this report)

$$
\begin{aligned}
R T_{N D T} & =R T_{N D T_{\circ}}+\Delta N \dot{D} T T \times \Delta t \\
& =10^{\circ} \mathrm{F}+3.82^{\circ} \mathrm{F} / E F P Y(100 \mathrm{MW}) \times \frac{1.97}{2.68} \times 26 \mathrm{EFPY}(100 \mathrm{MW}) \\
& =10+73=83^{\circ} \mathrm{F}
\end{aligned}
$$

The value of $\Delta N \dot{D} T T\left(3.82 \times \frac{1.97}{2.68}=2.81\right)$ is a best-estimate value at the inner surface of the vessel wall at the location described above. It was obtained by transposing the value corresponding to the Key 7, Position 8 location to the vessel site using the corresponding ratio of fast neutron fluxes $\left(\frac{1.97}{2.68}\right)$.

As discussed in Sect. 8, it may be that gammas, rather than fast neutrons, are primarily responsible for the observed damage, in which case the above flux ratios are not necessarily 
appropriate. The gamma fluxes required for transposition are not available; however, it is expected that the gradients in fast neutron and gamma fluxes are of the same sign. Thus, the appropriate flux ratio for transposition is less than unity. If unity is used, $\Delta \mathrm{RT}_{\mathrm{NDT}}=3.82 \mathrm{x}$ $2.6=99^{\circ} \mathrm{F}$ instead of $73^{\circ} \mathrm{F}$. The difference $\left(26^{\circ} \mathrm{F}\right)$ can be considered to represent three standard deviations, with $73^{\circ} \mathrm{F}$ being the best estimate. Thus, one standard deviation for transposition is $-9^{\circ} \mathrm{F}$. If the uncertainty factor of 1.5 imposed by DOE (see Appendix B) for $\triangle N \dot{N} T T$ (the experimental value) represents three standard deviations, then one standard deviation $(\sigma)$ for $\Delta \mathrm{RT}_{\mathrm{NDT}}$ at the tip of the flaw is

$$
\sigma \sim 9+\frac{1.5 \times 73-73}{3}=9+12=21^{\circ} \mathrm{F} .
$$

In Ref. 1 , a value of $24^{\circ} \mathrm{F}$ was used and was also used in this latest calculation.

The stresses used in Ref. 1 included only the primary stresses because the largest secondary stress, the residual stress, is self equilibrated and thus does not necessarily contribute to $\mathrm{K}_{\mathrm{I}}$ after the flaw has penetrated about half the vessel wall. A more conservative approach was taken in the present analysis by including the secondary stresses and assuming that the residual stress was uniform through the wall. This approach is consistent with calculating the probability of crack initiation (onset of propagation) rather than the probability of failure, which could be less.

Only the hydro-test loading condition $\left(\mathrm{p}=900\right.$ psi and $\mathrm{T}_{\mathrm{v}}=85^{\circ} \mathrm{F}$ ) was considered in the present analysis because it represents the worst case, and the criterion for acceptability is the same $\left[P(F \mid E) \leq 10^{-6}\right]$. The result of the analysis was $P(F \mid E)=0.9 \times 10^{-6}$.

In the above type of evaluation, the analysis can be performed for either the time of the final hydro test, using the corresponding hydro-test conditions, or the specified end of vessel life, using the "worst-case" (emergency/faulted) loading conditions. Not knowing when the last hydro test might be conducted, it was assumed, conservatively, that it was essentially at the end of the specified life [26 EFPY (100 MW)]. Because the corresponding value of P(FIE) is less than the maximum permissible value, the implication is, from a probability of failure point of view, that the life of the vessel could be extended beyond 26 EFPY (100 MW) by the maximum permissible time between successive hydro tests. This is because, as indicated 
by Eq. 10, the potential for failure at the time of a successive hydro test, and for the "worstcase" (emergency/faulted) loading condition, must be no greater than that for the previous hydro test. As mentioned in Sect. 5.6, however, there may be other factors to consider with regard to vessel life extension. 


\section{Calculation of Hydro-Test Conditions}

\subsection{Hydro-test concept}

As discussed in Ref. 1, the concern regarding radiation embrittlement of the HFIR pressure vessel is that the potential for sharp, crack-like defects (flaws) in the vessel propagating and resulting in breach of contaminant increases with increasing embrittlement. In addition to embrittlement (reduction in fracture toughness), parameters affecting the potential for vessel failure are size, shape, and location of possible flaws and the stresses in the vicinity of the flaws. Uncertainties in these three parameters are accommodated in an ASME-type evaluation of vessel integrity by the use of safety factors, but for HFIR this approach is too restrictive (see Sect. 3). A hydro test is less restrictive because, if the vessel does not fail during the test, it demonstrates that the combination of the actual (existing) conditions (fracture toughness, flaw characterization and stresses) is subcritical.

The hydro test must accommodate degradation of the vessel, over a specified period of time, that can affect the potential for failure during that period. One of these degradation mechanisms is, of course, radiation embrittlement, and the only other is increasing size of a flaw. The size of a flaw can increase as a result of corrosion and/or fatigue, but as will be discussed later, neither is of sufficient magnitude to be of concern. Thus, only the continuing radiation embrittlement must be considered in establishing appropriate hydro-test conditions.

The amount of embrittlement that must be accommodated by the hydro-test conditions is a function of the time between successive hydro tests, the vessel temperature and the location of the crack front (crack tip) in the vessel wall. The time between successive hydro tests and the vessel temperature can be calculated and/or specified, but the location of a crack front is not known. 
The stresses in the vicinity of the crack front are also used in the determination of the hydro-test conditions, and they, too, depend on the location of the crack front as well as type and size of flaw, neither of which is known.

There is also uncertainty in the amount of embrittlement between successive hydro tests, but as will be demonstrated later, the uncertainties in embrittlement rate and flaw characterization need not have a significant effect on the selection of hydro-test conditions.

\subsection{Criteria}

The hydro-test conditions that must be determined are the primary-system pressure, vessel temperature and time between successive hydro tests. This combination must be such that the potential for vessel failure during the hydro test is equal to or greater than the potential at the time of the successive hydro test with the vessel subjected to "worstcase" loading conditions (pressure and temperature). This criterion can be expressed mechanistically and mathematically as

$$
\frac{K_{I}(H T)}{K_{l c}(H T)} \geq \frac{K_{I}(S V)}{K_{I c}(\Delta t)}
$$

where

$$
\begin{aligned}
\mathrm{K}_{\mathrm{I}}(\mathrm{HT})= & \text { stress intensity factor at the time of the hydro test, } \\
\mathrm{K}_{\mathrm{I}}(\mathrm{SV})= & \begin{array}{l}
\text { stress intensity factor corresponding to "worst-case" operating } \\
\text { conditions, }
\end{array} \\
\mathrm{K}_{\mathrm{Ic}}(\mathrm{HT})= & \text { fracture toughness at the time of the hydro test, and } \\
\mathrm{K}_{\mathrm{Ic}}(\Delta \mathrm{t})= & \begin{array}{l}
\text { fracture toughness at the time of the successive hydro test and } \\
\text { corresponding to "worst-case" operating conditions. }
\end{array}
\end{aligned}
$$

$\mathrm{K}_{\mathrm{I}}$ can be thought of as the "load" that is trying to make the flaw propagate, and $\mathrm{K}_{\mathrm{Ic}}$ is a critical value (material property) of $\mathrm{K}_{\mathrm{I}}$ corresponding to the onset of propagation. Therefore, $\mathrm{K}_{\mathrm{I}} / \mathrm{K}_{\mathrm{Ic}}$ represents a potential for propagation of a flaw, and propagation 
takes place when $\mathrm{K}_{\mathrm{I}} \geq \mathrm{K}_{\mathrm{Ic}}$. As indicated by Eq. (10), the actual value of $\mathrm{K}_{\mathrm{I}} / \mathrm{K}_{\mathrm{Ic}}$ is not needed, only the relative value, for determining the hydro-test conditions. If, however, at the time of the hydro test $\mathrm{K}_{\mathrm{I}} / \mathrm{K}_{\mathrm{Ic}} \geq 1$, the vessel will fail. To avoid this possibility, a probabilistic analysis is performed to establish that the risk is sufficiently small (see Sect. 4).

As indicated above, $\mathrm{K}_{\mathrm{Ic}}$ is a material property. It represents the materials ability to resist propagation of a flaw in a brittle, unstable manner. It decreases with increasing exposure of the material to radiation and with decreasing temperature.

\subsection{Derivation of equations for $\mathrm{p}(\mathrm{HT})$ and $\Delta t$}

For the purpose of determining the hydro-test conditions, Eq. (10) is written as

$$
\frac{K_{I}(H T)}{K_{I}(S V)}=\frac{K_{I c}(H T)}{K_{I c}(\Delta t)}
$$

It is apparent from Eq. (11) that if $\mathrm{K}_{\mathrm{I}}$ and/or $\mathrm{K}_{\mathrm{Ic}}$ are multiplied by uncertainty factors, it does not change the hydro-test conditions because the factors cancel. There are other uncertainties, however, that do not cancel, and they are discussed later.

$\mathrm{K}_{\mathrm{I}}$ is calculated from ${ }^{1}$

$$
K_{I}=c \sigma \sqrt{\pi a}
$$

where

$$
\begin{aligned}
& \mathrm{c}=\text { crack characterization factor } \\
& \sigma=\text { far-field stress } \\
& \mathrm{a}=\text { crack dimension }
\end{aligned}
$$

Four types of stresses were considered in the original study: (1) membrane stress due to pressure, (2) bending stresses due to pressure and associated with discontinuities at 
the nozzles, (3) thermal stresses due to differences in temperature between the reflector water and pool water, and (4) residual stresses in the nozzle welds. The original studies ${ }^{1}$ indicated that the thermal stresses were relatively small, and thus they are not included in the determination of hydro-test conditions.

Equation (12) can be rewritten as

$$
K_{I}=\left[p\left(c_{m} s_{m}+c_{b} s_{b}\right)+c_{r} \sigma_{r}\right] \sqrt{\pi a},
$$

where

$$
\begin{aligned}
& \mathrm{p}=\text { primary-system pressure } \\
& \mathrm{s}=\sigma / \mathrm{p}
\end{aligned}
$$

$\mathrm{m}, \mathrm{b}, \mathrm{r}=$ membrane, bending, residual

Substituting Eq. (13) into Eq. (11) gives

$$
p(H T)=\frac{K_{I c}(H T)}{K_{l c}(\Delta t)} p(S V)+S\left(\frac{K_{l c}(H T)}{K_{l c}(\Delta t)}-1\right),
$$

or

$$
K_{l c}(\Delta t)=K_{I c}(H T)\left[\frac{p(S V)+S}{p(H T)+S}\right]
$$

where

$$
\begin{gathered}
\qquad S=\frac{c_{r} \sigma_{r}}{c_{m} s_{m}+c_{b} s_{b}} \\
\mathrm{p}(\mathrm{HT})=\text { hydro-test pressure } \\
\mathrm{p}(\mathrm{SV})=\text { "worst-case" operating pressure }
\end{gathered}
$$


An appropriate expression for $\mathrm{K}_{\mathrm{Ic}}$ is taken from Ref. 8:

$$
K_{l c}=A+B \exp \left[C\left(T-R T_{N D T}\right)\right] \text {, }
$$

where

$$
\begin{aligned}
\mathrm{T} & =\text { material temperature } \\
\mathrm{RT}_{\mathrm{NDT}}= & R T_{N D T_{\circ}}+\Delta R T_{N D T} \\
R T_{N D T_{\circ}} & \text { initial (no damage) value of the nil-ductility } \\
& \text { reference temperature } \\
\Delta \mathrm{RT}_{\mathrm{NDT}}= & \text { increase in } \mathrm{RT}_{\mathrm{NDT}} \text { due to radiation exposure } \\
& =\Delta \mathrm{NDTT} \\
\Delta \mathrm{NDTT} & =\text { increase in nil-ductility transition temperature } \\
\mathrm{A}, \mathrm{B}, \mathrm{C} & =\text { constants }
\end{aligned}
$$

The HFIR surveillance program provides $\triangle N D T T$ vs EFPY (see Sect. 2), and data available thus far indicate a linear relationship. Thus, Eq. (17) can be written as

$$
K_{I c}(H T)=A+B \exp [C \cdot E(H T)]
$$

and

$$
K_{l c}(\Delta t)=A+B \exp \{C[E(\Delta t)-e \cdot \Delta N D T T \cdot \Delta t]\}
$$

where

$$
\begin{aligned}
& E(H T)=T_{V}(H T)-R T_{N D T_{\odot}}-e \cdot \Delta N D T T \cdot \Delta t(H T) \\
& E(\Delta t)=T_{V}(\Delta t)-R T_{N D T_{\circ}}-e \cdot \Delta N D T T \cdot \Delta t(H T)
\end{aligned}
$$




$$
\begin{aligned}
\Delta \text { NDTT } & =\text { time-averaged rate of } \Delta \text { NDTT } \\
\mathbf{e} & =\text { uncertainty factor associated with } \Delta \text { NDTT } \\
\Delta t= & \text { time between successive hydro tests } \\
\Delta t(H T)= & \text { total operating time up to time of hydro test } \\
T_{v}(H T)= & \text { temperature of vessel during hydro test } \\
T_{v}(\Delta t)= & \text { "worst-case" (lowest) operating temperature of vessel } \\
& \text { (assumed to exist at any time during } \Delta t \text { ) }
\end{aligned}
$$

Substituting Eq. (19) into Eq. (15) and solving for $\Delta t$ gives

$$
\Delta t=\frac{E(\Delta t)-\frac{1}{C} \ln \left\{\frac{A}{B}\left[\frac{K_{I c}(H T)}{A}\left(\frac{p(S V)+S}{p(H T)+S}\right)-1\right]\right\}}{e \cdot \Delta N \dot{D} T T}
$$

The crack dimension, a, does not appear in Eqs. (14)-(22) because it cancels out when Eq. (13) is substituted into Eq. (11) to obtain Eqs. (14) and (15). However, values of $c_{b}, c_{m}, c_{r}$ and $\Delta N D T T$ are functions of crack size. The relationships are complex, and the effects of variable a on $\mathrm{p}(\mathrm{HT})$ and $\Delta t$ are small, as will be demonstrated. Thus, the relationships were not included in the foregoing equations.

The insensitivity of $\mathrm{p}(\mathrm{HT})$ and $\Delta \mathrm{t}$ to a can be qualitatively demonstrated by examining Eqs. (11), (14), (16) and (18)-(22). It is observed that the quantities $c_{b}, c_{m}, c_{r}$ and $\Delta N D T T$ tend to appear as ratios so that the effects of a on these parameters tend to cancel. A quantitative assessment of sensitivity was made by calculating values of $p(H T)$ and $\Delta t$ for two different values of $\underline{a}$, as discussed later.

Values of $c_{b}, c_{m}$, and $c_{r}$ are also functions of flaw type, location, and orientation, and of the relative position on the crack front at which $\mathrm{K}_{\mathrm{I}}$ is to be determined. The type of flaw selected for the HFIR vessel integrity evaluation is the type specified in the ASME Code for evaluation of PWR vessels, and the locations and orientations selected are those resulting in maximum values of $p(H T)$ or minimum values of $\Delta t$. 


\subsection{Uncertainties}

There are two uncertainties of particular concern in the determination of the hydro-test conditions: (1) the uncertainty in the value of $\triangle \mathrm{ND} T T$, which is designated by the factor e in Eqs. (9) -(11), and (2) the uncertainty in the shape of the $\mathrm{K}_{\mathrm{Ic}}$ vs T-RT $\mathrm{NDT}$ curve (Fig 5.1). If the uncertainty factor, e, is very large, $T_{V}-R T_{N D T}$ is very small, and thus, $\mathrm{K}_{\mathrm{Ic}}$ corresponds to the lower shelf of the $\mathrm{K}_{\mathrm{Ic}}$ vs $\mathrm{T}-\mathrm{RT}_{\mathrm{NDT}}$ curve (Fig. 5.1). For this case, $\mathrm{p}(\mathrm{HT}) \sim \mathrm{p}(\mathrm{SV})$ because very little radiation damage takes place during $\Delta \mathrm{t}$. At the other extreme, $e=0$, the same result is obtained. Thus, there tends to be a maximum in the $\mathrm{p}(\mathrm{HT})$ vs e curve and a minimum in the $\Delta t$ vs e curve. However, as will be demonstrated later, the values of e for which zero derivatives exist may be outside the range of reasonable values. In this event, the values of $p(H T)$ and $\Delta t$ specified for the hydro test could correspond to values of $e$ at one end or the other of the reasonable range. Or, if the specific values of $\mathrm{p}(H T)_{\max }$ and $\Delta \mathrm{t}_{\min }$ do not impose excessive constraints, they could be specified for the hydro test so as to negate the need for specifying limits on e. Even so, limits of 0.5 to 1.5 have been established (Appendix B).

As indicated by Eqs. (14) and (22), $p(H T)$ and $\Delta t$ are sensitive to the shape (slopes of the $\mathrm{K}_{\mathrm{Ic}}$ vs $\mathrm{T}-\mathrm{RT}_{\mathrm{NDT}}$ curve) and not the amplitude. "Bounding" curves were selected for the study by using the ASME lower-bound $\mathrm{K}_{\mathrm{Ic}}$ curve $^{8}$ (Fig. 5.1) and a recently derived mean $\mathrm{K}_{\mathrm{lc}}$ curve $^{9}$ (Fig. 5.1). The former curve has a relatively steep transition region $\left(\mathrm{T}-\mathrm{RT}_{\mathrm{NDT}}>0^{\circ} \mathrm{F}\right)$ and a relatively flat lower shelf. The two curves were used to establish the sensitivity of $\mathrm{p}(\mathrm{HT})$ and $\Delta \mathrm{t}$ to variations in the shape of the curve.

Uncertainties in $\triangle \mathrm{NDTT}$ are associated with measurement and interpretation of the surveillance-specimen data and with transposition of the $\Delta N D T T$ values at the location of the surveillance specimens to the hypothetical flaws in the vessel wall. This latter uncertainty depends to a large extent on how well the calculated neutron and/or gamma fluxes are known. As discussed in Appendix $\mathrm{C}$, which relies on information from Appendices $\mathrm{D}$ and $\mathrm{E}$, the uncertainty in the fluxes is well within the reasonable range of e values ( 0.5 to 1.5$)$. 


\subsection{Calculations}

\subsubsection{Input}

The flaw specified by the ASME Code ${ }^{4}$ for PWR pressure vessels, with a wall thickness equal to that for the HFIR vessel, is a semielliptical surface flaw with a major-diameter to minor-radius ratio of 6 and a depth (minor radius) of 1.0 in. This flaw was adopted for the HFIR vessel analysis, although one additional depth ( $\mathrm{a}=0.5$ in.) was considered for sensitivity studies. As discussed in Appendix F, 0.5 in. is an estimate of the minimum critical flaw size.

The critical location of the flaw was determined in Ref. 1 to be at the HB-3 nozzle weld, directly above the nozzle center, on the inner surface, with a longitudinal orientation. This "flaw" was used for determining the hydro-test conditions.

The "worst-case" operating conditions for HFIR for determining the hydro-test conditions included ${ }^{1}$ a primary-system pressure equal to the primary-system safety-valve (rupture disc) nominal rating (650 psi), plus its design tolerance and difference in vessel and pool heads, for a total of 679 psid. The corresponding vessel temperature [ $\left.T_{v}(\Delta t)\right]$ was specified as $85^{\circ} \mathrm{F}$, although values down to $65^{\circ} \mathrm{F}$ were included, also. These loading conditions ( 679 psid and $85^{\circ} \mathrm{F}$ ) correspond to ASME-Code-defined emergency/faulted operating conditions (see Sect. 3).

The hydro-test temperature $\left[\mathrm{T}_{\mathrm{V}}(\mathrm{HT})\right]$ can be any convenient value, with the understanding that the calculated, and thus specified, value of $p(H T)$ or $\Delta t$ will be dependent on the value of $T_{v}(H T)$ selected. For example, the higher $T_{v}(H T)$, the higher $\mathrm{p}(\mathrm{HT})$ or the smaller $\Delta \mathrm{t}$.

The value of $\Delta t(H T)$, which is the total operating time of the vessel up to the time of the "last" hydro test, is 19.4 EFPY(100MW). As mentioned above, the values of $\Delta N D T T, c_{m}, c_{b}$ and $c_{r}$ are functions of crack depth, and two crack depths were considered ( 0.5 and 1.0 in.). Values of these parameters for the two crack depths are provided in Table 5.1, which summarizes all the input data. 
The values of $\triangle$ NDTT in Table 5.1 are taken from Table 5.2 of Ref. 1, with modifications as discussed in Appendix A. Values of $c_{m}, c_{b}$ and $c_{r}$, for $a=1.0$ in., and for $s_{m}$, $s_{b}$ and $\sigma_{r}$ are taken from Tables 5.4 and 5.3, respectively, of Ref. 1. Values of $c_{m}, c_{b}$ and $c_{r}$ for $a=0.5$ in. were calculated separately. ${ }^{* * *}$

As mentioned earlier, values of $c_{m}, c_{b}$ and $c_{r}$ are also a function of position on the crack front. The ones given in Table 5.1 correspond to the deepest point because for this study that point results in the largest value of $\mathrm{K}_{\mathrm{I}} / \mathrm{K}_{\mathrm{Ic}}$.

As mentioned above, two "extreme" $\mathrm{K}_{\mathrm{Ic}}$ vs T-RT $\mathrm{T}_{\mathrm{NDT}}$ curves were included in the study as a means of addressing the uncertainty in the shape of the curve. Both are of the exponential form given by Eq. (7). The two sets of coefficients are given in Table 5.1, and the two curves are plotted in Fig. 5.1.

The number of effective full-power years at a power level of $100 \mathrm{MW}$ [EFPY(100 MW)] included in Table 5.1 for $\Delta t(H T)$ is based on 707,081 MWd, which corresponds to the end of HFIR fuel cycle number 323, and the time at which a hydro test was conducted with $\mathrm{p}(\mathrm{HT})=900$ psid and $\mathrm{T}_{\mathrm{v}}(\mathrm{HT})=85^{\circ} \mathrm{F}$. [The number of EFPY $(100$ $\mathrm{MW})=707,081 \mathrm{MWd} /(365 \mathrm{~d} / \mathrm{y} \times 100 \mathrm{MW})=19.4$.

.* J. G. Merkle, Oak Ridge National Laboratory, personal communication 
Table 5.1 Input data for the calculation of $p(H T)$ and $\Delta t$

\begin{tabular}{|c|c|c|}
\hline PARAMETER & \multicolumn{2}{|c|}{ \% } \\
\hline Fracture-toughness curve & $\operatorname{ASME~} K_{l c}^{8}$ & New mean' \\
\hline$A, k s i \sqrt{\text { in }}$ & 33.2 & 36.68 \\
\hline$B, k s i \sqrt{\text { in }}$ & 20.73 & 51.59 \\
\hline$C,{ }^{\circ} F^{1}$ & 0.020 & 0.0115 \\
\hline a, in. & 1.0 & 0.5 \\
\hline$c_{b}$ & 0.741 & 0.823 \\
\hline$c_{m}$ & 1.146 & 1.068 \\
\hline$c$, & 0.860 & 0.860 \\
\hline$s_{b}$ & \multicolumn{2}{|c|}{4.24} \\
\hline$s_{m}$ & \multicolumn{2}{|c|}{16.8} \\
\hline$\sigma, k s i$ & \multicolumn{2}{|c|}{8.5} \\
\hline$p(H T), p s i$ & \multicolumn{2}{|c|}{ variable/dependent variable } \\
\hline$p(S V), p s i$ & \multicolumn{2}{|c|}{679} \\
\hline$R T_{N D T_{0},{ }^{\circ} F}$ & \multicolumn{2}{|c|}{10} \\
\hline $\begin{array}{l}\triangle N \dot{D T T},{ }^{\circ} F / E F P Y(100 \mathrm{MW}) \\
(a=1.0 \mathrm{in})\end{array}$ & \multicolumn{2}{|c|}{2.44} \\
\hline $\begin{array}{l}\triangle N \dot{D} T T,{ }^{\circ} F / E F P Y(100 \mathrm{MW}) \\
(a=0.5 \mathrm{in} .)\end{array}$ & \multicolumn{2}{|c|}{2.62} \\
\hline$e$ & \multicolumn{2}{|c|}{ variable } \\
\hline$T_{V}(H T),{ }^{\circ} F$ & \multicolumn{2}{|c|}{85} \\
\hline$T_{\boldsymbol{V}}(\Delta t),{ }^{\circ} F$ & \multicolumn{2}{|c|}{$85,80,75,70,65$} \\
\hline$\Delta t(H T), E F P Y(100 M W)$ & \multicolumn{2}{|c|}{19.4} \\
\hline$\Delta t, E F P Y(100 M W)$ & \multicolumn{2}{|c|}{ variable/dependent variable } \\
\hline
\end{tabular}




\subsubsection{Calculation of $\mathrm{p}(\mathrm{HT}), \Delta \mathrm{t}$, and related parameters}

Three basic cases were evaluated in this report. In each case $p(H T)$ and $\Delta t$ were calculated as a function of e with $T_{v}(\Delta t)$ as a variable parameter. Calculations were made for two values of crack depth (a) to demonstrate that $\mathrm{p}(\mathrm{HT})$ and $\Delta \mathrm{t}$ are not sensitive to $\underline{\mathbf{a}}$, and for two "bounding" $\mathrm{K}_{\mathrm{Ic}}$ curves. The cases are defined concisely as follows and in more detail in Appendix $G$ (input for these cases is included in Table 5.1):

$\begin{array}{cl}\frac{\text { Case }}{\mathrm{A}} & \mathrm{\text {Description }} \\ \mathrm{B} & \mathrm{a}=1.0 \text { in., ASME } \mathrm{K}_{\mathrm{Ic}} \text { curve }^{8} \\ \mathrm{C} & \mathrm{a}=0.5 \text { in., ASME } \mathrm{K}_{\mathrm{Ic}} \text { curve }^{8} \\ & \mathrm{a}=1.0 \text { in., updated mean } \mathrm{K}_{\mathrm{Ic}} \text { curve }^{9}\end{array}$

For the calculation of $\mathrm{p}(\mathrm{HT})$, a single value of $\Delta t=1$ EFPY was used because that is the value initially specified by DOE for the hydro tests. ${ }^{1}$ For the calculation of $\Delta t$, a single value of $p(H T)=900$ psi was used because that is the value that DOE initially agreed to for the hydro tests. ${ }^{1}$ Increasing $p(H T)$ increases $\Delta t$, which is desirable, but it also increases the probability of vessel failure during the hydro test. On the basis of the earlier studies ${ }^{1}$ and these, it was concluded that $p(H T)=900$ psi is reasonable but does not necessarily represent an "optimum".

The more important aspects of the results of the analysis are as follows:

\section{Flaw-depth effects on $\mathrm{p}(\mathrm{HT})$ and $\Delta t$}

As mentioned in Sect. 5.3, $\mathrm{p}(\mathrm{HT})$ and $\Delta \mathrm{t}$ are rather weak functions of crack depth (a). To demonstrate this, calculations of $\mathrm{p}(\mathrm{HT})$ and $\Delta \mathrm{t}$ were made for two "extreme" values of a: 0.5 in., which is the minimum critical flaw size, and 1.0 in., which is the largest value of a required by the ASME Code. The results (Fig. 5.2) show that, for reasonable values of $e$, the corresponding values of $\mathrm{p}(\mathrm{HT})$ and $\Delta t$ differ by less than $5 \%$. 
$p(H T)$ and $\Delta t$ vs e for $T_{v}(\Delta t)=85^{\circ} \mathrm{F}$

As mentioned above, there is a maximum in the curve of $\mathrm{p}(\mathrm{HT})$ vs $e$ and a minimum in the curve of $\Delta t$ vs e. This is evident in Fig. 5.2 for $T_{v}(\Delta t)=85^{\circ} \mathrm{F}$ and $\Delta t=1$ EFPY $(100 \mathrm{MW})$, for the calculation of $\mathrm{p}(\mathrm{HT})$ vs $\mathrm{e}$; and for $\mathrm{T}_{v}(\Delta \mathrm{t})=85^{\circ} \mathrm{F}$ and $\mathrm{p}(\mathrm{HT})=$ 900 psid for the calculation of $\Delta t$ vs e. The corresponding values of $p(H T)$ and $\Delta t$ are $709 \mathrm{psi}$ and 8.0 EFPY(100 MW), using the ASME lower-bound fracture toughness curve, and 713 psi and 7.1 EFPY(100 MW) using the other "bounding" fracture toughness curve. The corresponding values of e, using the ASME fracture toughness curve, are $~ 1.5$ and, using the other fracture toughness curve, $<2.5$. The largest value of $e$ that needs to be considered, in accordance with Ref. 1 and Appendix B, is 1.5. For this value of e, the values of $\mathrm{p}(\mathrm{HT})$ and $\Delta t$ are about the same for the two fracture-toughness curves $[\mathrm{p}(\mathrm{HT})$ $\approx 709 \mathrm{psi}, \Delta \mathrm{t} \approx 8.0 \mathrm{EFPY}(100 \mathrm{MW})]$.

The above results are very similar to what was calculated previously," even though the fracture toughness curves used in this study are different than the one used in the earlier study. The earlier fracture toughness curve was the ASME $\mathrm{K}_{\mathrm{IR}}$ curve (lower bound of dynamic and crack arrest data) ${ }^{8}$, which tends to result in somewhat lower values of $p(H T)$, larger values of $\Delta t$, and smaller values of critical crack size. The recent analysis is the more realistic.

\section{$\mathrm{p}(\mathrm{HT})$ and $\Delta t \mathrm{vs}$ e for $\mathrm{T}_{\mathrm{v}}(\Delta \mathrm{t})<85^{\circ} \mathrm{F}$}

From a reactor operational point of view, there are incentives for allowing $T_{V}(\Delta t)$ $<85^{\circ} \mathrm{F}$, which is the presently specified minimum operating temperature of the vessel (minimum permissible temperature of the cooling tower basin). For that reason, calculations were also made with $T_{v}(\Delta t)=80,75,70$ and $65^{\circ} F$. As $T_{v}(\Delta t)$ decreases, the values of e corresponding to the maximum in $\mathrm{p}(\mathrm{HT})$ and the minimum in $\Delta t$ decrease. This raises the question as to how small a value of e needs to be considered. This

** Unpublished data prepared and presented at the time Ref. 1 was being published but that was not included therein. 
question is addressed in Appendix $\mathrm{B}$, and it is concluded that a reasonable lower limit of $e$ is 0.5 , as mentioned earlier. Thus, for $T_{v}(\Delta t)=65^{\circ} \mathrm{F}$, and considering the results corresponding to the ASME lower-bound fracture toughness curve, $\Delta t$ is less than zero. For $T_{V}(\Delta t)=70^{\circ} \mathrm{F}, \Delta t=1.4 \operatorname{EFPY}(100 \mathrm{MW})$, and for $\mathrm{T}_{\mathrm{V}}(\Delta \mathrm{t})=75^{\circ} \mathrm{F}$, the minimum in the curve occurs above $\mathrm{e}=0.5$; for this case, $\Delta t=4.5 \mathrm{EFPY}(100 \mathrm{MW})$. Results corresponding to the upper-bound fracture-toughness curve show that the minimum values occur above $\mathrm{e}=1.5$. For $\mathrm{T}_{\mathrm{v}}(\Delta \mathrm{t})=70^{\circ} \mathrm{F}, \Delta \mathrm{t}_{\min }=4.3 \mathrm{EFPY}(100 \mathrm{MW})$. Thus, for $T_{V}(\Delta t)=70^{\circ} \mathrm{F}$, the limiting value of $\Delta t$ is $1.4 \operatorname{EFPY}(100 \mathrm{MW})$, and for $T_{V}(\Delta t)$ $=75^{\circ} \mathrm{F}$, it is $4.5 \mathrm{EFPY}(100 \mathrm{MW})$. The "minimum" values corresponding to the two bounding fracture toughness curves are summarized in Table 5.2.

Table 5.2 "Minimum" values of $\Delta \mathrm{t}$ as a function of vessel temperature and corresponding to the two bounding fracture toughness curves

\begin{tabular}{|c|c|c|}
\hline \multirow[t]{2}{*}{$\mathrm{T}_{\mathrm{v}}(\Delta \mathrm{t}),{ }^{\circ} \mathrm{F}$} & \multicolumn{2}{|c|}{$\Delta t$, EFPY $(100 \mathrm{MW})$} \\
\hline & Curve $A^{2}$ & Curve $\mathrm{B}^{\mathrm{b}}$ \\
\hline 85 & 8.0 & $8.6^{c}$ \\
\hline 80 & 6.5 & \\
\hline 75 & 4.5 & \\
\hline 70 & $1.4^{\mathrm{d}}$ & $4.5^{c}$ \\
\hline 65 & $<0$ & \\
\hline \multicolumn{3}{|c|}{$\begin{array}{l}\text { ASME } \mathrm{K}_{\mathrm{Ic}} \text { curve (Ref. } 8 \text { ), } \mathrm{a}=1.0 \mathrm{in} \text {. } \\
\text { Mean } \mathrm{K}_{\mathrm{Ic}} \text { curve (Ref. 9), a = } 1.0 \mathrm{in} \text {. } \\
\text { Value at } \mathrm{e}=1.5 \text {; not a minimum } \\
\text { Value at } \mathrm{e}=0.5 \text {; not a minimum }\end{array}$} \\
\hline
\end{tabular}

5.6 The distinction between $\Delta t$ and vessel life extension

It is not the intent of this report to estimate vessel life extension beyond 26 EFPY (100 MW), but it is important to make a clear distinction between $\Delta t$ associated with hydro-test conditions and vessel life extension. 
The calculated maximum permissible time between successive hydro tests $(\Delta t)$ by itself does not represent a permissible life extension of the vessel, because as indicated by Eq. 11, it is based on the relative change in fracture toughness between successive hydro tests, not the absolute value. The change decreases with increasing time of operation, and thus $\Delta t$ increases with time.

By contrast, a criterion for vessel life extension is that the probability of failure during the hydro test and also during "normal" operation, including emergency/faulted conditions, must be less than a maximum permissible value, and the probability of failure increases with increasing time (decreasing fracture toughness).

Equation 10 implies that the probability of failure during the hydro test must be at least equal to the probability of failure at any other time during the period between successive hydro tests. Thus, if the probability of failure for the hydro test is acceptable, the vessel can be operated for an additional time $\Delta t$, or some fraction thereof, if a safety factor is applied. At some time thereafter, however, the probability of failure may be excessive because of the continuing decrease in fracture toughness, and that will signify the end of vessel life in its irradiated condition (annealing to mitigate the radiation damage might be considered as a means of extending the life further).

As mentioned in Ref. 1, other factors, such as the potential for fragmentation, might need to be considered when estimating life extension but not for the calculation of $\Delta t$. 


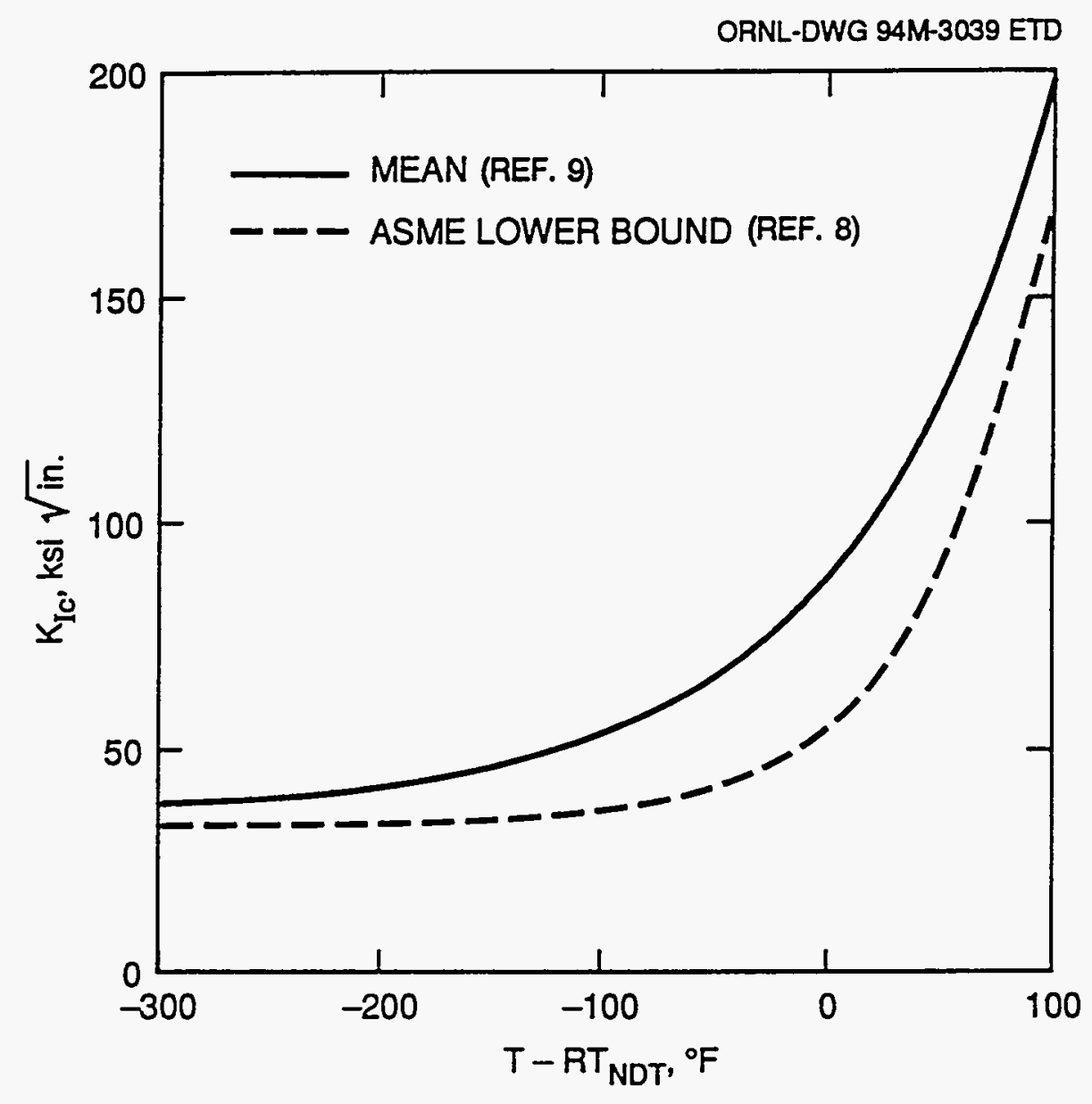

Fig. 5.1 Fracture toughness curves used in the calculation of $p(H T)$ and $\Delta t$ 


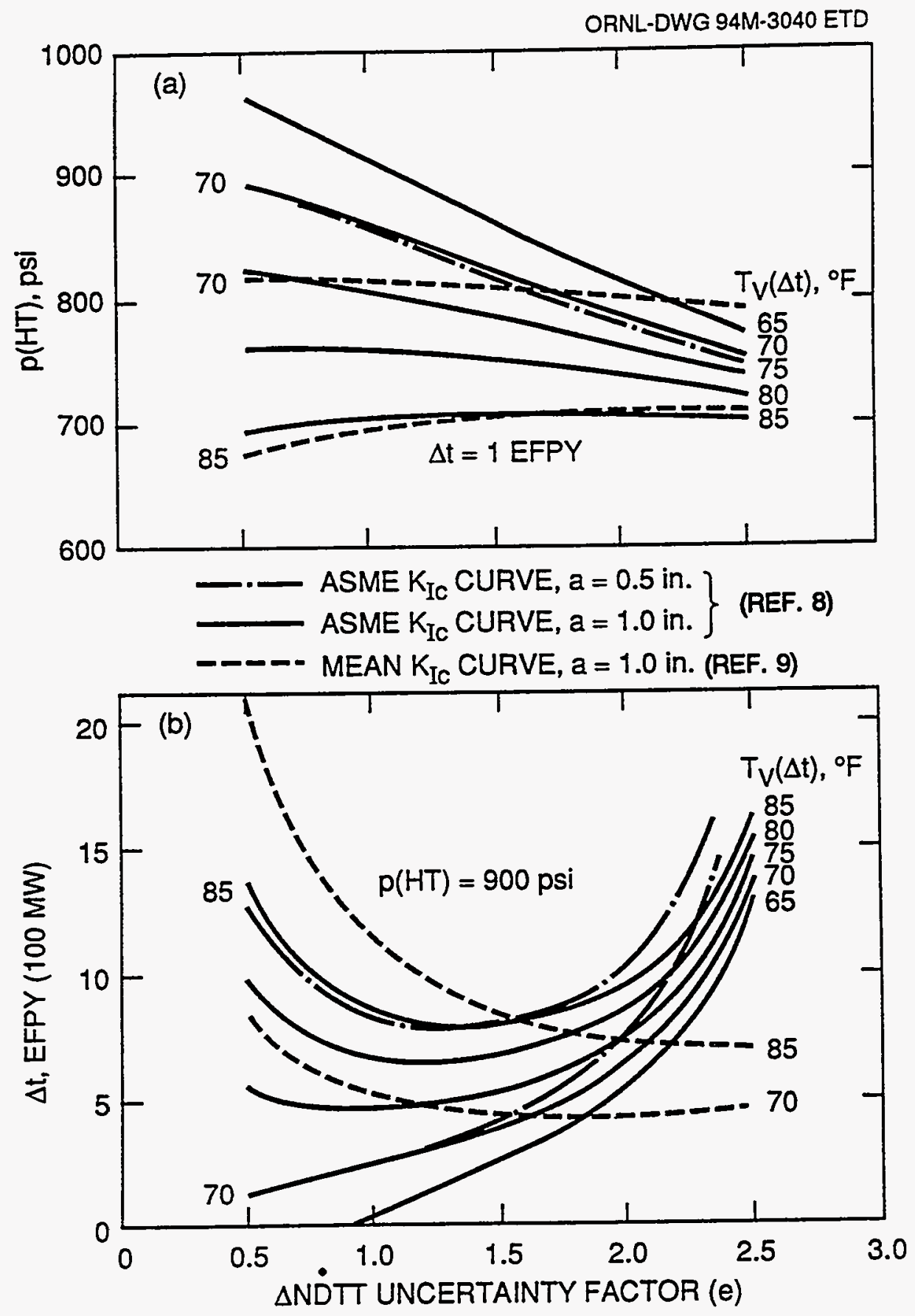

Fig. $5.2 p(H T)$ and $\Delta t$ vs e and $T_{v}(\Delta t)$ for two crack depths and two bounding fracture toughness curves 


\section{Reevaluation of Hydro-Test Conditions}

As mentioned in the Introduction, a Memo of Understanding (MOU) pertaining to the present HFIR surveillance activities ${ }^{2}$ states that "The ETD PVTSH shall be responsible for comparing embrittlement rates to the worst-case assumptions made in the calculations to establish the hydrostatic test pressure in ORNL/TM-10444 and ORNL/TM-1372/S1." In addition, the HFIR technical specifications ${ }^{3}$ state that "If embrittlement rates indicated by the surveillance tests exceed the worst-case assumption made in the calculation to establish the hydrostatic test pressure, a new hydrostatic test pressure or test frequency shall be established to maintain equivalent safety margins." The "worst-case assumptions" referred to in the MOU pertain primarily to the embrittlement rate ( $\triangle N \mathrm{NDTT}$ ), which is a best-estimate value obtained from the surveillance program, times an uncertainty factor. Other worst-case assumptions pertain to the off-normal maximum primary-system pressure and minimum vessel temperature; the type, location, and orientation of the hypothetical flaw; and the stresses at the location of the flaw.

A $\triangle$ NDTT uncertainty factor of 1.5 was specified by DOE ${ }^{1}$ and was used in Ref. 1 to help establish the hydro-test conditions for HFIR. Calculations performed at that time, but subsequent to the publication of Ref. 1, indicated that there could be an "optimum" uncertainty factor that results in the highest hydro-test pressure and/or maximum frequency of testing. Results in this report show (Fig. 5.2) that for the hydro-test conditions specified in Ref. $1\left[\mathrm{p}(\mathrm{HT})=900 \mathrm{psi}, \mathrm{T}_{\mathrm{v}}(\mathrm{HT})=85^{\circ} \mathrm{F}, \mathrm{T}_{\mathrm{v}}(\Delta \mathrm{t})=85^{\circ} \mathrm{F}\right)$ ], a minimum value of the maximum permissible time between successive hydro tests does exist in a plot of $\Delta t$ vs $e$ and is equal to $8.0 \mathrm{EFPY}(100 \mathrm{MW})$ or $9.4 \mathrm{EFPY}(85 \mathrm{MW})$. Coincidentally, the corresponding value of $\mathrm{e}$ is -1.5 . Thus, the worst-case assumption with regard to embrittlement rate can be defined as $1.5 \times 3.8=5.7^{\circ} \mathrm{F} / \mathrm{EFPY}(100 \mathrm{MW})$, where the specific best-estimate value of $\triangle \mathrm{ND} T \mathrm{~T}$ [3.8 $8^{\circ}$ F/EFP(100 MW)] is taken from Ref. 1 (Table 5.2) for nozzle weld material and normalized to Key 7, Position 8. As indicated in Table 2.6 of this report, the updated value of $\triangle N \dot{D} T T$ for the nozzle weld is the same as before $\left[3.8^{\circ} \mathrm{F} / \mathrm{EFPY}(100 \mathrm{MW})\right]$ and, thus, is substantially less than the permissible value of $5.7^{\circ} \mathrm{F} / \mathrm{EFPY}(100 \mathrm{MW})$. It is also observed with reference to Table 2.6 that the updated value of $\triangle N D$ TT for the seam weld is the same as determined previously, and for A212B it is $4 \%$ less than determined previously. Thus, the 
nozzle weld remains the critical material for evaluating hydro-test conditions, and the previously specified hydro-test conditions, stated above, are more than adequate.

As discussed in greater detail in Sect. 5 , the calculated value of $\Delta t$ is a function of the time at which the hydro test is conducted and increases with increasing time of reactor operation. The value of 8.0 EFPY (100 MW) is based on the time of the hydro test conducted following fuel cycle 323 [707,081 MWd or 19.4 EFPY(100 MW)]. 
7. Suggestions for Future Hydro Testing

\subsection{Increase in $\Delta t$}

Hydro testing of the HFIR vessel is an expensive operation, and this provides an incentive for reducing the frequency of testing. As indicated by the calculated results in Fig. 5.2, the maximum permissible time between successive hydro tests, based on $\mathrm{p}(\mathrm{HT})=900 \mathrm{psi}, \mathrm{T}_{\mathrm{V}}(\mathrm{HT})=85^{\circ} \mathrm{F}$ and $\mathrm{T}_{\mathrm{v}}(\Delta \mathrm{t})=85^{\circ} \mathrm{F}$, is $8.0 \mathrm{EFPY}(100 \mathrm{MW})$. The DOE McSpadden committee, however, recommended ${ }^{1} \Delta t=0.85$ EFPY (100 MW) [1.0 EFPY (85 MW))], presumably because (1) the location of the flaw dictating the hydrotest conditions was in a nozzle weld, (2) the only radiation-damage data for this material was obtained from the ORR (see Sect. 2), and (3) there was something unusual and unknown about the HFIR vessel irradiation conditions that resulted in a damage rate greater than expected ${ }^{1}$, and that raised questions about the accuracy of the ORR data. To help resolve this issue, nozzle weld material was included in the continuing surveillance program, but at the time of this writing (March 1994) a fluence of only $6 \times 10^{16} \mathrm{n} / \mathrm{cm}^{2}(\mathrm{E}>1 \mathrm{MeV})$ had been accumulated. The 1993 HFIR surveillance data (Sect. 2) are in reasonably good agreement with the ORR data, but because of the very low fluence, the uncertainty in extrapolating to the actual vessel fluences is rather large. Thus, there is not much more known today about the damage rate of the nozzle welds than there was in 1987 , when the hydro-test conditions were established.

Although the uncertainty in the damage rate of the nozzle welds has not yet been substantially reduced, it is known from the results in Fig. 5.2, as discussed earlier, that there is an "optimum" value of the uncertainty factor that corresponds to a minimum value of $\Delta t$. If this value of $\Delta t$ can be tolerated, then it is not necessary to know what the actual uncertainty factor is. Thus, the uncertainty in the damage rate is not a justifiable reason for applying a large safety factor to $\Delta t$.

Another consideration in establishing a safety factor for $\Delta t$ is the growth of flaws that may exist. In the calculation of the hydro-test conditions, it was assumed that the growth between successive hydro tests was negligible. This assumption is supported by 
-20 EFPY (100 MW) of operation and many hydro tests without any indication of a flaw of critical size. The maximum value of the minimum critical flaw size is $-1.0 \mathrm{in}$. (Appendix F). Assuming a constant growth rate, due to unspecified mechanisms, and zero initial flaw size, the growth rate required to achieve a 1.0-in.-deep flaw in 20 EFPY is -0.05 in./EFPY(100 MW). The results in Fig. 5.2 indicate that the hydro-test conditions are insensitive to flaw size, and thus, from this point of view, and for the presently specified conditions otherwise, $8 \mathrm{EFPY}(100 \mathrm{MW})$ between successive hydro tests would be acceptable.

Based on the above information, it appears reasonable to increase the value of $\Delta t$ above that presently specified [0.85 EFPY $(100 \mathrm{MW})]$. There are no specific technical criteria with which to make the choice. However, it is prudent to apply a safety factor of two to the calculated maximum permissible value, which for the presently specified values of $\mathrm{p}(\mathrm{HT}), \mathrm{T}_{\mathrm{v}}(\mathrm{HT})$ and $\mathrm{T}_{\mathrm{v}}(\Delta \mathrm{t})$, is $8.0 \mathrm{EFPY}(100 \mathrm{MW})$. Thus, $\Delta t=4.0$ EFPY $(100 \mathrm{MW})$ is reasonable.

\section{Decrease in $T_{v}(\Delta t)$}

In the calculation of the hydro-test conditions, the minimum temperature of the vessel while pressurized was specified as $85^{\circ} \mathrm{F}$ because this is the minimum control point for the coolant in the cooling-tower basin. Operational flexibility is improved by allowing a lower basin temperature, and presumably there are accident scenarios that could reduce the basin temperature below $85^{\circ} \mathrm{F}$. The information in Fig. 5.2 can be used to estimate values of $\Delta t$ that are consistent with different values of $T_{v}(\Delta t)$, assuming $p(H T)$ $=900$ psi and $\mathrm{T}_{\mathrm{v}}(\mathrm{HT})=85^{\circ} \mathrm{F}$. Results based on the minimum values of $\Delta \mathrm{t}$ within 0.5 se $s 1.5$ and a safety factor of 0.5 on $\Delta t$ are included in Table 7.1. The reasonableness of the limits on e are discussed in Appendix B. 
Table 7.1 Maximum permissible values of $\Delta t$ vs $T_{v}(\Delta t)$ for $p(H T)=900 p s i$, $T_{\mathrm{V}}(\mathrm{HT})=85^{\circ} \mathrm{F}$ and a safety factor of 0.5 on the calculated nominal value of $\Delta t$

\begin{tabular}{|c|c|c|}
\hline \multirow{2}{*}{$\mathrm{T}_{\mathrm{V}}(\Delta \mathrm{t}),{ }^{\circ} \mathrm{F}$} & \multicolumn{2}{|c|}{$\Delta \mathrm{t}, \mathrm{EFPY}$} \\
\cline { 2 - 3 } & $100 \mathrm{MW}$ & $85 \mathrm{M}$ \\
\hline 85 & 4.0 & 4.7 \\
\hline 80 & 3.3 & 3.8 \\
\hline 75 & 2.3 & 2.6 \\
\hline 70 & 0.7 & 0.8 \\
\hline
\end{tabular}




\section{Progress in Understanding Reasons for the "Accelerated" Damage Rate of the HFIR Vessel Surveillance Specimens}

In Ref. 1 and in the Introduction for this report, it is mentioned that the HFIR vessel surveillance data obtained in 1986 indicated an embrittlement rate that is greater than had been expected. Since that time, several possible explanations have been suggested and explored both theoretically and experimentally. This effort is summarized in Ref. 10, and a brief account is given below.

The suggested explanations include the following: (1) a fast-neutron-fluence rate effect; (2) contribution of thermal neutrons; (3) chemical composition, primarily $\mathrm{Cu}, \mathrm{Ni}, \mathrm{P}$, and $\mathrm{B}$; and (4) contribution of gammas.

The fast neutron flux (E $>1 \mathrm{MeV}$ ) in the HFIR surveillance specimens is less, by a factor of $\sim 10^{5}$, than that in the materials testing reactors that provided data for irradiation temperatures appropriate for HFIR ( $\leq 200^{\circ} \mathrm{F}$ ). A case was made in Refs. 1 and 11 for a negative fluence-rate effect (the lower the neutron flux the greater the damage per neutron), but data obtained later from testing of the Shippingport shield-tank material indicated essentially no rate effect.

Neutron spectral effects were suggested in Ref. 1, and a theory was developed later that indicated a significant contribution from thermal neutrons, if the ratio of thermal-to-fast (E $>1 \mathrm{MeV}$ ) flux were at least 20. Ratios $\geq 20$ do exist at some, but not all, surveillancespecimen locations. Surveillance data evaluated thus far are for locations with a ratio $<20$, and yet the accelerated rate is evident.

With regard to chemical composition, boron, copper, nickel and phosphorus are known to contribute to radiation damage to varying degrees and under various circumstances. As for their potential contributions to the "accelerated embrittlement" for HFIR, however, boron and phosphorus have been ruled out because of their very low concentrations in the vessel materials, and copper and nickel are ruled out because of the low irradiation temperature and very low fluence. 
The remaining contender for the cause of the higher rate of damage in the HFIR surveillance specimens is the contribution of gammas. The ratio of gamma flux to fast-neutron flux at the inner surface of the HFIR vessel wall is unusually high primarily because of the relatively large attenuation of neutrons, compared to gammas, through the $12 \mathrm{in}$. of beryllium and 24 in. of water between the core and vessel. Under these specific conditions, it is postulated that gamma radiation could dominate the embrittlement observed in the HFIR surveillance specimens. Experiments are being proposed to further explore the possibility, and the potential impact of this situation (damage due to gammas rather than neutrons) on the determination of hydro-test conditions is discussed in Sect. 5 and Appendix C. 


\section{References}

1. R. D. Cheverton, J. G. Merkle, and R. K. Nanstad, Evaluation of HFIR PressureVessel Integrity Considering Radiation Embrittlement, Oak Ridge National Laboratory, ORNL/TM-10444, April 1988.

2. Letter of transmittal from H. A. Glovier to D. F. Craig and J. E. Jones Jr., "Memorandum of Understanding (MOU) Between Research Reactor Division (RRD), Metals and Ceramics Division (M\&C), and Engineering Technology Division (ETD), for Removal, Testing, and Analysis of HFIR Pressure-Vessel Surveillance Specimens and Subsequent Reporting of Results and Recommendations," dated April 30, 1993.

3. HFIR Technical Specifications, ORNL/TM-5711/R2, Revised November 1992.

4. ASME Boiler and Pressure Vessel Code, Section III, Division 1, Appendix G, 1992 Edition.

5. ASME Boiler and Pressure Vessel Code, Section XI, Division 1, Appendix A, 1992 Edition.

6. U.S. NRC Standard Review Plan, NUREG-0800, Sect. 5.3.2, Rev. 1, July 1981.

7. Personal communication with Research Reactor Division, Oak Ridge National Laboratory.

8. T. U. Marston, Ed., Flaw Evaluation Procedures: ASME Section XI, EPRI NP719-SR, Electric Power Research Institute, Palo Alto, CA, August 1978, including corrections dated April 14, 1980.

9. R. K. Nanstad, J. A. Keeney and D. E. McCabe, Preliminary Review of the Bases for the $K_{I c}$ Curve in the ASME Code, ORNL/NRC/LTR-93/15, July 12, 1993.

10. K. Farrell et al., "An Evaluation of Low Temperature Radiation Embrittlement Mechanisms in Ferritic Alloys" to be published in the Journal of Nuclear Materials.

11. R. D. Cheverton et al., "Impact of an Apparent Radiation Embrittlement Rate on the Life Expectancy of PWR Vessel Supports," Nuclear Safety, VoL 32, No. 1, January - March 1991. 
Appendix A Comments on the Derivation and Use of $\Delta$ NDiTT for the Nozzle Weld Material

As discussed in Sect. 2 of this report, the surveillance data obtained in 1993 for the nozzle weld material did not alter the trend curve ( $\triangle \mathrm{ND} T \mathrm{TT}$ vs EFPY) generated from previous data. However, a review of all the data, including the calculated neutron fluxes and ratios of calculated to measured fluxes, resulted in a revision of the data given in Ref. 1. For the sake of clarity, a detailed explanation is included herein.

The only data point obtained for the nozzle weld prior to the availability of the 1993 data was from the ORR in 1987. As discussed in Ref. 1 and Sect. 2 of this report, Charpy specimens of HFIR nozzle weld material and archive shell material [A212B(LT)] were irradiated together in the ORR in the same flux and to the same fluence. By including the A212B, which was also included in the HFIR surveillance program (weld metals were not), it was possible with the aid of a few assumptions to index the ORR data to the HFIR surveillance data. Thus, within the limits of the necessary assumptions, the dose received by the A212B and nozzle weld specimens in the ORR was the same as if these specimens had been irradiated in HFIR at the average location of the reference A212B specimens for 23.4 EFPY(100 MW).

As with all other "surveillance" data, it was necessary to transpose the surveillance data to locations in the vessel wall corresponding to the crack front of assumed flaws. This was done assuming that $\Delta$ NDTT $\propto \phi$, the neutron flux, an assumption that is based on the trend curves in Fig. 2.5. Thus, a value of $\phi$ must be defined for each surveillance data point. Several Charpy specimens (generally nine) must be tested to obtain a value of $\triangle$ NDTT, and thus an average flux is associated with the data point. 
From the ORR data, $\triangle$ NDTT (nozzle weld) $=80^{\circ} \mathrm{F}$, and the corresponding exposure time in HFIR is $\frac{100^{\circ} \mathrm{F}}{75^{\circ} \mathrm{F}} \times 17.53 \mathrm{EFPY}(100 \mathrm{MW})=23.4 \mathrm{EFPY}(100 \mathrm{MW})$ (see pages 94,150 and 151, Ref. 1.) Thus, $\Delta \mathrm{NDTT}=\frac{80}{23.4}=3.42^{\circ} \mathrm{F} / \mathrm{EFPY}(100 \mathrm{MW})$.

This value is given in Table 5.2 of Ref. 1, and it corresponds to the average flux at the location of the reference A212B specimens in HFIR. The average flux can be estimated from the data in Table D.4 of Ref. 1, using flux values for specimens A-136, A-145, A-140, A-141, A-96, A-120, A-97, A-99 and A-161 (the three relatively high-test-temperature specimens in the set were not included because they were not used in the determination of the transition temperature for the irradiated specimens). The corresponding average flux is $2.47 \times 10^{8} \mathrm{n} / \mathrm{cm}^{2} \cdot \mathrm{s}$. Specimen A-96, A-97 and A-99 were located at Key 7, Position 8, for which the flux is 2.76 $\mathrm{x} 10^{8} \mathrm{n} / \mathrm{cm}^{2} \cdot \mathrm{s}$. This location is used for normalization purposes in some instances.

The fluxes in Table D.4 of Ref. 1 are the calculated values times a correction factor that is the ratio of calculated to experimental fluxes, and since the ratios turned out to be different for different specimen locations, an average value was used (see Appendix E of Ref. 1). The value used for Table D.4 (Ref. 1) was 0.69 . However, when the fracture mechanics studies were being performed and the data in Table 5.2 (Ref. 1) were being compiled, the correction factor was specified as $\mathbf{0 . 7 1}$. Using this latter value gives a flux at Key 7, Position 8, of 2.68 x $10^{8}$ instead of $2.76 \times 10^{8}$; the smaller value was included in Table 5.2 (Ref. 1).

The text associated with Table 5.2 (Ref. 1) states that the flux of $2.68 \times 10^{8}\left(2.76 \times 10^{8}\right.$ when corrected) corresponds to Key 7, Position 8; however, as mentioned above, the value of $\triangle N \dot{N} T T$ included in the table $\left(3.42^{\circ} \mathrm{F} / \mathrm{EFPY}\right)$ corresponds to an average flux $\left(2.47 \times 10^{8}\right)$. Thus, in order to use the fluxes in Table 5.2 (Ref. 1) for transposition purposes, the values of $\Delta$ NDTT must be transposed to Key 7, Position 8: $\Delta$ NDTT (nozzle weld, Key 7, Position 8) $=3.42$ $\mathrm{x} 2.76 / 2.47=3.82^{\circ} \mathrm{F} / \mathrm{EFPY}(100 \mathrm{MW})$. This is the value that is given in Table 2.6 of this report. 
For the purpose of transposing, it does not matter that the fluxes in Table 5.2 (Ref. 1) are not based on the "latest" correction factor because it was assumed that the same correction factor applied to all locations, including those in the vessel wall, in which case the correction factor cancels out. Thus, the value of $\triangle$ NDTT for the deepest point on the specified flaw with $\mathrm{a}=1.0 \mathrm{in}$. is

$$
\left(\frac{1.71}{2.68}\right) \times 3.82=2.44^{\circ} \mathrm{F} / \mathrm{EFPY}(100 \mathrm{MW})
$$

and for $\mathrm{a}=0.5 \mathrm{in}$. it is

$$
\left(\frac{1.84}{2.68}\right) \times 3.82=2.62^{\circ} \mathrm{F} / \mathrm{EFPY}(100 \mathrm{MW})
$$




\section{Appendix B. Establishing a Reasonable Range of e, the Uncertainty Factor for $\Delta$ NDTT}

The surveillance data obtained in 1986 for the nozzle weld material was obtained from material irradiated in the ORR, and the recent data from HFIR correspond to a very low dose. Thus, there is still substantial uncertainly, and a reasonable upper limit of $e$ for the nozzle weld material is 1.5 , the value specified by the McSpadden Committee. ${ }^{1}$ However, as discussed in Sections 5.4 and 5.5.2, because of the existence of a maximum in the $p(H T)$ vs e curve and a minimum in the $\Delta t$ vs e curve, large values of $e(>1.5)$ are of no real concern.

Low values of $e(<1.0)$ can be of concern for $T_{v}(\Delta t)<75^{\circ} \mathrm{F}$ (Fig. 5.2), and thus a reasonable lower value must be established. As e is decreased, the reduction in fracture toughness due to radiation damage also decreases, which means that the fracture toughness increases. At some value of fracture toughness, the ASME Code requirements for vessel integrity are satisfied, and a hydro test is not necessary to demonstrate integrity. The appropriate value of e can be calculated by letting $K_{l}=K_{l_{c}}$ and solving for $\mathrm{e}$.

$$
K_{I}=K_{I c}=A+B \exp \left\{C\left[T_{V}-R T_{N D T_{\circ}}-e \cdot \Delta N D T T \cdot \Delta t\right]\right\},
$$

and thus

$$
e=\frac{T_{V}-R T_{N D T_{\circ}}-\frac{1}{C} \ln \left\{\frac{1}{B}\left[K_{I}-A\right]\right\}}{\Delta N \dot{D} T T \cdot \Delta t},
$$

where

$$
\begin{aligned}
\Delta \mathrm{t} & =\text { expected total service life of vessel } \\
& =17.5+8.5=26.0 \mathrm{EFPY}(100 \mathrm{MW}) \\
\mathrm{K}_{\mathrm{I}} & =\sqrt{\pi a}\left[p\left(f c_{m} s_{m}+c_{b} s_{b}\right)+c_{r} \sigma_{r}\right]
\end{aligned}
$$$$
\text { (see Sect. 5, Table 5.1, for values of } c_{m}, c_{b}, c_{r}, s_{m}, s_{b}, \sigma_{r} \text { ) }
$$ 
$\mathrm{f}=$ safety factor required by ASME Code

$=2$ for normal and upset conditions

$=\sqrt{2}$ for emergency and faulted conditions

$\mathrm{p}=508$ psi for normal and upset conditions (Ref. 1)

$=679$ psi for emergency and faulted conditions

$\mathrm{T}_{\mathrm{V}}=70^{\circ} \mathrm{F}$ (assumed extreme value consistent with range of $T_{v}(\Delta t)$ considered in

Fig. 5.2)

$$
\begin{aligned}
\mathrm{a} & =0.5 \text { and } 1.0 \text { in (ASME Code requires } \mathrm{a}=1.0 \mathrm{in} .) \\
\Delta \mathrm{NDTT} & =2.62^{\circ} \mathrm{F} / \mathrm{EFPY}(100 \mathrm{MW}) \text { for } \mathrm{a}=0.5 \mathrm{in} . \\
& =2.44 \text { for } \mathrm{a}=1.0 \mathrm{in} .
\end{aligned}
$$

A, $B, C=$ constants for fracture-toughness curve

\begin{tabular}{|l|c|c|c||}
\hline Constant & $\begin{array}{c}\mathrm{A} \\
(\mathrm{ksi} \sqrt{\text { in }}\end{array}$ & $\begin{array}{c}\mathrm{B} \\
(\mathrm{ksi} \sqrt{\text { in }})\end{array}$ & $\begin{array}{l}\mathrm{C} \\
{ }^{\circ} \mathrm{F}^{-1}\end{array}$ \\
\hline ASME K $_{\mathrm{Ic}}$ curve $^{\mathrm{a}}$ & 33.2 & 20.73 & 0.0200 \\
\hline ASME K $\mathrm{IR}$ curve & 26.8 & 12.44 & 0.0145 \\
\hline \\
${ }^{\mathrm{a}}$ accident and faulted conditions \\
${ }^{\mathrm{b}}$ normal and upset conditions
\end{tabular}


For normal and upset conditions:

$$
\begin{aligned}
\mathrm{K}_{\mathrm{I}}(\mathrm{a}=0.5) & =\sqrt{0.5 \pi}[0.508(2 \times 1.068 \times 16.8+0.823 \times 4.24)+0.86 \times 8.5] \\
& =34.23 \mathrm{ksi} \sqrt{\text { in }} \\
\mathrm{K}_{\mathrm{I}}(\mathrm{a}=1.0) & =\sqrt{1.0 \pi}[0.508(2 \times 1.146 \times 16.8+0.741 \times 4.24)+0.86 \times 8.5] \\
& =50.46 \mathrm{ksi} \sqrt{\text { in }} \\
\mathrm{e}(\mathrm{a}=0.5) & =\frac{70-10-\frac{1}{0.0145} \ln \left\{\frac{1}{2.62 \times 2.44}[34.23-26.8]\right\}}{2.0} \\
& =1.40 \\
\mathrm{e}(\mathrm{a}=1.0) & =\frac{70-10-\frac{1}{0.0145} \ln \left\{\frac{1}{12.44}[50.46-26.8]\right\}}{2.4426 .0} \\
& =0.25
\end{aligned}
$$

For emergency and faulted conditions:

$$
\begin{aligned}
\mathrm{K}_{\mathrm{I}}(\mathrm{a}=0.5) & =\sqrt{0.5 \pi}[0.679(\sqrt{2} \cdot 1.068 \times 16.8+0.823 \times 4.24)+0.86 \times 8.5] \\
& =33.72 \mathrm{ksi} \sqrt{\text { in }} \\
\mathrm{K}_{\mathrm{I}}(\mathrm{a}=1.0) & =\sqrt{1.0 \pi}[0.679(\sqrt{2} \times 1.146 \times 16.8+0.741 \times 4.24)+0.86 \times 8.5] \\
& =49.51 \mathrm{ksi} \sqrt{\text { in }} \\
\mathrm{e}(\mathrm{a}=0.5) & =\frac{70-10-\frac{1}{0.0200} \ln \left\{\frac{1}{20.73}[33.72-33.2]\right\}}{2.62 \times 26.0} \\
& =3.59 \\
\mathrm{e}(\mathrm{a}=1.0) & =\frac{70-10-\frac{1}{0.0200} \ln \left\{\frac{1}{20.73}[49.51-33.2]\right\}}{2.44 \times 26.0} \\
& =1.13
\end{aligned}
$$


The controlling value of $e$ is the smallest of the above (0.25), but this value is unreasonably low. As an alternative, an uncertainty of $\pm 50 \%$ can be used, which is consistent with the upper limiting value of e of 1.5 mentioned above and which yields a lower limit of e of 0.5 .

Contributing to the uncertainty in $\triangle N D T T$ is the lack of knowledge regarding the type of radiation causing the damage (see Sect. 8). However, this is more of a problem in the transposition of the surveillance data than it is in establishing the value of $\Delta$ NDTTT for a specific surveillance-specimen location. The transposition problem is discussed in Appendix A. 
Appendix C. Comments on the Accuracy of the Neutron Fluxes Used for Transposing $\Delta$ NDTT

Values of $\triangle N D T T$ corresponding to locations of surveillance specimens are transposed to the locations of hypothetical flaws by assuming that $\Delta N D T T \propto \phi$, consistent with the trend curves in Fig. 2.5. The accuracy of calculated fluxes far from the source (reactor core) is questionable, and thus, dosimeters are included in the grooves of the CVN specimens in the capsules to obtain greater accuracy. The ratio of calculated to experimental flux (C/E) is a measure of the error in the calculated flux and includes the error in the nominal flux distribution as well as the perturbation in the capsule/specimen.

As indicated by data included in Ref. 1, the C/E ratios are different for different capsule locations, and there were no dosimeters at or in the vessel wall. The C/E ratios for the capsules cannot be used for these latter locations because they include the perturbation effect, which cannot be factored out, and because they vary from one location to another. Thus, it is convenient, if not necessary, to use a single value for all locations, and because the transposition of $\triangle N D T T$ relies only on flux ratios, the C/E ratios cancel out. There is, of course, a remaining uncertainty with regard to the flux ratios, and the variation in $\mathrm{C} / \mathrm{E}$ ratios is somewhat indicative of what the uncertainty is. The C/E ratios calculated in 1987 for the 1986 surveillance specimens (Appendix E of Ref. 1) indicate an average for all capsules and both activated elements ( $\mathrm{Ni}$ and $\mathrm{Fe}$ ) of 0.69 with a one standard deviation of $10 \%$. In 1993, the fluxes were recalculated using updated neutron cross sections (see Appendix E), and the corresponding mean value of $\mathrm{C} / \mathrm{E}$ for the 1986 data was 0.78 with a standard deviation of $27 \%$ (see Appendix D). C/E ratios have also been calculated for the 1993 surveillance data, using the updated fluxes. The mean value is 0.86 with a standard deviation of $17 \%$ (see Appendix D). If the 1986 and 1993 sets of data, based on the updated fluxes, are combined and then separated in accordance with key position, the following results are obtained:

\begin{tabular}{|c|c|c|}
\hline Key & Mean C/E & Std. Dev. (\%) \\
\hline 1 and 4 & 0.82 & 22.6 \\
\hline 2 & 1.03 & 8.0 \\
\hline 6 and 7 & 0.67 & 7.4 \\
\hline
\end{tabular}


It would be expected that the fluxes would be difficult to calculate around both the HB-1 and HB-4 nozzles, because of lack of symmetry, and relatively less difficult for Key 2, which is symmetrical, and Keys 6 and 7, which are further removed from the nozzles. Key 3, from a symmetry point of view, would tend to be between Keys 1 and 4 and Key 2 in terms of difficulty, and thus a standard deviation of $15 \%$ is estimated for Key 3, for which C/E ratios are not available. Because the limiting flaw is in the HB-3 nozzle weld, the uncertainty in calculated fluxes at the location of the flaw is $\sim 15 \%$.

The other location of interest with regard to determining the damage rate at the tip of the limiting flaw is Key 7, Position 8. From Appendix D, the standard deviation for C/E ratios at Keys 6 and 7 is $7 \%$. Thus, for the ratio of fluxes, an uncertainty of $\sim 24 \%$ is reasonable and is well within the limits assumed for the damage rate $( \pm 50 \%)$, as discussed in Appendix B.

The fluxes used in this report for estimating the damage rate at the tip of the hypothetical flaw are those calculated in 1987, because the set of fluxes calculated in 1993 (Appendix E) does not include all of the necessary fluxes. Considering the insensitivity of $p(H T)$ and $\Delta t$ to the uncertainty in the damage rate (see Sect. 5), the differences in the two sets of fluxes did not warrant obtaining a complete new set for the 1993 evaluation of hydro-test conditions.

The question of accuracy of the calculated neutron fluxes may be a moot point if, as suggested in Sect. 8, gamma and/or thermal neutrons (rather than fast neutrons) are responsible for the observed radiation damage. Not knowing which is responsible, however, does not prevent a determination of hydro-test conditions, if the minimum value of $\Delta t$ in the $\Delta t$ vs e curve is acceptable because, as explained elsewhere, in that case knowledge of the damage rate $(\triangle \mathrm{NDTT})$ is not necessary. This is the approach taken at this time. 
Appendix D. Analysis of HFIR Pressure Vessel Wall Surveillance Dosimetry 
September 29, 1993

R. K. Nanstad

REAEIMEL

Analysis of HFIR Pressure Vessel Wall Surveillanco Dosimetry

OCTO 51993

OFFHE OF

R. X RHISTAD

As part of the HFIR Pressure Vessel Surveillance Program, metallurgical specimens of actual and simulated pressure vessel materials are irradiated near the inner surface of the vessel wall. At predetermined intervals a series of specimens are removed and tested to determine changes in the material properties caused by irradiation effects. Property changes in the metallurgical specimens are correlated with neutron fiuence parameters and the results are extrapolated to predict the condition of the pressure vessel. Recenthy, 9 surveillance capsules were removed from the HFIR at the end of cycle 320 in accordance with the revised surveillance plan. Of the 9 capsules removed, 6 were installed in the vessel during the 1986 - 1989 extended shutdown. The 3 remaining capsules are original surveillance capsules that were relocated to new positions during the extended shutdown.

The capsules removed after cycle 320 were disassembled by the Research Reactors Division. HFIR surveillance capsules consist of 3 charpy specimens encapsulated in a stainless steel box with a single stainless steel dosimeter wire located in the aligned notches of the charpy specimens. The metallurgical specimens were shipped to the Metals and Ceramics Division's Fracture Mechanics Group for testing and the stainiess steel dosimeters were taken to the Analytical Chemistry Division's Neutron Activation Analysis Facility (NAAF) where they were weighed and counted to determine the absolute activities of ${ }^{\text {so }} \mathrm{Co}$ and ${ }^{54} \mathrm{Mn}$. An additional count of each dosimeter was performed at the Iradiated Fuels Examination Laboratory (IFEL) and compared to the NAAF's results. Consensus between the two laboratories was excellent with most of the measurements in agreement to better than $\pm 3 \%$.

The stainiess steel dosimeters included in the surveillance capsules are used to measure two activation reactions of interest in determining fast neutron fluence rates. The two reactions are the ${ }^{53} \mathrm{Ni}(n, p){ }^{50} \mathrm{Co}$ and ${ }^{54} \mathrm{Fe}(n, p){ }^{54} \mathrm{Mn}$ reactions which have similar threshold energies and response ranges. The product nuclei of these reactions have half-lives of 70.9 days and 312.2 days, respectively. Compared to the complete operating history of the HFIR, the half-lives of the product nuclei are relatively short thus limiting their sensitivity to earty irradiation periods. A build-up and decay analysis for these two isotopes using the complete power time history for the HFIR revealed that more than 99\% of the activity measured at the end of cycle 320 was due to irradiations which occurred after the extended shutdown of the HFIR. This fact simplifies the analysis of the three dosimeters which came from the capsules that were relocated during the extended 
shutdown. For all intents and purposes these dosimeters can be treated as though they were initially installed during the extended shutdown.

Generally, measurements and neutron transport calculations are combined to determine the neutron fluence parameters necessary to correlate irradiation damage in vessel materials. A process called unfolding is used to scale and/or adjust the calculated neutron spectrum using information obtained from dosimeters which are sensitive to different parts of the neutron spectrum. The adjusted spectrum is then folded with the appropriate response function to provide the parameter of interest. In this instance, the limited dosimetry provided in the HFIR surveillance capsules would only have a scaling effect on the calculated neutron spectrum because the ${ }^{51} \mathrm{Ni}(n, p)^{50} \mathrm{Co}$ and ${ }^{54} \mathrm{Fe}(n, p)^{54} \mathrm{Mn}$ reactions have similar response functions. This neutron spectrum scaling can be accomplished in a straightfonward fashion by using calculated to experimental (C/E) ratios based on the ${ }^{50} \mathrm{Co}$ and ${ }^{51} \mathrm{Mn}$ activity measurements. The C/E ratio scaling approach was used in the previous analysis of the surveillance capsules removed in 1986' and has been adopted here.

Saturation activities for ${ }^{58} \mathrm{Co}$ and ${ }^{54} \mathrm{Mn}$ were determined for each dosimeter using the detailed power time history and composition data provided by J. R. Inger and the measured activities at end-of-irradiation provided by the NAAF. These results are reported in Table 1 along with corresponding calculated values obtained from a threedimensional discrete ordinates calculation of the HFIR provided by J. V. Pace (see attachment). Note that caiculated values for key locations 1 and 6 were obtained by taking advantage of symmetry with key locations 4 and 7. For key location 2 an anomalous oscillation was observed in the calculated data. Activities calculated for one capsule position changed by a factor of 2 when compared to the next adjacent position. The symmetry of the capsule positions in key 2 relative to the source would lead one to expect a uniform exposure and the experimental measurements support this expectation. It has been suggested that "ray effects" caused by an inadequate angular quadrature set are responsible for the oscillating behavior in the calculation. It was decided that since the transport calculation could not be repeated with an improved quadrature set, the best approach would be to average the calculated activities for the key 2 positions.

For each capsule in Table 1 the C/E ratios for both activities were computed and then averaged to provide the final $\mathrm{C} / \mathrm{E}$ ratio for the capsule. It was noted that agreement

1 R. D. Cheverton, J. G. Merkle, R. K. Nanstad, Eds., Evaluation of HFIR PressureVessel Integrity Considering Radiation Embrittlement, ORNLTM-10444, Oak Ridge National Laboratory, Oak Ridge, Tennessee, April 1988.

2 J. V. Pace III, C. O. Slater, M. S. Smith, "Letter Report on Beginning-Of-Cycle HFIR Flux/Response Calculations at Keys 2, 4, 5, and 7," Oak Ridge National Laboratory, July 30, 1992. 
between calculated and experimental values seemed to be dependent on key location. To provide additional information, measured activities obtained from the previous series of capsules removed in 1986 were compared with the current calculation. These results are provided in Table 2. Note that prior to 1986 the HFIR operated at a nominal power of $100 \mathrm{MW}$, so, the experimental data in Table 2 have been re-nomalized to $85 \mathrm{MW}$. Overall there appears to be good consistency between the two series of tests in that like key locations have similar C/E ratios. If the C/E ratios from the two series of capsules are analyzed in terms of key location, the standard deviations of the mean C/E ratios are greathy reduced for keys 2, 6, and 7 as shown in Table 3. For keys 1 and 4 the standard deviation of the mean C/E ratio is only slightly improved.

In addition to the calculated ${ }^{58} \mathrm{Co}$ and ${ }^{34} \mathrm{Mn}$ activities needed for comparison with measurements, 3 parameters useful for correlating irradiation damage in the metallurgical specimens were calculated for each key position. The 3 parameters are the neutron fiuence rate for ( $E>1.0 \mathrm{MeV}$, the neutron fluence rate for ( $E>0.1 \mathrm{Mev}$ ), and the displacements per atom (dpa) of iron rate. Calculated values of these parameters are given in Tables 4 and 5 for the surveillance capsules removed in 1993 and 1986, respectively. The analysis of the metallurgical data requires the total accumulated fluence or dpa not the rate as given by the calculation. To obtain the total fiuence or dpa it is first necessary to scale the calculated rate values with the average C/E ratios from Tables 1 and 2. Next, the calculated rate value is adjusted by a power normalization factor to account for the different periods of $100 \mathrm{MW}$ and $85 \mathrm{MW}$ operation. Finally, the adjusted rate values are multiplied by the appropriate effective full power time to obtain the fiuence or dpa. For the 3 capsules that were relocated during the extended shutdown it was necessary to perform this calculation twice; once for the initial location and once for the relocated position. The total fluence or dpa for these 3 capsules is the sum obtained from the 2 irradiation periods. Note that for the initial positions of the 3 relocated capsules there were no measured $C / E$ ratios available, so, an estimated $C / E$ ratio from Table 3 was used. To provide estimates for future surveillance capsules, fluence and dpa rate results for each key and position have been tabulated in Tables 6 and 7 for $85 \mathrm{MW}$ and $100 \mathrm{MW}$ operation, respectively.

If you have any questions or need additional information, please call me.

$$
\text { C.A. Baldwin }
$$

C. A. Baldwin, 3525, MS-6295 (4-6552)

Attachment

cc: R. D. Cheverton

D. F. Craig

J. R. Inger

F. B. Kam

M. J. Kania

J. V. Pace III 
Table 1. Comparison of calculated and experimental reaction rates for capsules removed in 1993.

\begin{tabular}{|c|c|c|c|c|c|c|c|c|c|}
\hline \multirow[b]{2}{*}{$K y$} & \multirow[b]{2}{*}{ Positten } & \multirow[b]{2}{*}{$\begin{array}{l}\text { Buil } \\
\text { Idert }\end{array}$} & \multicolumn{3}{|c|}{ S8NI(n,p)58Co } & \multicolumn{3}{|c|}{ SAFo(n,p)SAMn } & \multirow{2}{*}{$\begin{array}{c}\text { Awrego } \\
\text { QÉ } \\
\text { Reto }\end{array}$} \\
\hline & & & $\begin{array}{l}93 \text { al } \\
\text { (Bofatom) } \\
\text { (85nm) }\end{array}$ & $\begin{array}{l}23 \text { Exp. } \\
\text { (Bd/ctom) } \\
\text { (85 km) }\end{array}$ & $\begin{array}{c}\text { CEE } \\
\text { Rotio }\end{array}$ & $\begin{array}{l}\text { es cel. } \\
\text { (Be/atom) } \\
\text { (8SMM) }\end{array}$ & $\begin{array}{l}\text { os Ex. } \\
\text { (Ba/tom) } \\
\text { (25Mm) }\end{array}$ & $\begin{array}{c}\text { CEE } \\
\text { RAto }\end{array}$ & \\
\hline 1 & 7 & SW.1.7 & 4.495 .17 & $5.11 E-17$ & 0.878 & 3.40E-17 & 3.34E-17 & 1.046 & $0 \operatorname{sen}$ \\
\hline 1 & 8 & SW-1-8 & 3.31E17 & 5.02E-17 & 0.659 & $260 E-17$ & 3.47E.17 & 0.748 & 0.704 \\
\hline 1 & 9 & SW-10 & 4.49517 & 5.28E-17 & 0.850 & 340517 & $3.525-17$ & 0.002 & $0.2 x$ \\
\hline 2 & 2 & NW2-1 & 216E-16 & 2.37E-16 & 0.981 & 1.71ES16 & 1.61E-10 & 1.002 & 0.857 \\
\hline 2 & 6 & NME-4 & 216516 & 2.41E-16 & 0.000 & 1.71E-16 & $1.00 E-16$ & 1.000 & 0.000 \\
\hline 2 & 18 & MN2-8 & 2.16E-16 & $2.22 E-16$ & 0.973 & $1.71 E-18$ & $1.48 E 16$ & 1.155 & 1.004 \\
\hline 6 & 4 & HB-IA-64 & $3.145-17$ & 4.44E-17 & 0.707 & $240-517$ & 3TIE-17 & 0.681 & 0.084 \\
\hline 6 & $5 *$ & HE-IA-71 & 3255.17 & 4.32E-17 & 0.751 & 258E-17 & 3.06517 & 0.704 & 0.728 \\
\hline 7 & $4 *$ & HB-4A-76 & 325E-17 & 4.25E-97 & 0.764 & 258E-17 & $3.71 E-17$ & 0.005 & 0.720 \\
\hline Ruber & p & & $\begin{array}{l}\text { Marm } \\
\text { Minim } \\
\text { M }\end{array}$ & $\begin{array}{l}\text { CIE Ratio = } \\
\text { CE Ratio = } \\
\text { CE Ratio = } \\
\text { STd. Dw. = }\end{array}$ & $\begin{array}{c}0.973 \\
0.659 \\
0.821 \\
12794\end{array}$ & $\begin{array}{r}\text { Mexm } \\
\text { Minin } \\
\text { Me }\end{array}$ & $\begin{array}{l}\text { CE RAto = } \\
\text { CE RAto = } \\
\text { CE RAto = } \\
\text { Sd DN. = }\end{array}$ & $\begin{array}{c}1.155 \\
0.601 \\
0.504 \\
21.795\end{array}$ & \\
\hline
\end{tabular}

Table 2 Comparison of calculated and experimemal reaction rates for capsules removed in 1986.

\begin{tabular}{|c|c|c|c|c|c|c|c|c|c|}
\hline Koy & Position & $\begin{array}{l}\text { Bail } \\
\text { Idamt }\end{array}$ & $\begin{array}{l}93 \mathrm{Cat} \\
\text { (Bq/atom) } \\
\text { (8sMW) }\end{array}$ & $\begin{array}{l}\text { 8Ni(n,p)58Co } \\
86 \text { Exp.=: } \\
\text { (Bdatom) } \\
\text { (85MM) }\end{array}$ & $\underset{\text { Ratio }}{C E}$ & $\begin{array}{l}\text { so Cal } \\
\text { (Bdatom) } \\
\text { (Bsimn }\end{array}$ & $\begin{array}{l}4 F(n, p) 54 M \\
\text { 'es Exp } \\
\text { (Boftom) } \\
\text { (25MM) }\end{array}$ & $\begin{array}{c}C E \\
\text { Patio }\end{array}$ & $\begin{array}{c}\text { Averago } \\
\text { CIE } \\
\text { Ruto }\end{array}$ \\
\hline 1 & 3 & $\mathrm{HB}-1.25$ & $6.58 E-17$ & $1.25 \mathrm{E} \cdot 16$ & 0.527 & 522517 & 9.4AE-17 & 0.553 & 0.540 \\
\hline 4 & 3 & $\mathrm{HB}-31$ & 3.31E-17 & 4.97E-17 & 0.668 & 260517 & 299E-17 & 0.850 & 0.767 \\
\hline 4 & 8 & HB-42 & 6.58E-17 & 7.24E-17 & 0.900 & 520E-17 & 4.84E-17 & 1.070 & 0.004 \\
\hline 2 & 5 & HB-2-11 & 216E-16 & 200E-16 & 1.081 & 1.71E-16 & $1.55 E-16$ & 1.105 & 1.003 \\
\hline 2 & 7 & $H B-2.9$ & 216E-16 & $2105-16$ & 1.020 & 1.71 E-16 & $1.66 E-18$ & 1.032 & 1.030 \\
\hline 6 & 2 & HB-1A68 & $3205-17$ & $4.83 E-17$ & 0.683 & 25AE17 & 4.15EST & 0.612 & 0.038 \\
\hline 6 & 3 & HB-1A-D & $3205-17$ & $4.83 E-17$ & 0.653 & 254E-17 & 4.15E-17 & 0.612 & 0.038 \\
\hline 7 & 6 & HB-AA77 & $3205-17$ & 4.68E-17 & 0.683 & 2545-17 & $3.925-17$ & 0.648 & 0.688 \\
\hline 7 & 8 & $\mathrm{HB}-4 A .73$ & $3.84 E-17$ & 5.95E-17 & 0.644 & $3.035-17$ & 5.07ㅌ-17 & 0.508 & 0.021 \\
\hline $\begin{array}{r}\text { Expo } \\
\text { 10 } 85\end{array}$ & $W$ & rormalized & $\begin{array}{r}\text { Maxm } \\
\text { Minim } \\
M\end{array}$ & $\begin{array}{l}\text { CIE Ratio = } \\
\text { CEE Ratio = } \\
\text { CEE Ratio = } \\
5 \text { Std. Dev. = }\end{array}$ & $\begin{array}{l}1.081 \\
0.527 \\
0.760 \\
25.350\end{array}$ & $\begin{array}{l}\text { Maxum } \\
\text { Minim } \\
\text { Me }\end{array}$ & $\begin{array}{l}\text { C/E Ratio = } \\
\text { CE Rnto = } \\
\text { CVE Rntio = } \\
\text { S Std. DN. = }\end{array}$ & $\begin{array}{c}1.105 \\
0.563 \\
0.750 \\
29.139\end{array}$ & \\
\hline
\end{tabular}

Table 3. Analysis of C/E ratios by key location.

\begin{tabular}{|c|c|}
\hline $\begin{array}{r}\text { Koye } 184 \text { Maximum CE Ratio = } \\
\text { Keys } 184 \text { Minimum CE Retio = } \\
\text { Keys } 184 \text { Mean CE Ratio = } \\
\times \text { SLd DN. = }\end{array}$ & $\begin{array}{l}1.079 \\
0.027 \\
0815 \\
20612\end{array}$ \\
\hline $\begin{array}{r}\text { Koy } 2 \text { Maximum CFE Ratio = } \\
\text { Koy } 2 \text { Minimum CFE Ratio = } \\
\text { Koy } 2 \text { Mean CE Ratio = } \\
\text { \% Std. Dw. = }\end{array}$ & $\begin{array}{l}1.155 \\
0.808 \\
1.001 \\
8.062\end{array}$ \\
\hline 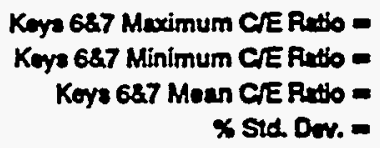 & $\begin{array}{l}0.764 \\
0.508 \\
0.672 \\
7.350\end{array}$ \\
\hline
\end{tabular}


Table 4. Neutron damage correlation parameters for surveillance capsules removed in 1993.

\begin{tabular}{|c|c|c|c|c|c|c|c|c|c|c|c|c|c|c|}
\hline Koy & Poatton & $\begin{array}{l}\text { Ball } \\
\text { Idont. }\end{array}$ & 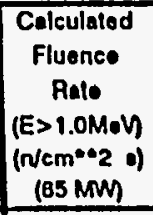 & $\begin{array}{l}\text { Calculatod } \\
\text { Fluonce } \\
\text { Rato } \\
(E>0.1 \mathrm{MoV}) \\
\left(\mathrm{n} / \mathrm{cm}^{\circ} \circ \mathrm{L}^{\circ}\right) \\
(85 \mathrm{MM}) \\
\end{array}$ & $\begin{array}{c}\text { Culculalod } \\
\text { Fo DPA } \\
\text { Pate } \\
\text { (dpa/s) } \\
\text { (BS MM) } \\
\end{array}$ & $\begin{array}{c}\text { Avologe } \\
\text { C/E } \\
\text { Ratlo }\end{array}$ & $\begin{array}{l}\text { Powor } \\
\text { Norm. } \\
\text { Factor }\end{array}$ & 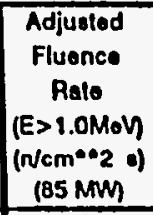 & $\begin{array}{l}\text { Adjunled } \\
\text { Fluence } \\
\text { Anto } \\
\text { (E>0.1MoV) } \\
\text { (ncm*2 }) \\
\text { (85 MW) } \\
\end{array}$ & $\begin{array}{c}\text { Adjualed } \\
\text { Fo DPA } \\
\text { Rate } \\
\text { (dpa/a) } \\
\text { (BS MMN) } \\
\end{array}$ & $\begin{array}{l}\text { Efloctlve } \\
\text { Full } \\
\text { Power } \\
\text { Tlme } \\
\text { (1) }\end{array}$ & $\begin{array}{l}\text { Adjustod } \\
\text { Fluence } \\
\text { (E>1.0Mon } \\
\left.\text { (n/em }{ }^{\circ} \cdot 2\right)\end{array}$ & $\begin{array}{l}\text { Adjunted } \\
\text { Fluonce } \\
\text { (E>0.1Mon) } \\
\left(n / \mathrm{cm}^{\circ \bullet}\right)\end{array}$ & $\begin{array}{l}\text { Adjustod } \\
\text { Fo DPA } \\
\text { (dpa) }\end{array}$ \\
\hline 1 & 7 & SW-1.7 & $2.49 E+08$ & $4.96 E+08$ & 3.55E-13 & 0.962 & 1.000 & $2.58 E+08$ & $5.16 E+08$ & $3.70 E-13$ & $6.25 E+07$ & $1.62 E+10$ & $323 E+16$ & 2.31E-05 \\
\hline t & 8 & SW-1-6 & $1.59 E+08$ & $2.89 E+08$ & $2.28 E-13$ & 0.704 & 1.000 & $2.26 E+08$ & $4.10 E+08$ & 3.23E-13 & $6.25 E+07$ & $1.41 E+16$ & $2.56 E+10$ & 2.02E-05 \\
\hline 1 & 0 & SW-1.9 & $2.48 E+08$ & $4.96 \mathrm{E}+08$ & 3.55E-13 & 0.821 & 1.000 & $2.70 E+08$ & $8.39 E+08$ & $3.86 E-13$ & $0.25 E+07$ & $1.69 E+16$ & $3.37 E+16$ & 2.41E-0S \\
\hline 2 & 2 & $N W \cdot 2-1$ & $0.18 E+08$ & $1.27 E+09$ & 1.18E-12 & 0.987 & 1.000 & $6.30 \mathrm{E}+08$ & $1.28 \mathrm{E}+09$ & 1.21E-12 & $6.25 \mathrm{E}+07$ & $6.19 E+16$ & $8.02 E+16$ & 7.54E-05 \\
\hline 2 & 6 & NW.2.4 & $0.19 E+08$ & $1.27 E+09$ & 1.18E-12 & 0.983 & 1.000 & $0.34 E+08$ & $1.29 E+09$ & 1.21E-12 & $6.25 E+07$ & $8.21 E+16$ & $8.06 E+16$ & 7.56E-05 \\
\hline 2 & 16 & NW.2.8 & $8.18 E+08$ & $1.27 E+09$ & 1.18E-12 & 1.064 & 1.000 & $7.70 E+08$ & $1.19 E+09$ & 1.12E-12 & $6.25 E+07$ & $4.81 E+16$ & $7.44 E+16$ & $6.89 E-05$ \\
\hline 6 & $4 "$ & HB-IA-64 & $1.17 E+08$ & $1.75 E+08$ & 1.70E-13 & 0.684 & 1.000 & $1.71 E+08$ & $2.56 \mathrm{E}+08$ & $2.48 E-13$ & $6.25 E+07$ & $1.07 E+10$ & $1.60 E+16$ & $1.55 E-05$ \\
\hline - & 5* & HB-1A.7I & $1.10 E+\infty 0$ & $1.72 E+08$ & 1.71E-13 & 0.728 & 1.000 & $1.63 E+08$ & 2.37E+08 & $2.36 \mathrm{E}-13$ & $6.25 E+07$ & $1.02 E+16$ & 1. $48 E+10$ & 1.47E-0S \\
\hline 7 & $4^{\circ}$ & HB. 4 A.78 & $1.18 E+08$ & $1.72 E+08$ & $1.71 E-13$ & 0.729 & 1.000 & $1.62 E+08$ & $2.36 \mathrm{E}+08$ & 2.35E-13 & 6.25E +07 & $1.01 E+18$ & $1.48 E+16$ & 1.47E-05 \\
\hline
\end{tabular}

\begin{tabular}{|c|c|c|c|c|c|c|c|c|c|c|c|c|c|c|}
\hline $\mathrm{Koy}$ & Poation & $\begin{array}{l}\text { Ball } \\
\text { Idant. }\end{array}$ & 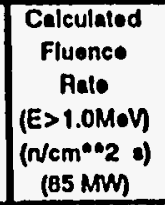 & 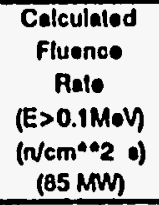 & $\begin{array}{c}\text { Calculated } \\
\text { Fo DPA } \\
\text { Pate } \\
\text { (dpa/d) } \\
\text { (B5 MW) } \\
\end{array}$ & $\begin{array}{c}\text { Eallimalod } \\
\text { C/E } \\
\text { Ratlo }\end{array}$ & $\begin{array}{l}\text { Power } \\
\text { Norm. } \\
\text { Factor }\end{array}$ & $\begin{array}{c}\text { Adjustod } \\
\text { Fluence } \\
\text { Pato } \\
(E>1.0 \mathrm{MoV}) \\
\text { (n/cm**2 } \\
(100 \mathrm{Mm}) \\
\end{array}$ & $\begin{array}{l}\text { Adjustod } \\
\text { Fluence } \\
\text { Pale } \\
\text { (E>0.1MoV } \\
\text { (n/cm**2 o) } \\
\text { (100 MM }\end{array}$ & $\begin{array}{c}\text { Adjurtod } \\
\text { Fo DPA } \\
\text { Rato } \\
\text { (dpa/o) } \\
\text { (100 Mm } \\
\end{array}$ & $\begin{array}{l}\text { EHoctlve } \\
\text { Full } \\
\text { Powor } \\
\text { Time } \\
\text { (0) }\end{array}$ & $\begin{array}{l}\text { Adfustod } \\
\text { Fluence } \\
\text { (E>1.0M०V) } \\
\left(n / \mathrm{cm}^{\circ} \cdot \mathrm{z}\right)\end{array}$ & $\begin{array}{l}\text { Adlusted } \\
\text { Fluence } \\
\text { (E>0.1Mlon } \\
\left(n / \mathrm{cm}^{\circ}-\infty\right)\end{array}$ & $\begin{array}{c}\text { Adjueted } \\
\text { Fo DPA } \\
\text { (dpa) }\end{array}$ \\
\hline $\begin{array}{l}6 \\
6 \\
7\end{array}$ & 7"* & $\begin{array}{l}\text { HB-1A-64 } \\
\text { HB-1A-71 } \\
\text { HB-1A.76 }\end{array}$ & $\begin{array}{l}1.24 E+08 \\
1.20 E+08 \\
1.20 E+08\end{array}$ & $\begin{array}{l}1.75 E+08 \\
1.68 E+08\end{array}$ & $\begin{array}{l}1.61 E-13 \\
1.75 E-13 \\
1.75 E-13\end{array}$ & $\begin{array}{l}0.672 \\
0.672 \\
0.672\end{array}$ & $\begin{array}{l}1.177 \\
1.177 \\
1.177\end{array}$ & $\begin{array}{l}2.17 E+08 \\
2.10 E+08 \\
2.10 E+08\end{array}$ & $\begin{array}{l}3.07 E+08 \\
2.04 E+08\end{array}$ & $\begin{array}{l}.17 E-13 \\
3.07 E-13 \\
3.07 E-13\end{array}$ & $\begin{array}{l}6.53 E+08 \\
6.53 E+08 \\
5.53 E+08\end{array}$ & $\begin{array}{l}1.20 E+17 \\
1.16 E+17 \\
1.16 E+17\end{array}$ & $\begin{array}{l}1.69 E+17 \\
1.63 E+17 \\
1.03 E+17\end{array}$ & $\begin{array}{l}1.75 E-04 \\
1.69 E-04\end{array}$ \\
\hline
\end{tabular}

- Rolocaled epocimene

- Intial locallona of rolocatod epeclmone

The response function for tron dpa has a cutolf energy ol $0.0 \mathrm{KoV}$.

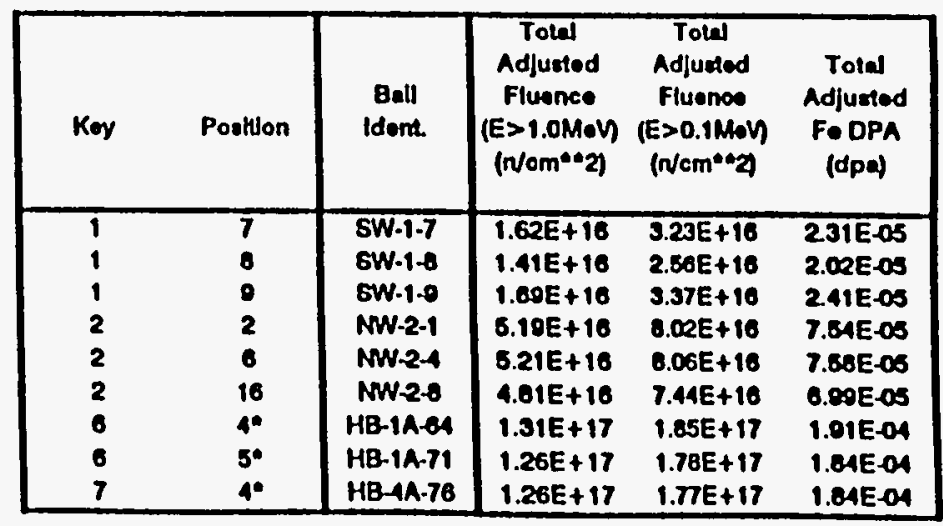


Table 5. Neutron damage correlation parameters for surveillance capsules removed in 1986.

\begin{tabular}{|c|c|c|c|c|c|c|c|c|c|c|c|c|c|c|}
\hline Koy & Postiton & $\begin{array}{l}\text { Ball } \\
\text { Idont. }\end{array}$ & 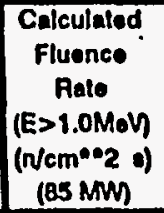 & 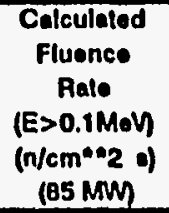 & $\begin{array}{c}\text { Calculated } \\
\text { Fo DPA } \\
\text { Pato } \\
\text { (dpa/o) } \\
\text { (65 MW) }\end{array}$ & $\begin{array}{c}\text { Avorago } \\
\text { C/E } \\
\text { Ratlo }\end{array}$ & $\begin{array}{l}\text { Power } \\
\text { Norm. } \\
\text { Factor }\end{array}$ & $\begin{array}{l}\text { Adjustod } \\
\text { Fluonce } \\
\text { Rato } \\
(\text { E> 1.0MoV } \\
\left(n / \mathrm{cm}^{\circ \cdots 2} \text { ) }\right. \\
(100 \mathrm{MM})\end{array}$ & $\begin{array}{l}\text { Adjueted } \\
\text { Fluonce } \\
\text { Rote } \\
\text { (E>0.1Mov) } \\
\text { (n/cm*A2 } 2) \\
\text { (100 MW) }\end{array}$ & $\begin{array}{c}\text { Adjusted } \\
\text { Fo DPA } \\
\text { Rate } \\
\text { (dpa/s) } \\
\text { (100 MM) }\end{array}$ & $\begin{array}{l}\text { Etfocthe } \\
\text { Full } \\
\text { Power } \\
\text { Time } \\
\text { (1) }\end{array}$ & $\begin{array}{l}\text { Tolal } \\
\text { Adjunted } \\
\text { Fluenes } \\
(E>1.0 \mathrm{M} \text { on } \\
\left(\mathrm{n} / \mathrm{cm}^{\circ} \cdot 2\right)\end{array}$ & $\begin{array}{l}\text { Tolal } \\
\text { Adjueted } \\
\text { Fluence } \\
\text { (E>0.1Mon } \\
\text { (n/cm"ans) }\end{array}$ & $\begin{array}{l}\text { Total } \\
\text { Adjuated } \\
\text { Fo DPA } \\
\text { (dps) }\end{array}$ \\
\hline 1 & $\begin{array}{l}3 \\
3\end{array}$ & $\begin{array}{l}\text { HE-1.25 } \\
\text { H8-4-31 }\end{array}$ & $\begin{array}{l}3.66 E+08 \\
1.59 E+08\end{array}$ & $\begin{array}{l}7.68 E+08 \\
2.89 E+08\end{array}$ & $\begin{array}{l}5.31 E-13 \\
2.28 E-13\end{array}$ & $\begin{array}{l}0.540 \\
0.767\end{array}$ & $\begin{array}{l}1.17 \\
1.17\end{array}$ & $\begin{array}{l}7.98 E+08 \\
2.44 E+08\end{array}$ & $\begin{array}{l}1.67 E+09 \\
4.43 E+08\end{array}$ & $\begin{array}{l}1.16 \mathrm{E}-12 \\
3.50 \mathrm{E}-13\end{array}$ & $\begin{array}{l}6.53 E+00 \\
6.53 E+08\end{array}$ & $\begin{array}{l}4.41 E+17 \\
1.35 E+17\end{array}$ & $\begin{array}{l}0.26 E+17 \\
2.45 E+17\end{array}$ & $\begin{array}{l}\text { 6.40E-01 } \\
1.03 E-04\end{array}$ \\
\hline 4 & 6 & HB-1-32 & $3.66 \mathrm{E}+00$ & $7.68 E+08$ & 5.31E-13 & 0.994 & 1.177 & $4.33 E+08$ & $9.09 E+08$ & 6.29E-13 & $6.63 E+08$ & $2.40 E+17$ & $5.03 E+17$ & 3.48E-04 \\
\hline 2 & 8 & HB-2-11 & $0.19 E+08$ & $1.27 E+00$ & 1.19E-12 & 1.093 & 1.177 & 8.82E+08 & $1.36 E+09$ & 1.28E-12 & $6.53 E+03$ & 4.07E+17 & $7.54 E+17$ & 7.08E-04 \\
\hline 2 & 7 & HB-2.9 & $0.19 E+08$ & $1.27 E+00$ & 1.18E-12 & 1.030 & 1.177 & $0.36 E+08$ & $1.45 E+09$ & $1.36 \mathrm{E}-12$ & $5.53 E+08$ & 6.17E+17 & $6.00 E+17$ & 7.52E-04 \\
\hline 8 & 2 & HB-1A 68 & $1.26 E+00$ & $1.06 E+08$ & 1.01E.13 & 0.630 & 1.177 & $2.33 E+08$ & $3.62 E+08$ & 3.34E-13 & $6.53 E+00$ & $1.29 E+17$ & $2.00 E+17$ & 1.05E-09 \\
\hline 6 & 3 & HB-1A-69 & $1.19 E+\infty 8$ & $1.76 E+08$ & 1.72E-13 & 0.638 & 1.177 & $2.20 \mathrm{E}+08$ & $3.25 E+08$ & 3.18E-13 & 6.63E+00 & $1.21 E+17$ & $1.00 E+17$ & $1.76 \mathrm{E}-\mathrm{O}$ \\
\hline 7 & 6 & HB-AA.7 & $1.18 E+08$ & $1.76 E+08$ & 1.72E-13 & 0.666 & 1.177 & $2.10 E+08$ & $3.11 E+08$ & 3.04E-13 & $6.63 E+00$ & $1.16 E+17$ & $1.72 E+17$ & 1.60E-O4 \\
\hline 7 & 6 & HB-1A-73 & $1.57 E+08$ & $2.53 E+08$ & $2.26 \mathrm{E}-13$ & 0.621 & 1.17 & 2.97E+08 & $4.79 E+08$ & 4.28E-13 & $5.53 E+08$ & $1.64 E+17$ & $2.65 E+17$ & 2.37E-04 \\
\hline
\end{tabular}

$1,85 \times 10^{\circ} .5100 \mathrm{mw}$

The respones function for lron dpa hase a cutoll enargy of $0.0 \mathrm{KoV}$. 
Tabla 6. Estimated neutron damage correlation parameters for 85 MW operation

\begin{tabular}{|c|c|c|c|c|c|c|c|c|c|}
\hline Kay & Position & 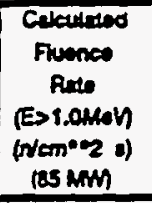 & 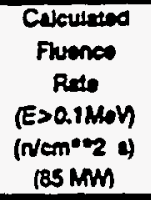 & $\begin{array}{l}\text { Celcalesed } \\
\text { Fo OPA } \\
\text { Rat } \\
\text { (dpa/d) } \\
\text { (es MM) }\end{array}$ & $\begin{array}{c}\text { CE } \\
\text { Adjutunert } \\
\text { Fator }\end{array}$ & $\begin{array}{c}\text { Pown } \\
\text { Nomitation } \\
\text { Factex }\end{array}$ & 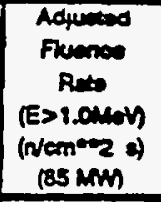 & 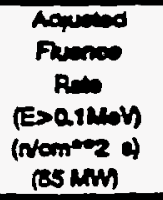 & 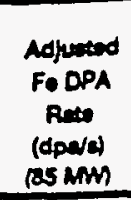 \\
\hline 1 & 1 & $400 E+08$ & $756 E+\infty$ & 502513 & 0.815 & 1.000 & $4.91 E+\infty$ & $0205+\infty$ & 7.14E-13 \\
\hline 1 & 2 & $5.49 E+08$ & $9 D B E+\infty$ & $2.00 E \cdot 13$ & 0.815 & 1.000 & $6.74 E+\infty 6$ & $12005+00$ & $9.825-13$ \\
\hline 1 & 3 & 3ESE+CS & $7.68 E+C 0$ & S3IE-13 & 0.815 & 1.000 & $4.405+\infty$ & Qcastos & CS2E-13 \\
\hline 1 & 4 & $540 E+08$ & $9.08 E+00$ & $8.005 \cdot 13$ & 0.815 & 1.000 & $6.74 E+\infty$ & $1205+00$ & 9xDE-13 \\
\hline 1 & $\mathbf{s}$ & $400 E+\infty$ & $7.56 E+\infty$ & $5.025-13$ & 0.815 & 1.000 & $4.91 E+\infty$ & $9200+00$ & 7.14E-13 \\
\hline 1 & 6 & $284 E+08$ & $6.3 t E+\infty$ & 4.00 E.13 & 0.815 & 1.000 & $3.48 E+\infty 0$ & 7.74E+CO & 5.005E-13 \\
\hline 1 & 7 & $2495+00$ & $4.86 E+\infty$ & 35SE-13 & 0.815 & 1.000 & $3.05 E+00$ & $6.00 E+00$ & 4.38E-13 \\
\hline 1 & 8 & $1.59 E+\infty 8$ & $200 E+\infty$ & 220513 & 0.815 & 1.000 & $1.05 E+\infty$ & SSAE+OS & 270E-13 \\
\hline 1 & 9 & 249E+C8. & 4.98E+08 & 35SE-13 & 0.815 & 1.000 & $3.05 E+\infty$ & $6.00 E+\infty$ & $4.385-13$ \\
\hline 1 & 10 & $204 E+\infty 8$ & $6.31 E+\infty$ & 4.09E-13 & 0.815 & 1.000 & $3.48 E+\infty$ & $7.74 E+\infty 0$ & 500 E.13 \\
\hline 2 & $t$ & $2.19 E+\infty$ & $127 E+\infty$ & $1.19 E-12$ & $t .031$ & 1.000 & $7.04 E+\infty$ & $12 a x+\infty$ & 1.35E-12 \\
\hline 2 & 2 & $2.19 E+\infty$ & $127 E+\infty$ & 1.19E-12 & 1.031 & 1.000 & $7.84 E+\infty 8$ & $123 E+\infty$ & 1.15E-12 \\
\hline 2 & 3 & $2.19 E+\infty$ & $127 E+\infty$ & 1.19E-12 & 1.031 & 1.000 & $7.94 E+\infty 6$ & $12 x E+\infty$ & $1.15 E-12$ \\
\hline 2 & 4 & 2.19E+08 & $127 E+\infty$ & 1.19E-12 & 1.031 & 1.000 & $7.94 E+\infty$ & $12 \pi 5+\infty$ & 1.15E-12 \\
\hline 2 & 5 & $8.19 E+\infty$ & $127 E+\infty$ & ใ.19E-12 & 1.031 & 1.000 & $7.94 E+\infty$ & $12 x E+\infty$ & $1.15 E-12$ \\
\hline 2 & 6 & $8.19 E+\infty$ & $127 E+\infty$ & 1.19E-12 & 1.031 & 1.000 & $7.04 E+\infty O$ & $12 A E+\infty$ & 1.15E-12 \\
\hline 2 & 7 & $2.19 E+\infty$ & $127 E+\infty$ & 1.19E-12 & 1.031 & $1 . \infty 0$ & $7.94 E+\infty$ & $1220+\infty$ & 1.15E-12 \\
\hline 2 & B & 2.19E+C8 & $127 E+\infty$ & 1.19E:12 & 1.031 & 1.000 & 7.94E+CS & $12 x E+\infty$ & $1.155-12$ \\
\hline 2 & 9 & 6.19E+ $+\infty$ & $127 E+\infty 9$ & 1.19E-12 & 1.031 & 1.000 & 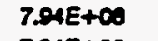 & $120 E+\infty$ & 1.15E-12 \\
\hline 2 & 10 & $8.10 E+\infty 8$ & $1.27 \mathrm{E}+\infty$ & 1.19E-12 & 1.001 & 1.000 & $7.24 E+\infty$ & $12 x E+\infty$ & 1.15E-12 \\
\hline 2 & 11 & Q.19E+DS & $127 E+\infty$ & $1.19 E-12$ & 1.031 & 1.000 & 7.S4E+08 & $123 \varepsilon+\infty$ & 1.15E-12 \\
\hline 2 & 12 & $8.19 E+\infty 3$ & $1.27 E+\infty$ & 1.19E-12 & 1.081 & 1.00 & $7.94 E+\infty$ & $1205+\infty$ & 1.15E-12 \\
\hline 2 & 13 & $8.19 E+08$ & $127 E+\infty$ & 1.19E-12 & 1.031 & 1.000 & $7.94 E+\infty 8$ & $12 A E+\infty$ & 1.15E-12 \\
\hline 2 & 14 & $8.19 E+08$ & $127 E+\infty$ & $1.19 E-12$ & 1.031 & 1.000 & $7.24 E+\infty 8$ & $12 x \varepsilon+\infty$ & 1.95E-12 \\
\hline 2 & 15 & Q.19E+ +08 & $127 \varepsilon+\infty$ & 1.19E-12 & 1.031 & 1.000 & 7.S4E+OS & $12 a E+\infty$ & 1.15E-12 \\
\hline 2 & 16 & $2.19 E+\infty$ & $127 E+\infty$ & 1.19E-12 & 1.031 & 1.000 & $7.94 E+\infty$ & $123 E+\infty$ & 1.15E-12 \\
\hline 4 & 1 & $284 E+08$ & $6.31 E+\infty$ & $4.09 E-13$ & 0.815 & 1.000 & $3.48 E+\infty 8$ & $7.74 E+\infty 0$ & $5.025-13$ \\
\hline 4 & 2 & $249 E+08$ & $4.96 E+\infty$ & 3.5SE-13 & 0.815 & 1.000 & $305 E+\infty$ & $6.09 E+\infty$ & $4.385-13$ \\
\hline 4 & 3 & $1.59 E+08$ & $2.89 E+08$ & 228E-13 & 0.815 & 1.000 & $1.25 E+08$ & $3.54 E+\infty$ & 2TIE-13 \\
\hline 4 & 4 & $249 E+08$ & $4.96 E+\infty$ & 3.55E 13 & 0.815 & 1.000 & $3.058+\infty$ & $6.005+\infty$ & $4.355-13$ \\
\hline 4 & 5 & $284 E+08$ & $6.31 E+\infty 8$ & 4.09E-13 & 0.815 & 1.000 & $3.40 E+\infty 8$ & $7.74 E+\infty 8$ & $5.02 E-13$ \\
\hline 4 & 6 & $400 E+00$ & $7.56 E+\infty$ & 5.20E-13 & 0.615 & 1.000 & $491 \varepsilon+\infty$ & $920 E+\infty$ & 7.14E-13 \\
\hline 4 & 7 & $5.49 E+\infty B$ & $9.98 E+\infty$ & $0.00 E-13$ & 0.815 & 1.000 & $6.74 E+\infty$ & $1205+\infty$ & 9.225-13 \\
\hline 4 & 8 & $3.66 E+\infty$ & $7.68 E+\infty$ & 5.31E-13 & 0.875 & 1.000 & 4.49E+C3 & $0.42 E+\infty$ & $6.525-13$ \\
\hline 4 & 9 & S.49E+08 & $9.98 E+\infty$ & O.COE-13 & 0.815 & 1.000 & $6.74 E+\infty$ & $1202=00$ & O.ARE-13 \\
\hline 4 & 10 & $4.00 E+08$ & $7.56 E+\infty$ & $5.02 E-13$ & 0.815 & 1.000 & $491 E+\infty$ & $920 E+\infty$ & $7.14 E-13$ \\
\hline 6 & 1 & $1.57 \varepsilon+\infty$ & $253 E+\infty$ & 226E-13 & 0.672 & $1 . \infty 0$ & $234 E+\infty 3$ & $3.78 E+\infty 6$ & 3.38513 \\
\hline 6 & 2 & $126 E+00$ & $1.95 E+\infty$ & $1.81 E-13$ & 0.672 & 1.000 & $1.88 E+\infty 8$ & $200 x+00$ & $200 E-13$ \\
\hline 6 & 3 & $1.19 E+\infty$ & $1.76 E+\infty$ & 1.71E-13 & 0.672 & 1.000 & 1.TTE+ $+\infty$ & $20-25+\infty$ & 254E-13 \\
\hline 6 & 4 & $1.17 E+08$ & $1.75 E+\infty$ & 1.70E-13 & 0.672 & 1.000 & $1.74 E+\infty$ & $261 E+\infty$ & $2525-13$ \\
\hline 6 & 5 & $1.18 E+08$ & $1.72 E+\infty 8$ & 1.71E-13 & 0.672 & 1.000 & $1.76 E+08$ & $25 T E+\infty$ & $2558-13$ \\
\hline 6 & 6 & $122 E+08$ & $1.73 E+\infty$ & $1.78 E-13$ & 0.672 & 1.000 & $1.2025+\infty$ & 25TE+C8 & 205513 \\
\hline 6 & 7 & $124 E+08$ & $1.75 E+08$ & 1.81E-13 & 0.672 & 1.000 & $1.85 E+00$ & $200 E+\infty$ & 200E.13 \\
\hline 6 & $\mathbf{8}$ & $120 E+\infty$ & $1.68 E+\infty$ & 1.75E-13 & 0.672 & 1.000 & $1.79 E+\infty$ & $250 E+\infty$ & $200 E-13$ \\
\hline 7 & 1 & $120 E+06$ & $1.68 E+\infty$ & 1.75E-13 & 0.672 & 1.000 & $1.70 E+\infty 6$ & $250 E+\infty 6$ & 200E-13 \\
\hline 7 & 2 & $124 E+\infty 8$ & $1.75 E+\infty$ & $1.81 E-13$ & 0.672 & 1.000 & $1.05 E+\infty 0$ & $2.00 E+\infty$ & $200 E-13$ \\
\hline 7 & 3 & $1202+\infty$ & $1.73 E+08$ & $9.78 E-13$ & 0.672 & $1 . \infty 00$ & $1.025+\infty$ & 2STE+CS & 2.5E-13 \\
\hline 7 & 4 & $1.18 E+\infty 8$ & $1.72 E+\infty$ & 1.71E-13 & 0.672 & 1.000 & $1.76 E+\infty 8$ & $257 E+\infty$ & 255E-13 \\
\hline 7 & 5 & $1.37 E+\infty$ & $1.75 E+\infty 6$ & 1.70E-13 & 0.672 & 1.000 & $1.74 E+\infty$ & $201 E+\infty$ & $252 E-13$ \\
\hline 7 & 6 & $1.19 \varepsilon+\infty$ & $1.76 E+\infty$ & 1.7 E13 & 0.672 & 1.000 & 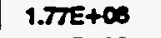 & $2005+C$ & 2SAE-13 \\
\hline 7 & 7 & $128 E+\infty 8$ & $1.96 E+\infty$ & 1.81E-13 & 0.672 & 1.000 & $1.28 E+00$ & $200 E+\infty$ & 200613 \\
\hline 7 & 8 & $1.57 \mathrm{E}+08$ & $253 E+\infty$ & 220513 & 0.672 & 1.000 & $234 E+03$ & $3.70 E+\infty$ & 3.305 .13 \\
\hline
\end{tabular}

The response function for iron dpa has a cutott energy of $0.8 \mathrm{KoV}$. 
Table 7. Estimazed noutron damage correlation parameters tor $100 \mathrm{MW}$ operetion

\begin{tabular}{|c|c|c|c|c|c|c|c|c|c|}
\hline$k y$ & Poalion & 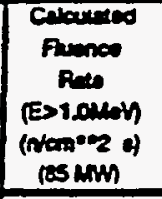 & 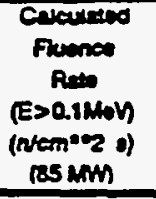 & 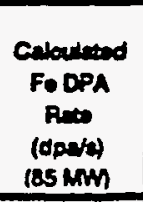 & $\begin{array}{l}\text { CE } \\
\text { Adpucenon } \\
\text { Fecter }\end{array}$ & 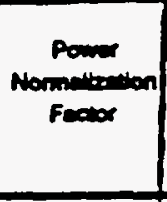 & 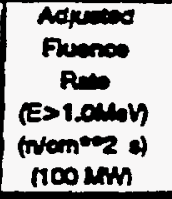 & 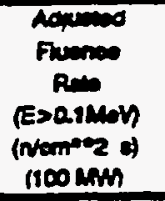 & $\begin{array}{l}\text { Aonud } \\
\text { Fo DPA } \\
\text { Am } \\
\text { (dpate) } \\
\text { noo chin }\end{array}$ \\
\hline 1 & 1 & $400 E+\infty$ & $73 x E+\infty$ & 500513 & 0.815 & 1.177 & sTHE+CS & $100=+\infty$ & LAIE-IS \\
\hline 1 & 2 & $500+\infty$ & $9.035+\infty$ & 200E-13 & e.s15 & 1.177 & 7 PaE+CS & 1.44E+CO & 1.16512 \\
\hline 1 & 3 & $30 s e+03$ & $7.08 E+\infty$ & 531E-13 & u.6ts & 1.177 & $5 \geq 9 E+\infty$ & $1.11 E+\infty$ & 7.ATE-1S \\
\hline 1 & 4 & swe+o & $0.00 E+\infty$ & 2.00513 & 0.895 & 1.17 & $7 E S E+C S$ & $1.44 E+00$ & $1.160-12$ \\
\hline 1 & 5 & $400 E+\infty$ & $758 E+06$ & 582E-13 & 0.815 & 1.177 & STEE+O & $1 \infty x+\infty$ & ALIEI3 \\
\hline 1 & 6 & $2 M E+\infty$ & OS1E+CS & $4.005-13$ & 0.815 & 1.177 & $4.10 E+03$ & $0.91 E+\infty 0$ & GAIE-13 \\
\hline 1 & 7 & $20 \leq+\infty$ & $A S A E+\infty$ & ISSE 13 & 0.815 & 1.177 & 200E+Cs & $7.10 E+00$ & E.t5:-13 \\
\hline 1 & 8 & Ispetos & $2005+\infty$ & 220E-13 & 0.815 & 1.877 & $250 E+08$ & 4.17E+C & 220513 \\
\hline 1 & 9 & 2थE+os & $4 S E+08$ & SSSE-13 & 0.815 & 1.97 & $250+\infty$ & $7.90 E+00$ & $5.13 \times 513$ \\
\hline 1 & 10 & 2UE+Cs & $6.31 E+\infty 8$ & $4.00 E-13$ & 0.815 & 1.177 & $4.10 E+08$ & Q.11E+C. & 5OIE-13 \\
\hline 2 & 1 & Etcetos & $12 \pi E+\infty$ & 1.19E-12 & 1.001 & 1.177 & SSSE+CS & $1.45 E+\infty$ & 1.50512 \\
\hline 2 & 2 & e.19E+Co & 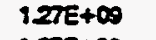 & $1.195-12$ & 1.031 & 1.177 & $9.35 E+\infty$ & $1.45 E+\infty 0$ & $1305-12$ \\
\hline 2 & 3 & Q10E+OS & $127 \varepsilon+\infty$ & 1.19E-12 & 1.031 & 1.377 & $935 E+00$ & $1.45 E+\infty$ & 130512 \\
\hline 2 & 4 & $2.19 E+\infty$ & $127 E+\infty$ & 1.15E-12 & 9.039 & 1.177 & $9.35 E+00$ & $1.45 E+\infty$ & 1.35512 \\
\hline 2 & 5 & $2.19 E+08$ & $127 E+\infty$ & 1.19E-12 & 1.031 & 1.177 & $9.25 E+00$ & $1.45 E+\infty 0$ & $1305-12$ \\
\hline 2 & 6 & Q.19E+00 & $1201 E+\infty$ & $1.195-12$ & 1.001 & 1.977 & OSSE+CS & $1.45 E+\infty$ & 136512 \\
\hline 2 & 7 & $210=+\infty$ & $12 \pi E+\infty$ & 1.10512 & 1.001 & 1.977 & ossetos & $1.45 E+00$ & 1.30512 \\
\hline 2 & 8 & aigetos & $12 \pi E+\infty$ & 1.10512 & 1.031 & 1.177 & OSSE+CO & $1.45 E+\infty$ & $1305-12$ \\
\hline 2 & 9 & 6.19E+ +08 & $127 E+\infty$ & 1.19E-12 & 1.039 & 1.177 & $9.35 E+0$. & $1.45 E+\infty$ & 1.36512 \\
\hline 2 & 10 & $0.19 E+06$ & $12 \pi E+\infty$ & 1.19E-12 & 1.031 & 1.17 & $2.358+\infty$ & $1.4 S E+\infty$ & I.S6E12 \\
\hline 2 & 11 & a.19E+os & $12 \pi E+\infty$ & 1.19E-12 & 1.009 & 1.177 & 9.35E+0. & $1.45 E+\infty$ & 134512 \\
\hline 2 & 12 & Q.19E+06 & $127 E+\infty$ & 1.19E.12 & 1.031 & 1.177 & $9.35 E+00$ & $1.45 E+00$ & 130512 \\
\hline 2 & 13 & $2.10 E+\infty$ & $127 E+\infty$ & $1.19 E-12$ & 1.001 & 1.177 & QSSE+CS & $1.4 S E+\infty$ & 1.30512 \\
\hline 2 & 14 & 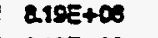 & $127 E+\infty$ & 1.19E-12 & 1.031 & 1.177 & $935 E+\infty 3$ & $1.45 E+\infty$ & 130512 \\
\hline 2 & 15 & $2195+\infty$ & 1.27E+09 & $1.195-12$ & 1.031 & 1.177 & $9.35 E+00$ & $1.45 E+\infty 0$ & $1,365-12$ \\
\hline 2 & 16 & $8.19 E+\infty$ & $12 \pi E+\infty$ & 1.19512 & 1.031 & 1.177 & $935 E+03$ & $1.45 E+\infty$ & $1 \leq 6512$ \\
\hline 4 & 1 & $284 E+00$ & $6.31 E+\infty$ & $4.00 E 13$ & 0.815 & 1.17 & $4.10 E+\infty 0$ & $0.11 E+\infty$ & SONE-13 \\
\hline 4 & 2 & $240 E+00$ & $4 S E E+\infty$ & 3.55E-13 & 0.815 & 1.17 & $350 E+\infty$ & 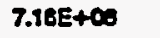 & 5.15E-13 \\
\hline 4 & 3 & $1505+\infty$ & $200 E+\infty 8$ & 220E-13 & 0.815 & 1.177 & $200 E+\infty$ & 4.17E+OS & $32=513$ \\
\hline 4 & 4 & $249 E+00$ & $4.06 E+\infty$ & 3.55E-13 & 0.895 & 1.977 & $350 E+\infty$ & 7.16E+Co & $5.135-13$ \\
\hline 4 & 5 & 2Q4E+CO & $6.31 E+08$ & 400513 & 0.815 & 1.177 & $4.105+\infty$ & $9.11 E+\infty$ & 5NE-13 \\
\hline 4 & 6 & $400 E+\infty$ & $7.58 E+\infty$ & 502513 & 0.815 & 1.177 & $5.70 E+\infty$ & $1.00 E+\infty$ & 8.41E-13 \\
\hline 4 & 7 & $5405+\infty$ & $9 S O E+\infty$ & 200513 & 0.815 & 1.17 & $7235+6$ & $1.44 E+\infty$ & 1.10512 \\
\hline 4 & b & $300+00$ & $7.085+\infty$ & S.31E13 & 0.815 & 1.177 & $520 E+\infty$ & $1.21 E+\infty 0$ & 7.0TES13 \\
\hline 4 & 9 & $540+\infty$ & $9.005+\infty$ & 8.00E-13 & 0.815 & 1.177 & $7.03 E+\infty$ & $1.44 E+\infty 0$ & $1.165-12$ \\
\hline 4 & 10 & $4005+\infty$ & $7565+\infty 0$ & 5.02513 & 0.815 & 1.177 & $5.705+\infty$ & $100 E+\infty$ & 8.4tE-13 \\
\hline 6 & 1 & $1.5 \pi E+\infty$ & $253 E+08$ & 20.013 & 0.672 & 1.177 & 27SE+C0 & 4.4AE+0s & $20 E-13$ \\
\hline $\boldsymbol{\theta}$ & 2 & $1205+\infty$ & $1.56+03$ & IAIEIS & 0.672 & 1.177 & 221E+O & 24SE+0 & 317613 \\
\hline 6 & 3 & $1.195+00$ & $1.78 E+0$. & I.7IEI3 & 0.672 & 1.177 & 200E+OS & 30SE+OS & 300513 \\
\hline 6 & 4 & $1.97 E+\infty$ & 1.75E+0s & $1.70 E-13$ & 0.672 & 1.177 & 200E+C & sore+os & $207 \leq-13$ \\
\hline 6 & $\mathbf{5}$ & $1.185+\infty$ & $1.72 E+\infty$ & 1.71E-13 & 0.672 & 1.177 & $207 t+0 s$ & $3005+0$ & socets \\
\hline 6 & 6 & $1205+08$ & $1.735+\infty$ & 1.78513 & 0.672 & 1.177 & $214 E+\infty$ & sosetes & 3.12513 \\
\hline 6 & 7 & $124 E+\infty$ & $1.75 E+\infty$ & I.81E13 & 0.672 & 1.377 & $217 E+\infty$ & SOTE+CS & 3.17F-13 \\
\hline 6 & 8 & $1205+\infty$ & $1.60 E+08$ & 1.755 .13 & 0.672 & 1.577 & $2105+0$ & 2OAE+CS & 30r:13 \\
\hline 7 & 1 & $1205+08$ & $1.00 E+00$ & 1.75E-13 & 0.672 & 3.177 & $2805+\infty$ & $204 E+\infty$ & SortE-13 \\
\hline 7 & 2 & $124 E+\infty$ & $1.75 E+08$ & 1.81E-13 & 0.672 & 1.177 & $217 E+\infty$ & $307 e+\infty$ & 3.17E-13 \\
\hline 7 & 3 & $1205+\infty$ & $1.73 E+03$ & $1.705-13$ & 0.672 & 1.177 & 214E+0s & $3005+0$ & 3.125-13 \\
\hline 7 & 1 & 1.1CE+CS & $1.725+\infty$ & I.J1ES13 & 0.672 & 1.177 & $20 n=+\infty$ & $300 x+\infty$ & $300 \leq 13$ \\
\hline 7 & 5 & $1.17 E+\infty$ & $8.755+00$ & 1.70513 & 0.672 & 1.177 & 20se+co & SOTE+CS & 2UTE1S \\
\hline 7 & 6 & 1.15E+C & $1.76 E+\infty$ & 1.TIEST & 0.012 & 1.177 & 200E+C & sonetas & 300515 \\
\hline 7 & 7 & $1205+0$ & $1065+\infty$ & IDIEIS & 0.672 & 1.177 & 221E+CS & SAREtCS & S.17ESIS \\
\hline 7 & 8 & $1.57 E+\infty$ & $200 E+\infty$ & $2205-13$ & 0.672 & 1.177 & 275E+00 & 4.45E+OS & $3.0 \times 13$ \\
\hline
\end{tabular}

The response tunetion for iron cos hes a criot energy of $0.8 \mathrm{KeV}$. 
Appendix E. Neutron Fluxes Calculated for HFIR in Connection with 1993 Vessel-Material Surveillance Activities 
June 16, 1993

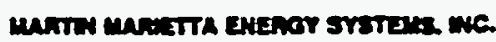

C.A. Baldwin, Bldg. 3525, MS-6295, 4-6552

BOC HFIR Kevs 2, 4, and 7 Fluxes. Response Facrors, and Responses

References: 1. W.L. 21jp, H.J. Nolthenius, G.C.H.M Verhaag, "Damage Cross-Section Library DAYsIG84 (in a 640 group scructure of the SAND-II type)", ECN-159, October 1984.

The neutron-energy-group boundaries, neutron fluxes, and response factors you requested have been determined and are provided on the accomanying floppy disk; informacion on each directory is as follows:

1. The neutron group boundaries are lacated in directory EBDY and are in MeV, arranged from high energy to low.

2. The beginning of cycie (BOC) 3-dimensional fluxes for each key (2, 4, and 7) are locared in direcrory FLUX and have units of (neutrons/ $\mathrm{cm}^{2} .5$ ). The positions given are related to the accusi posicions as shown in the following table:

\begin{tabular}{|c|c|}
\hline & $y 2$ \\
\hline Given & Actual \\
\hline $\begin{array}{l}1 \\
2 \\
3 \\
4\end{array}$ & $\begin{array}{l}1,8,9,16 \\
2,7,10,15 \\
3,6,11,14 \\
4,5,12,13\end{array}$ \\
\hline
\end{tabular}

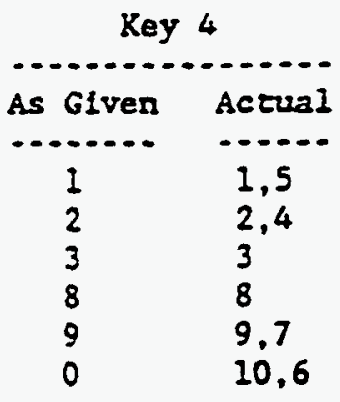

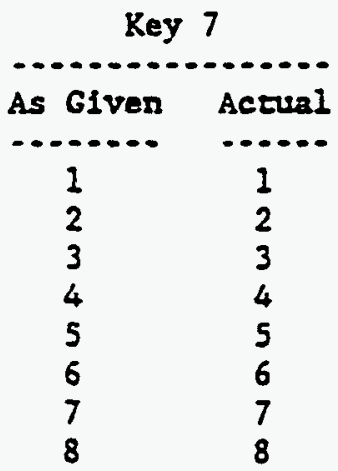

3. Energy dependent, response damage factors are given in the directory RESPONSE and have units of (reactions. $\mathrm{cm}^{2} /$ neutron.ator). All danage responses were taken from Ref. 1 ., which contains 640-neutron-energ damage cross sections. Two iron displacement-per-aton (DPA) cross sections and three stainless steel (SS) DPA cross sections were taken from the flles of Ref. 1. The cross sections were collapsed to the HFIR 64-neucron-energy-group structure using the following procedure: The fluxes at each of the positions for a key were normaifized to 1.0 , then averaged over all positions of the key. using the arithmetic mean. This averaged flux for the key was expanded to the 640-neutron-energy-group structure. The 640-neutron-energy-group danage cross sections were then weighted with the expanded flures and reduced to the HFIR 64-neucron-energy-group seructare.

The response file names can be deciphered as follows: 


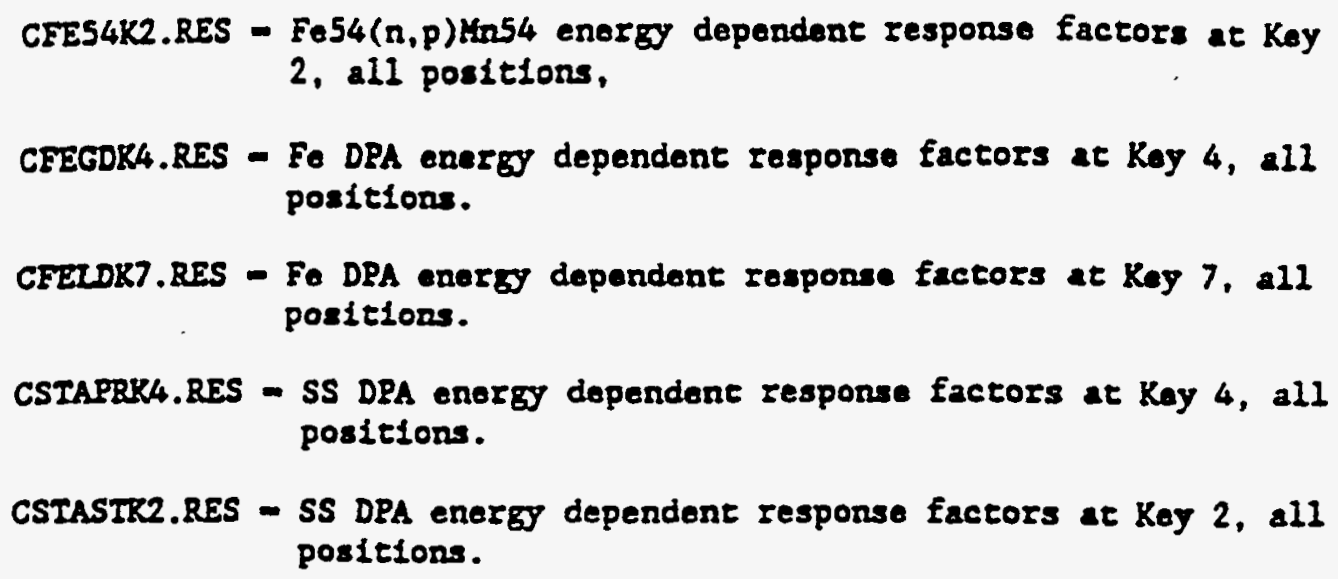

When the reaponse damage factors are multiplied by the fluxes and sumed over all energy groups, the units are (reactions/atom,s). These results are shown in Tables HFIRK2RES, HFIRK4RES, and HFIRK7RES. If these results are then multiplied by the ratio of Adrogadro's number (atoms/g-mole) to the molecular weight $(g / g-m o l e)$, the final units are (reactions/g.s).

If you have any questions or need additional information, please call me. Thanks.

J.V. Pace III, B1dg, 6025, MS-6363, 4-5285 
Table HFIRK2RES. BOC HFIR Key 2 Responses Using 3-D TORT Flwas

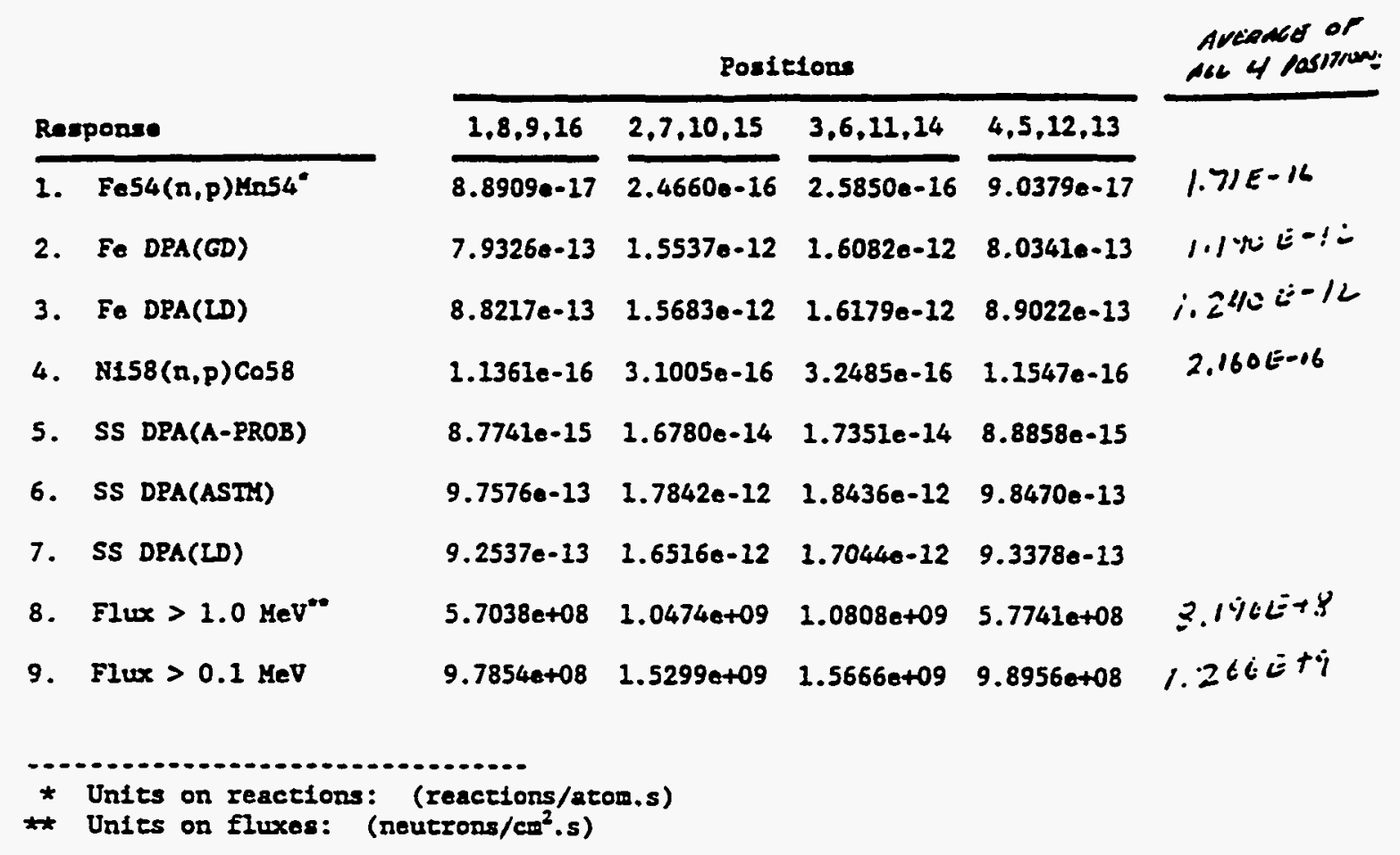


Table HFIRK4RES. BOC HFIR Key 4 Responses Using 3-D TORI Fluxes

\begin{tabular}{|c|c|c|c|c|}
\hline \multirow{2}{*}{\multicolumn{2}{|c|}{ Response }} & \multicolumn{3}{|c|}{ Positions } \\
\hline & & \multirow{2}{*}{$\frac{1.5}{3.4355 e-17}$} & \multirow{2}{*}{$\frac{2,4}{3.4935 e-17}$} & \multirow{2}{*}{$\frac{3}{2.5960 e-17}$} \\
\hline 1. & $\operatorname{Fe} 54(n, p) \operatorname{Mn} 54^{\circ}$ & & & \\
\hline 2. & Fe $D P A(G D)$ & $4.0943 e-13$ & $3.5543 e-13$ & $2.2753 e-13$ \\
\hline 3. & Fe DPA(LD) & $4.9986 e-13$ & $5.5643 e-13$ & $2.8806 e-13$ \\
\hline & $\mathrm{N} 158(\mathrm{n}, \mathrm{p}) \mathrm{Co58}$ & $4.4482 \mathrm{e}-17$ & $4.4857 e-17$ & $3.3090 e \cdot 17$ \\
\hline & SS DPA(A-PROB) & $4.7377 e-15$ & $4.0279 e-15$ & $2.5353 e-15$ \\
\hline & SS DPA(ASTM) & $5.5888 \mathrm{e}-13$ & $6.4830 e-13$ & $3.2905 e-13$ \\
\hline & SS DPA(LD) & $5.3210 \mathrm{e}-13$ & $6.0376 e-13$ & $3.0822 e-13$ \\
\hline & Flux $>1.0 \mathrm{MeV}^{4 *}$ & $2.8414 e+08$ & $2.4852 e+08$ & $1.5902 e+08$ \\
\hline & Flux $>0.1 \mathrm{MeV}$ & $6.3096 e+08$ & $4.9613 e+08$ & $2.8852 e+08$ \\
\hline
\end{tabular}

\begin{tabular}{|c|c|}
\hline Res! & ponse \\
\hline 2. & $\operatorname{Fe} 54(n, p) \sin 54$ \\
\hline 2. & Fe $D P A(G D)$ \\
\hline 3. & Fe DPA(LD). \\
\hline 4. & $\operatorname{N158}(\pi, p) \operatorname{Co58}$ \\
\hline 5. & SS DPA(A-PROB) \\
\hline & SS DPA(ASTM) \\
\hline & SS DPA(LD) \\
\hline & Flux $>1.0 \mathrm{MeV}$ \\
\hline 9. & Flux $>0.1 \mathrm{MeV}$ \\
\hline
\end{tabular}

\begin{tabular}{ccc}
\multicolumn{3}{c}{ Positions } \\
\hline $5.2173 e-17$ & $9.7376 e-17$ & $6.7217 e-17$ \\
$5.3058 e-13$ & $7.9960 e-13$ & $5.8233 e-13$ \\
$5.7640 e-13$ & $1.1052 e-12$ & $7.7969 e-13$ \\
$6.5846 e-17$ & $1.2365 e-16$ & $8.5560 e-17$ \\
$6.0653 e-15$ & $8.9012 e-15$ & $6.5294 e-15$ \\
$6.3576 e-13$ & $1.2799 e-12$ & $8.9727 e-13$ \\
$6.0709 e-13$ & $1.1890 e-12$ & $8.3702 e-13$ \\
$3.6613 e+08$ & $5.4885 e+08$ & $4.0001 e+08$ \\
$7.6840 e+08$ & $9.9750 e+08$ & $7.5601 e+08$
\end{tabular}

* Units: (reactions/atom.s)

* Units: (neutrons $/ \mathrm{cm}^{2} . s$ ) 

Table HFIRKTRES. BOC HFIR Key 7 Responses Using 3-D TORT Fluxes
Positions

\begin{tabular}{|c|c|c|c|c|c|}
\hline \multirow{2}{*}{\multicolumn{2}{|c|}{ Response }} & \multirow{3}{*}{$\frac{1}{2.7446 e-17}$} & \multirow{3}{*}{$\frac{2}{2.8313 e-17}$} & \multirow{3}{*}{$\frac{3}{2.7604 e-17}$} & \multirow{3}{*}{$\frac{4}{2.5776 e-17}$} \\
\hline & & & & & \\
\hline 1. & $\operatorname{Fe} 54(n, p) \sin 54^{\circ}$ & & & & \\
\hline 2. & Fe DPA(GD) & $1.7485 e-13$ & $1.8122 e-13$ & $1.7812 e-13$ & $1.7142 \mathrm{e}-13$ \\
\hline 3. & Fe DPA(LD) & $1.6888 e-13$ & $1.7523 e \cdot 13$ & $1.7239 e-13$ & $1.6563 \mathrm{e}-13$ \\
\hline 4. & $\operatorname{N158}(n, p) \operatorname{Co58}$ & $3.4495 e-17$ & $3.5592 e-17$ & $3.4713 e-17$ & $3.2451 \mathrm{e}-17$ \\
\hline 5. & SS DPA(A-PROB) & $1.8715 e-15$ & $1.9403 \mathrm{e}-15$ & $1.9086 e-15$ & $1.8445 e-15$ \\
\hline 6. & SS DPA(ASII) & $1.9077 e-13$ & $1.9769 e-13$ & $1.9425 e-13$ & $1.8590 \mathrm{e}-13$ \\
\hline & SS DPA(LD) & $1.7747 e \cdot 13$ & $1.8401 \mathrm{e}-13$ & $1.8096 e-13$ & $1.7369 e-13$ \\
\hline 8. & Flux > $1.0 \mathrm{MeV}^{\circ *}$ & $1.1982 \mathrm{e}+08$ & $1.2436 \mathrm{e}+08$ & $1.2242 e+08$ & $1.1826 e+08$ \\
\hline 9. & Flux $>0.1 \mathrm{YeV}$ & $1.6846 \mathrm{e}+08$ & $1.7523 e+08$ & $1.7349 e+08$ & $1.7244 e+08$ \\
\hline
\end{tabular}

\begin{tabular}{|c|c|c|c|c|c|}
\hline \multirow{2}{*}{\multicolumn{2}{|c|}{ Respanse }} & \multicolumn{4}{|c|}{ Positions } \\
\hline & & \multirow{2}{*}{$\frac{5}{2.4921 e-17}$} & \multirow{2}{*}{$\frac{6}{2.5376 e-17}$} & \multirow{2}{*}{$\frac{7}{2.5365 e-17}$} & \multirow{2}{*}{$\frac{8}{3.0339 e-17}$} \\
\hline 1. & $\mathrm{Fe} 54(\mathrm{n}, \mathrm{p}) \mathrm{MnS4}$ & & & & \\
\hline 2. & Fe DPA(GD) & $1.6951 e-13$ & $1.7175 e-13$ & $1.8117 e-13$ & $2.2577 e-13$ \\
\hline 3. & Fe DPA(LD) & $1.6336 e-13$ & $1.6629 e-13$ & $1.7616 e-13$ & $2.2289 e-13$ \\
\hline 4. & $\mathrm{Ni} 58(n, p) \operatorname{Co} 58$ & $3.1405 e-17$ & $3.1975 e-17$ & $3.2032 e-17$ & $3.8380=-17$ \\
\hline & SS DPA(A-PROB) & $1.8321 e-15$ & $1.8521 \mathrm{e}-15$ & $1.9691 e-15$ & $2.4660 e-15$ \\
\hline & SS DPA(ASTM) & $1.8292 \mathrm{e}-13$ & $1.8609 e-13$ & $1.9604 e-13$ & $2.4714 e-13$ \\
\hline & SS DPA(LD) & $1.7124 e-13$ & $1.7417 \mathrm{e} \cdot 13$ & $1.8432 \mathrm{e} \cdot 13$ & $2.3302 e-13$ \\
\hline & Flux $>1.0 \mathrm{MeV}$ & $1.1705 e+08$ & $1.1877 e+08$ & $1.2561 e+08$ & $1.5676 \mathrm{e}+08$ \\
\hline & Flux $>0.1 \mathrm{SeV}$ & $1.7528 \mathrm{e}+08$ & $1.7566 e+08$ & $1.9577 e+08$ & $2.5302 e+08$ \\
\hline
\end{tabular}

* Units: (reactions/arom.s)

* Units: (neutrons/ $\mathrm{cm}^{2} . s$ ) 
Appendix F. Selection of Flaw Sizes for Calculating $p(H T)$ and $\Delta t$

The range of flaw depths that needs to be considered in calculating $p(H T)$ and $\Delta t$ is established by consideration of ASME Code requirements for flaw size and the calculated minimum critical flaw size. In accordance with the Code, the maximum flaw depth that needs to be considered for the HFIR vessel is 1.0 in. (larger flaws are not likely to exist because the confidence level in nondestructively detecting such flaws is sufficiently high). The smallest flaw that needs to be considered can be calculated using Eqs. (13) and (18) from the text. The critical value of $\underline{a}$ is obtained by letting $\mathrm{K}_{\mathrm{I}}=\mathrm{K}_{\mathrm{Ic}}$. Thus,

$$
\left[p(H T)\left(c_{m} s_{m}+c_{b} s_{b}\right)+c_{r} \sigma_{r}\right] \sqrt{\pi a_{c}}=A+B \exp [C \cdot E(H T)]
$$

or

$$
a_{c} \approx \frac{1}{\pi}\left\{\frac{A+B \exp [C \cdot E(H T)]}{p(H T)\left(c_{m} s_{m}+c_{b} s_{b}\right)+c_{r} \sigma_{r}}\right\}^{2},
$$

where $\mathrm{E}(\mathrm{HT})$ is given by Eq. (20) of the text.

The approximate sign is used because $c_{m}, c_{b}, c_{r}$ and $\Delta$ NDTT are also functions of flaw depth. However, the effect on $a_{c}$ is only secondary.

Reasonable input for Eq. (F.2) is taken from Table 5.1. The lower of the two toughness curves will result in the smallest value of $a_{c}$; values of $c_{b}, c_{m}, c_{r}$ and $\triangle N D T T$ should correspond to $\mathrm{a}=0.5 \mathrm{in}$; the largest required value of $\mathrm{e}(1.5)$ should be used, $\Delta \mathrm{t}(\mathrm{HT})$ should be $26 \operatorname{EFPY}(100 \mathrm{MW})(17.5+8.5=26)$, and $\mathrm{p}(\mathrm{HT})=900$ psi is a reasonable maximum pressure. Thus, 


$$
\begin{aligned}
E(H T)=85-10-1.5 \cdot 2.62 \cdot 26=-27.2^{\circ} \mathrm{F} \\
a_{c}=\frac{1}{\pi}\left\{\frac{33.2+20.73 \exp [0.020(-27.2)]}{0.900(1.068 \times 16.8+0.823 \times 4.24)+0.86 \times 8.5}\right\}^{2} \\
=0.92 \text { in. }
\end{aligned}
$$

Because this value of $a_{c}$ is based on the ASME lower-bound $K_{I c}$ curve and an uncertainty factor of 1.5 for $\triangle N D T T$, the probability of a flaw of this depth propagating is quite small.

The above calculation of $a_{c}$ did not include the customary ASME safety factor of $\sqrt{2}$ on primary stresses for emergency/faulted loading conditions. If this factor is added,

$$
a_{c}=0.59 \mathrm{in}
$$

This value is consistent with the value of a selected for obtaining the above values of $c_{b}, c_{m}$, $c_{r}$ and $\triangle N D T T$, and thus the result is reasonably accurate but at the same time quite conservative. At any rate, based on the evaluation, a reasonable range of flaw depth for this study is 0.5 to 1.0 in. 
Appendix G: Calculation of $p(H T)$ and $\Delta t=f(e)$

Appendix $\mathrm{G}$ is included to assist those that may wish to make additional calculations and/or check the results of calculations included in this report. The equations involved are Eqs. (14), (16) and (18-22) of the text, and the input is from Table 5.1 Three cases (A, B and C) are evaluated that include two different crack depths and two different fracture toughness curves.

Case A: $a=1.0$ in., $T_{v}(\Delta t)=$ variable, ASME $K_{I c}$ curve

$$
\begin{aligned}
& S= \frac{0.860 \times 8.5 \times 10^{3}}{1.146 \times 16.8+0.741 \times 4.24}=326 p s i \\
& \Delta N \dot{D} T T=\left(\frac{1.71}{2.68}\right)^{*} x 3.82=2.44^{\circ} F / E F P Y(100 \mathrm{MW}) \\
& \quad * \text { see Appendix A } \\
& \mathrm{E}(\mathrm{HT})= 85-10-\mathrm{e} \cdot 2.44 \cdot 19.4 \\
&= 75-47.3 \mathrm{e} \\
& \mathrm{E}(\Delta \mathrm{t})= \mathrm{T}_{\mathrm{v}}(\Delta \mathrm{t})-10-\mathrm{e} \cdot 2.44 \cdot 19.4 \\
&= \mathrm{T}_{\mathrm{v}}(\Delta \mathrm{t})-10-47.3 \mathrm{e} \\
& \mathrm{K}_{\mathrm{Ic}}(\mathrm{HT})= 33.2+20.73 \exp [0.020 \mathrm{E}(\mathrm{HT})] \\
& \mathrm{K}_{\mathrm{Ic}}(\Delta \mathrm{t})= 33.2+20.73 \exp \{0.020[\mathrm{E}(\Delta \mathrm{t})-2.44 \mathrm{e} \Delta \mathrm{t}]\} \\
& p(H T)= 679 \frac{K_{l c}(H T)}{K_{l c}(\Delta t)}+326\left[\frac{K_{l c}(H T)}{K_{l c}(\Delta t)}-1\right]
\end{aligned}
$$


For $p(H T)=900 p s i$,

$$
\begin{aligned}
\Delta t & =\frac{E(\Delta t)-\frac{1}{0.020} \ln \left\{\frac{33.2}{20.73}\left[\frac{K_{I c}(H T)}{33.2}\left(\frac{679+326}{900+326}\right)-1\right]\right\}}{244 e} \\
& =\frac{E(\Delta t)-50.0 \ln \left\{1.602\left[0.02469 K_{I c}(H T)-1\right]\right\}}{2.44 e}
\end{aligned}
$$

Case B: $a=0.5$ in.; otherwise, same as Case A

$$
\begin{aligned}
& S= \frac{0.860 \times 8.5 \times 10^{3}}{1.068 \times 16.8+0.823 \times 4.24}=341 p s i \\
& \Delta N \dot{D} T T=\left(\frac{1.84}{2.68}\right)^{*} \times 3.82=2.62^{\circ} F / E F P Y(100 \mathrm{MW}) \\
& \quad * \text { see Appendix A } \\
& \mathrm{E}(\mathrm{HT})= 85-10-\mathrm{e} \cdot 2.62 \cdot 19.4 \\
&= 75-50.8 \mathrm{e} \\
& \mathrm{E}(\Delta \mathrm{t})= \mathrm{T}_{\mathrm{V}}(\Delta \mathrm{t})-10-\mathrm{e} \cdot 2.62 \cdot 19.4 \\
&= \mathrm{T}_{\mathrm{V}}(\Delta \mathrm{t})-10-50.8 \mathrm{e} \\
& \mathrm{K}_{\mathrm{Ic}}(\mathrm{HT})= 33.2+20.73 \exp [0.020 \mathrm{E}(\mathrm{HT})] \\
& \mathrm{K}_{\mathrm{Ic}}(\Delta \mathrm{t})= 33.2+20.73 \exp \{0.020[\mathrm{E}(\Delta \mathrm{t})-2.62 \mathrm{e} \Delta \mathrm{t}]\} \\
& p(H T)= 679 \frac{K_{I c}(H T)}{K_{\mathrm{Ic}}(\Delta t)}+341\left[\frac{K_{I c}(H T)}{K_{I c}(\Delta t)}-1\right]
\end{aligned}
$$


For $p(H T)=900 p s i$,

$$
\begin{aligned}
\Delta t & =\frac{E(\Delta t)-\frac{1}{0.020} \ln \left\{\frac{33.2}{20.73}\left[\frac{K_{I c}(H T)}{33.2}\left(\frac{679+341}{900+341}\right)-1\right]\right\}}{2.62 e} \\
& =\frac{E(\Delta t)-50.0 \ln \left\{1.602\left[0.02476 K_{I c}(H T)-1\right]\right\}}{2.62 e}
\end{aligned}
$$

Case C: Updated mean $\mathrm{K}_{\mathrm{Ic}}$ curve; otherwise, same as Case $\mathrm{A}$

$$
\begin{aligned}
\mathrm{S} & =326 \mathrm{psi} \\
\Delta \mathrm{NDTT} & =2.44^{\circ} F / E F P Y(100 \mathrm{MW}) \\
\mathrm{E}(\mathrm{HT}) & =75-47.3 \mathrm{e} \\
\mathrm{E}(\Delta \mathrm{t}) & =\mathrm{T}_{\mathrm{V}}(\Delta \mathrm{t})-10-47.3 \mathrm{e} \\
\mathrm{K}_{\mathrm{Ic}}(\mathrm{HT}) & =36.68+51.59 \exp [0.0115 \mathrm{E}(\mathrm{HT})] \\
\mathrm{K}_{\mathrm{Ic}}(\Delta \mathrm{t}) & =36.68+51.59 \exp \{0.0115[\mathrm{E}(\Delta \mathrm{t})-2.44 \mathrm{e} \Delta \mathrm{t}]\} \\
p(H T) & =679 \frac{K_{l c}(H T)}{K_{I c}(\Delta t)}+326\left[\frac{K_{l c}(H T)}{K_{I c}(\Delta t)}-1\right]
\end{aligned}
$$


For $p(H T)=900 p s i$,

$$
\begin{aligned}
\Delta t & =\frac{E(\Delta t)-\frac{1}{0.0115} \ln \left\{\frac{36.68}{51.59}\left[\frac{K_{l c}(H T)}{36.68}\left(\frac{679+326}{900+326}\right)-1\right]\right\}}{2.44 e} \\
& =\frac{E(\Delta t)-86.96 \ln \left\{0.7110\left[0.02235 K_{I c}(H T)-1\right]\right\}}{2.44 e}
\end{aligned}
$$




\section{Internal Distribution}

1. D. J. Alexander

2. C. A. Baldwin

3. R. S. Brackett

4. W. K. Brown

5. S. E. Burnette

6. M. H. Carpenter

7. S. J. Chang

8 - 12. R. D. Cheverton

13. D. H. Cook

14. W. R. Corwin

15. D. F. Craig

16. R. A. Crone

17. R. E. Daniels

18. T. S. Dickson

19. H. R. Fair

20. M. B. Farrar

21. K. Farrell

22. G. F. Flanagan

23. R. G. Gilliland

24. H. A. Glovier

25. F. M. Haggag

26. R. E. Hale

27. H. W. Hayden, Jr.

28. G. J. Hirtz

29. R. W. Hobbs

30. P. H. Hughs

31. J. R. Inger

32. S. K. Iskander

33. J. E. Jones Jr.
34. F. B. K. Kam

35 J. E. Lee

36. B. L. Lepard

37. M. A. Linn

38. D. E. McCabe

39. D. M. McGinty

40. J. G. Merkle

41. L. D. Merryman

42. K. A. Morgan

43. G. W. Morris

44. R. K. Nanstad

45. J. V. Pace III

46. L. D. Proctor

47. C. E. Pugh

48. J. B. Richard

49. R. B. Rothrock

50. A. F. Rowcliffe

51. R. M. Stinnett

52. R. E. Stoller

53. R. L Stover

54. J. R. Weir, Jr.

55. B. S. Willis

55. G. T. Yahr

56 - 60. Research Reactor Division - DCC

61. ORNL Patent Section

62. Central Resarch Library

63. Document Reference Section

64 - 65. Laboratory Records

66. Laboratory Records (RC) 


\section{External Distribution}

67. M. A. Hutmaker, Jr., Office of Nuclear Energy, NE-47-GTN, Department of Energy, Washington, D.C. 20585

68. M. E. Mayfield, Division of Engineering, U.S. Nuclear Regulatory Commission, Office of Nuclear Regulatory Research, Mail Stop NS217C, Washington, D.C. 20555-0001

69. G. R. Odette, Department of Chemical and Nuclear Engineering, University of California, Ward Memorial Drive, Santa Barbara, CA 93106

70. Office of Assistant Manager for Energy Research and Development, Department of Energy - ORO, Oak Ridge, TN 37831

71 -72. Office of Scientific and Technical Information, Post Office Box 62, Oak Ridge, TN 37831 